NBER WORKING PAPER SERIES

STRUCTURAL EMPIRICAL ANALYSIS OF CONTRACTING IN VERTICAL MARKETS

\author{
Robin S. Lee \\ Michael D. Whinston \\ Ali Yurukoglu \\ Working Paper 29282 \\ http://www.nber.org/papers/w29282 \\ NATIONAL BUREAU OF ECONOMIC RESEARCH \\ 1050 Massachusetts Avenue \\ Cambridge, MA 02138 \\ September 2021
}

This chapter is prepared for the forthcoming Handbook of Industrial Organization, Volume 4. We thank the editors, three anonymous referees, and Paulo Somaini for helpful comments. The views expressed herein are those of the authors and do not necessarily reflect the views of the National Bureau of Economic Research.

At least one co-author has disclosed additional relationships of potential relevance for this research. Further information is available online at http://www.nber.org/papers/w29282.ack

NBER working papers are circulated for discussion and comment purposes. They have not been peer-reviewed or been subject to the review by the NBER Board of Directors that accompanies official NBER publications.

(C) 2021 by Robin S. Lee, Michael D. Whinston, and Ali Yurukoglu. All rights reserved. Short sections of text, not to exceed two paragraphs, may be quoted without explicit permission provided that full credit, including $\odot$ notice, is given to the source. 
Structural Empirical Analysis of Contracting in Vertical Markets

Robin S. Lee, Michael D. Whinston, and Ali Yurukoglu

NBER Working Paper No. 29282

September 2021

JEL No. L1,L13

\section{ABSTRACT}

This chapter presents an overview of advances in the structural analysis of contracting in vertical markets over the past fifteen years. We provide a discussion of theoretical models of contracting and bargaining that form the basis of recent empirical work, and then present common approaches used by researchers to take these models to the data. We also briefly survey the structural empirical literature on topics in vertical markets (including horizontal and vertical mergers, price discrimination, and nonlinear and exclusionary contracts), and conclude with a discussion of potential topics for future research.

Robin S. Lee

Department of Economics

Harvard University

Littauer Center 120

Cambridge, MA 02138

and NBER

robinlee@fas.harvard.edu

Michael D. Whinston

Sloan School of Management

and Department of Economics

Massachusetts Institute of Technology

100 Main St

Cambridge, MA 02142

and NBER

whinston@mit.edu

\author{
Ali Yurukoglu \\ Graduate School of Business \\ Stanford University \\ Stanford, CA 94305 \\ and NBER \\ ayurukog@stanford.edu
}




\title{
Structural empirical analysis of contracting in vertical markets *
}

\author{
Robin S. Lee $\quad$ Michael D. Whinston ${ }^{\ddagger} \quad$ Ali Yurukoglu ${ }^{\S}$ \\ September 14, 2021
}

\begin{abstract}
This chapter presents an overview of advances in the structural analysis of contracting in vertical markets over the past fifteen years. We provide a discussion of theoretical models of contracting and bargaining that form the basis of recent empirical work, and then present common approaches used by researchers to take these models to the data. We also briefly survey the structural empirical literature on topics in vertical markets (including horizontal and vertical mergers, price discrimination, and nonlinear and exclusionary contracts), and conclude with a discussion of potential topics for future research.
\end{abstract}

\section{Introduction}

Researchers have made significant advances in the empirical analysis of vertical markets in industrial organization (IO) in the last fifteen years. While empirical studies of vertical and intermediate good markets and related issues have a rich history in IO, ${ }^{1}$ recent work has leveraged developments in the theory of vertical contracting and demand estimation literatures to build and deploy structural empirical industry models with a supply-side featuring more realistic vertical relationships. The motivation behind these advancements, and much structural empirical industry modeling in general, often is to deliver more accurate quantitative predictions of the positive and normative effects of counterfactual policy choices. ${ }^{2}$ By adding a vertical structure, a researcher aims to incorporate additional margins of adjustment and more credibly capture strategic interactions among firms.

A key feature of many industries is a vertical supply chain characterized by an oligopolistic market structure at each level of the chain. Policies that affect firms in one level of the chain can induce reactions by firms at other levels. A model that allows for such margins of adjustment will often be necessary for an accurate prediction of the effects of a policy. Furthermore, appropriately

${ }^{*}$ This chapter is prepared for the forthcoming Handbook of Industrial Organization, Volume 4. We thank the editors, three anonymous referees, and Paulo Somaini for helpful comments.

${ }^{\dagger}$ Department of Economics, Harvard University, robinlee@fas.harvard.edu.

${ }^{\ddagger}$ Department of Economics and Sloan School of Management, MIT, whinston@mit.edu.

${ }^{\S}$ Graduate School of Business, Stanford University, ayurukog@stanford.edu

${ }^{1}$ For example, Porter (1974), Monteverde and Teece (1982), Joskow (1985), Lafontaine (1992), and Chipty and Snyder (1999) represent earlier empirical work on vertical markets.

${ }^{2}$ That said, the focus of some papers is primarily better understanding how vertical contracting works. 
accounting for the nature of firm interactions can matter for such predictions. For example, assuming price taking by one level and price setting by another level - a common assumption in the older literature on vertical relations - may not be appropriate for markets in which only a few large firms are present along the supply chain. Rather, a researcher may need a more sophisticated model of bargaining to appropriately capture negotiations over supply contracts.

As a motivating example, consider the market for consumer packaged goods. A small number of retailers that include Walmart, Target, and Amazon have large market shares and exhibit some degree of market power over consumers. Some manufacturers of these goods, which include large conglomerates such as Proctor \& Gamble (P\&G) and Unilever, possess established brand names and hence also possess a degree of market power. The interactions between these retailers and the manufacturers are not properly described by price-setting or price-taking behavior. Similarly, in many U.S. health care markets, large hospital systems and medical providers engage in sometimes contentious negotiations over the payments that they will receive from large national health insurers. And in media markets, content makers such as Disney bargain with telecommunications providers such as Comcast over terms by which these providers can offer Disney content to their subscribers. Market configurations that involve a supply chain in which a small number of downstream firms negotiate with a small number of upstream producers are prevalent, and have featured prominently in recent antitrust trials involving healthcare, ${ }^{3}$ media and telecommunications, ${ }^{4}$ and technology providers; ${ }^{5}$ and in policy and regulatory debates, including those regarding price negotiations over prescription drugs in the U.S..

The empirical work that we describe in this chapter attempts to specify and estimate realistic models of these types of market scenarios. A number of challenges arise in doing so. First, researchers must work with underlying theoretical models that feature both contracting and competition, yet are tractable and estimable. A challenge arises because contracting and bargaining between two firms in the supply chain often affects all the other firms through competition. In the previous example, Walmart's negotiation with $\mathrm{P} \& \mathrm{G}$ affects Target, because if Walmart negotiates a lower wholesale price with $\mathrm{P} \& \mathrm{G}$, Target will be at a competitive disadvantage with consumers. At the same time, P\&G's deal with Walmart may affect the terms that both $\mathrm{P} \& \mathrm{G}$ and other manufacturers such as Unilever are willing to agree to with Target. A suitable equilibrium model should allow for such interlinked negotiations, and contracting externalities more generally. Furthermore, in reality, the contracts between Walmart and $\mathrm{P} \& \mathrm{G}$ will often include additional terms beside unit prices. They could include nonlinear pricing schemes, such as quantity discounts or bundled discounts for purchasing other brands of $\mathrm{P} \& \mathrm{G}$, fixed payments for shelf space, or allowances for in-store marketing. That firms engage in contracting over multiple contractual provisions also differentiates vertical markets from typical firm to consumer markets.

Another challenge is that the development and estimation of these more complex models generally requires more detailed data and rich institutional knowledge. For instance, data on wholesale

\footnotetext{
${ }^{3}$ E.g., United States v. Anthem, Inc., 236 F. Supp. 3d 171 (D.D.C. 2017).

${ }^{4}$ E.g., United States v. AT\&T Inc., Civil Case No. 17-2511 (RJL) (D.D.C. Jun. 12, 2018).

${ }^{5}$ E.g., United States v. Apple Inc., 952 F. Supp. 2d 638 (S.D.N.Y. 2013).
} 
prices - alongside more standard data that often includes product characteristics, quantities, consumer prices, and costs - is extremely useful, and in some cases necessary, for estimating the class of models that we discuss here. Knowledge of institutional details will be required in order to gauge the appropriateness of myriad assumptions that tend to go into structural models. Such assumptions include the appropriate contractual form to use (e.g., do wholesale contracts typically feature a two-part tariff with a fixed fee, or just a linear price?), and the manner in which other supply-side actions - including pricing, product availability, and investment - are determined.

We discuss these and related issues in this chapter. We begin in Section 2 with an overview of the theoretical models of vertical contracting and bargaining that form the basis of structural empirical work. Section 3 develops a common industry framework to discuss various ways that researchers have taken these theoretical models to the data. Section 4 describes a handful of prominent studies that utilize approaches presented in the chapter to study various issues in vertical markets, including the competitive and welfare effects of horizontal and vertical mergers, price discrimination, and nonlinear and exclusive contracts. Last, Section 5 concludes, offering a brief discussion of what we see as important directions for future research.

\section{Theory}

A starting point for thinking about vertical contracting is to consider a situation in which a single upstream seller $\mathrm{U}$ and single downstream firm $\mathrm{D}$ contract. The two parties can agree to a contract $\mathbb{C}$, chosen from some feasible set $\mathcal{C}$, that may contain various contractual provisions. These provisions may include a lump-sum transfer payment $t \in \mathcal{T} \subseteq \mathbb{R}$ from $\mathrm{D}$ to $\mathrm{U}(t=0$ if the contract does not contain such a payment), as well as other provisions that we denote by the vector $\boldsymbol{y} \in \mathcal{Y}$. The variables $\boldsymbol{y}$ may include all of the payoff relevant variables (in addition to $t$ ), or only a subset of them, in which case the other payoff relevant variables will be determined in some non-cooperative fashion. ${ }^{6}$ Provisions $\boldsymbol{y}$ may also specify a procedure for deciding these other variables. For example, it may give one party an option to choose how much to buy or sell, coupled with a (possibly nonlinear) tariff schedule that determines a resulting payment (in addition to $t$ ). Since $t$ is a lump-sum transfer, these subsequent actions will depend only on $\boldsymbol{y}{ }^{7}$ The contract $\mathbb{C}=(\boldsymbol{y}, t)$, combined with any resulting non-cooperative choices, then gives rise to payoffs for the downstream and upstream firms, which we denote by $\Pi_{D}(\mathbb{C}) \equiv \pi_{D}(\boldsymbol{y})-t$ and $\Pi_{U}(\mathbb{C}) \equiv \pi_{U}(\boldsymbol{y})+t$. respectively.

If $\mathrm{U}$ and $\mathrm{D}$ bargain and these payoffs are common knowledge, we expect them to agree to a Pareto efficient contract; i.e., one that solves

$$
\begin{array}{cc}
\max _{\mathbb{C} \in \mathcal{C}} & \Pi_{U}(\mathbb{C}) \\
\text { s.t. } & \Pi_{D}(\mathbb{C}) \geq \Pi_{D}
\end{array}
$$

for some $\Pi_{D} \in \mathbb{R}$. In the case where it is feasible to include a lump-sum transfer, problem (1)

\footnotetext{
${ }^{6}$ In later sections, we introduce these other variables explicitly.

${ }^{7}$ We assume no income effects throughout.
} 
becomes

$$
\begin{array}{cc}
\max _{(\boldsymbol{y}, t) \in \mathcal{Y} \times \mathbb{R}} & \pi_{U}(\boldsymbol{y})+t \\
\text { s.t. } & \pi_{D}(\boldsymbol{y})-t \geq \Pi_{D}
\end{array}
$$

Since the constraint in (2) binds with equality in any solution, the optimal choice $\boldsymbol{y}^{*}$ must in this case maximize the bilateral surplus (or joint profit) of the two parties:

$$
\boldsymbol{y}^{*} \in \arg \max _{\boldsymbol{y} \in \mathcal{Y}} \pi_{U}(\boldsymbol{y})+\pi_{D}(\boldsymbol{y})
$$

That is, if two parties negotiate under complete information and lump-sum transfers are possible, we expect the outcome to maximize their bilateral surplus, which we will refer to as the bilateral contracting principle.

As is evident in (3), when a lump-sum transfer is feasible, the optimal contractually-specified variables $\boldsymbol{y}^{*}$ are independent of the share of the bilateral surplus captured by the downstream firm, $\Pi_{D}$. Put differently, when a lump-sum transfer is possible, the choices of all other variables are independent of the bargaining powers of the two parties.

Example 1. A successive monopoly setting. Consider a situation in which a monopolist manufacturer ( $M$; the upstream firm) produces a single product, that is sold by a local monopoly retailer ( $R$; the downstream firm) to consumers at retail price $p$. The retail demand given price $p$ is $D(p), c_{R}$ is the per-unit retailing cost, and $c_{M}$ is the per-unit manufacturing cost. From the perspective of the joint profit of the manufacturer and retailer only the retail price matters, which is the only source of interaction with the consumer. Thus, if the manufacturer and retailer were vertically integrated, their joint profit would be maximized by setting retail price $p^{m}\left(c_{M}+c_{R}\right)$, where we denote by

$$
p^{m}(c) \equiv \arg \max _{p}(p-c) D(p)
$$

the profit-maximizing price for a monopolist who faces demand $D(p)$ and has marginal cost c.

In the classical treatment of this successive monopoly problem (Spengler, 1950), the manufacturer unilaterally sets a simple linear wholesale price $w$, and chooses a level $w>c_{M}$ that maximizes her profit given the anticipated response of the retailer. Specifically, letting $\bar{D}(w) \equiv D\left(p^{m}\left(w+c_{R}\right)\right)$ denote the sales that result with wholesale price $w$ given the retailer's subsequent price choice, the manufacturer chooses $w$ to solve $\max _{w}\left(w-c_{M}\right) \bar{D}(w)$, which has first-order condition

$$
\left(w-c_{M}\right) \bar{D}^{\prime}(w)+\bar{D}(w)=0
$$

The retailer, who then faces marginal cost $w+c_{R}$, sets the retail price $p^{m}\left(w+c_{R}\right)$. Since $p^{m}(c)$ is increasing in $c$, this retail price exceeds the price $p^{m}\left(c_{M}+c_{R}\right)$ that maximizes the manufacturer's and retailer's joint profit. This inefficiency from the perspective of the manufacturer and retailer arises because of a vertical externality: the retailer, ignoring the fact that lower sales reduce the manufacturer's profit when $w>c_{M}$, sets too high a price from their joint perspective. This is the famous "double marginalization problem." 
In contrast, imagine that the manufacturer and retailer can instead negotiate over a contract $\mathbb{C}=(\boldsymbol{y}, t)$ that specifies $\boldsymbol{y}=(p, w)$ and lump-sum transfer $t$. That is, the contract can specify not only a wholesale price $w$, but also a lump-sum transfer $t$ and a "resale price maintenance" clause that dictates the retail price $p{ }^{8}$ The payoff functions $\pi_{M}(\cdot)$ and $\pi_{R}(\cdot)$ given a contract specifying $(p, w)$ are

$$
\begin{aligned}
\pi_{M}(p, w) & =\left(w-c_{M}\right) D(p) \\
\pi_{R}(p, w) & =\left[p-\left(w+c_{R}\right)\right] D(p)
\end{aligned}
$$

and the bilateral surplus is

$$
\pi_{M}(p, w)+\pi_{R}(p, w)=\left(p-c_{M}-c_{R}\right) D(p)
$$

By the bilateral contracting principle, we expect the manufacturer and retailer to agree to a contract that maximizes this bilateral surplus. One possibility is to simply specify retail price $p^{m}\left(c_{M}+c_{R}\right)$. The wholesale price is then indeterminate, as $w$ and $t$ are perfect substitutes for transferring profit once $p$ is set. This contract avoids the vertical externality problem by specifying $p$ directly.

The manufacturer and retailer can alternatively achieve joint profit maximization without specifying the retail price $p$ directly. Suppose, instead, that the contract specifies a two-part tariff, comprised of the lump-sum fee $t$ and linear wholesale price $w$, and allows the retailer to set the retail price and choose how much to buy from the manufacturer. In that case, given any contracted wholesale price $w$, the retailer will set retail price $p^{m}\left(w+c_{R}\right)$ resulting in payoff functions

$$
\begin{aligned}
\pi_{M}(w) & =\left(w-c_{M}\right) D\left(p^{m}\left(w+c_{R}\right)\right) \\
\pi_{R}(w) & =\left[p^{m}\left(w+c_{R}\right)-\left(w+c_{R}\right)\right] D\left(p^{m}\left(w+c_{R}\right)\right)
\end{aligned}
$$

and bilateral surplus

$$
\pi_{M}(w)+\pi_{R}(w)=\left[p^{m}\left(w+c_{R}\right)-\left(c_{M}+c_{R}\right)\right] D\left(p^{m}\left(w+c_{R}\right)\right) .
$$

To maximize bilateral surplus, the parties need to set $w$ so that $p^{m}\left(w+c_{R}\right)=p^{m}\left(c_{M}+c_{R}\right)$, which can be achieved by setting $w=c_{M} \cdot{ }^{9}$ Intuitively, when $w=c_{M}$, the retailer's choice of $p$ imposes no externalities on the manufacturer, resulting in a retail price choice that maximizes bilateral surplus. ${ }^{10}$ The transfer payment $t$ is then used to split the resulting bilateral surplus.

A somewhat different way to capture this setting (and one related to our later discussion of

\footnotetext{
${ }^{8}$ In the U.S., the legality of resale price maintenance provisions in manufacturers' contracts with retailers has varied over time.

${ }^{9}$ Viewed through the lens of the principal-agent literature (the retailer is the agent, choosing the non-contractible $p$ ), this is a "sell-out contract," as it makes the retailer bear the full marginal effects on bilateral surplus caused by his choice of the retail price.

${ }^{10}$ For this reason, this contract can also maximize bilateral surplus when the retailer takes other actions (e.g., advertising) or, after contracting, observes a private signal about demand conditions.
} 
empirical work), is to suppose that the contract $\mathbb{C}=(\boldsymbol{y}, t)$ emerges from a bargaining process characterized by the Nash bargaining solution (Nash, 1953). Denote by $\mathbb{C}_{0}$ the "null contract"; 11 i.e., the outcome that arises if the parties fail to agree, and let $\bar{\Pi}_{j} \equiv \Pi_{j}\left(\mathbb{C}_{0}\right)$ for $j=U, D$. Then, if there is a contract that results in gains from trade for both parties, i.e., if the set

$$
\mathcal{C}^{+} \equiv\left\{\mathbb{C} \in \mathcal{C}: \Delta \Pi_{D}(\boldsymbol{y}, t) \equiv \Pi_{D}(\boldsymbol{y}, t)-\bar{\Pi}_{D} \geq 0 \text { and } \Delta \Pi_{U}(\boldsymbol{y}, t) \equiv \Pi_{U}(\boldsymbol{y}, t)-\bar{\Pi}_{U} \geq 0\right\}
$$

is non-empty, the parties will agree to a contract that solves

$$
\max _{\mathbb{C} \in \mathcal{C}^{+}}\left[\Pi_{D}(\mathbb{C})-\bar{\Pi}_{D}\right]^{b}\left[\Pi_{U}(\mathbb{C})-\bar{\Pi}_{U}\right]^{1-b},
$$

given a bargaining power parameter $b \in[0,1]$, and they will fail to reach an agreement (leading to the the null contract $\mathbb{C}_{0}$ ) otherwise. ${ }^{12}$ In the former case, (6) indicates that the chosen agreement will depend on the bargaining power parameter $b$, which weights the gains from trade for the two parties.

Any contract that solves (6) and gives both parties strictly positive gains from trade will be Pareto efficient: given a profit level for one party, the other party's profit must be maximized. Hence, when a lump-sum transfer is feasible it therefore involves a $\boldsymbol{y}^{*}$ that maximizes the two parties' bilateral surplus. More specifically, letting $\Pi_{U}(\boldsymbol{y}, t) \equiv \pi_{U}(\boldsymbol{y})+t$ and $\Pi_{D}(\boldsymbol{y}, t) \equiv \pi_{D}(\boldsymbol{y})-t$, the contract $(\boldsymbol{y}, t)$ must be a solution to

$$
\max _{(\boldsymbol{y}, t) \in \mathcal{C}^{+}}\left[\Pi_{D}(\boldsymbol{y}, t)-\bar{\Pi}_{D}\right]^{b}\left[\Pi_{U}(\boldsymbol{y}, t)-\bar{\Pi}_{U}\right]^{1-b} .
$$

When $\boldsymbol{y}=\left(y_{1}, \ldots, y_{K}\right)$ the first-order conditions for this problem are

$$
b \frac{\frac{\partial \pi_{D}(\boldsymbol{y})}{\partial y_{k}}}{\Delta \Pi_{D}(\boldsymbol{y}, t)}+(1-b) \frac{\frac{\partial \pi_{U}(\boldsymbol{y})}{\partial y_{k}}}{\Delta \Pi_{U}(\boldsymbol{y}, t)}=0 \text { for } k=1, \ldots, K
$$

and, for $t$,

$$
b \frac{1}{\Delta \Pi_{D}(\boldsymbol{y}, t)}+(1-b) \frac{-1}{\Delta \Pi_{U}(\boldsymbol{y}, t)}=0 .
$$

Substituting (9) into (8) implies that we have

$$
\frac{\partial \pi_{D}(\boldsymbol{y})}{\partial y_{k}}+\frac{\partial \pi_{U}(\boldsymbol{y})}{\partial y_{k}}=0 \text { for } k=1, \ldots, K,
$$

which are exactly the first-order conditions for maximizing the bilateral surplus (3). By (9), the parameter $b$ determines the ratio of the two parties' gains from trade, achieved through the choice of the lump-sum transfer $t$.

Absent lump-sum transfers, however, the contract solving (6) will not generally maximize bi-

\footnotetext{
${ }^{11}$ Formally, we do not include $\mathbb{C}_{0}$ in the $\operatorname{set} \mathcal{C}$.

${ }^{12} \mathrm{We}$ assume here that a contract is agreed to if and only if both parties do at least as well as their disagreement payoffs. One can modify the definition to require one or both parties to get a strict gain.
} 


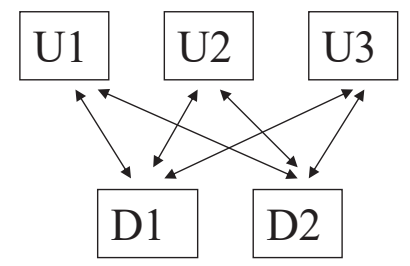

Figure 1

lateral surplus, as the following example illustrates.

Example 2. Nash bargaining in successive monopoly without lump-sum transfers. Consider again the successive monopoly setting of Example 1 in which the only contract term is the wholesale price $w$ (leaving the retailer to decide how much to buy), but assume now that the outcome of the manufacturer and retailer bargaining is described by the Nash bargaining solution. The resulting level of $w$ must therefore satisfy condition (8). Since in this setting $\bar{\Pi}_{M}=\bar{\Pi}_{R}=0$,

$$
\frac{\partial \pi_{M}(w)}{\partial w}=\left(w-c_{M}\right) \bar{D}^{\prime}(w)+\bar{D}(w)
$$

and (by the Envelope Theorem)

$$
\frac{\partial \pi_{R}(w)}{\partial w}=-\bar{D}(w)
$$

we can write condition (8) for this setting as

$$
-b \cdot \frac{\bar{D}(w)}{\left[p^{m}\left(w+c_{R}\right)-\left(w+c_{R}\right)\right] \bar{D}(w)}+(1-b) \cdot \frac{\left(w-c_{M}\right) \bar{D}^{\prime}(w)+\bar{D}(w)}{\left(w-c_{M}\right) \bar{D}(w)}=0,
$$

or equivalently

$$
\left(w-c_{M}\right) \bar{D}^{\prime}(w)+\bar{D}(w)=\left(\frac{b}{1-b}\right)\left(\frac{w-c_{M}}{p^{m}\left(w+c_{R}\right)-\left(w+c_{R}\right)}\right) \bar{D}(w) .
$$

If $b=0$, so that the manufacturer has all the bargaining power, then condition (12) becomes condition (5), and the solution is the same as in the classic treatment of successive monopoly. If, instead, $b \rightarrow 1$, so that the retailer has all the bargaining power, then (12) implies that $w \rightarrow c_{M}$, maximizing bilateral surplus.

\subsection{Multilateral Settings with Externalities}

In most vertical settings, more than one firm is present at either the upstream or downstream level, and usually both, as illustrated in Figure 1. At the same time, contracting in such vertical settings is typically bilateral. ${ }^{13}$

\footnotetext{
${ }^{13}$ Antitrust law forbids, in most circumstances, contracts between rivals at a given level of the vertical structure. An exception are horizontal mergers that are not judged to lessen competition.
} 
Formally, with $I$ upstream firms indexed by $i=1, \ldots, I$ and $J$ downstream firms indexed by $j=1, \ldots, J$, the contract between upstream firm $i$ and downstream firm $j$ is now denoted $\mathbb{C}_{i j} \in \mathcal{C}_{i j}$, where $\mathbb{C}_{i j}$ may contain a lump-sum transfer $t_{i j}$ and other contractual terms $\boldsymbol{y}_{i j}$. Of particular interest from an antitrust policy perspective, these other provisions $\boldsymbol{y}_{i j}$ may now include, to the extent allowed by law, provisions that "reference rivals" such as exclusive dealing provisions or loyalty pricing provisions that condition discounts on the share of downstream firm $j$ 's purchases that come from upstream firm $i .^{14}$

The key new feature relative to a bilateral setting is the potential for contracting externalities: the contract agreed to by one pair of firms ij may affect the payoffs of other contracting parties. (There may also be externalities on parties that are not involved in the contracting process, such as final consumers or potential entrants; indeed, even in Examples 1 and 2, consumers' payoffs are affected by the contract signed by the manufacturer and retailer.)

The following two examples illustrate this concept:

Example 3. The Hart and Tirole (1990) Cournot retailer model. Consider a setting with one manufacturer and $J \geq 2$ retailers, in which consumer demand for the manufacturer's product is given by the strictly decreasing inverse demand function $P(\cdot)$. Each retailer $j$ may purchase $q_{j}$ units of the manufacturer's product in return for a total payment $t_{j}$, and can resell the product with (for simplicity) no additional marginal costs incurred..$^{15}$ The feasible contracts are restricted to be "quantity-forcing" contracts specifying the quantity $q_{j}$ and payment $t_{j}$, so a contract is $\mathbb{C}_{j}=\left(q_{j}, t_{j}\right)$. The retail price clears the market so, given agreed-upon purchases $\left(q_{1}, \ldots, q_{J}\right)$, the resulting retail price is $P\left(\Sigma_{j} q_{j}\right)$. The manufacturer's costs are c per unit produced. Thus, the manufacturer's payoff is $\Sigma_{j} t_{j}-c \cdot \Sigma_{j} q_{j}$, while each retailer $j$ earns $P\left(\Sigma_{j} q_{j}\right) q_{j}-t_{j}$. Note that contracting externalities are present: each retailer $j$ 's payoff depends not only on his own purchase $q_{j}$ but also, if $q_{j}>0$, on the purchases of the other retailers: for any given $q_{j}>0$, the more rival retailers purchase from the manufacturer, the lower is retailer $j$ 's payoff. ${ }^{16}$ The joint payoff of the manufacturer and all of the retailers equals $P(Q) Q-c Q$, where $Q=\Sigma_{j} q_{j}$ is the aggregate quantity traded; we will assume this joint profit is a concave function in later discussions of this model. It is maximized when the aggregate quantity equals the monopoly quantity for a monopolist with marginal cost equal to $c$. A central question is whether bilateral contracting will lead to this outcome, and if not, what the outcome will be.

\footnotetext{
${ }^{14}$ Contracts that condition pricing on the buyer meeting certain conditions are sometimes called "conditional pricing practices." These provisions may include nonlinear pricing (such as all-units discounts that discount all units the buyer purchases if purchases exceed some threshold) and bundled discounts that condition discounts for one product on purchases of another. A special class of such conditional pricing practices are those in which pricing is conditioned on the level of purchases from or supply to rivals, in which case the contract is one that "references rivals." See, for example, Scott Morton (2013), Akkus-Clemens and Asker (2014), Genchev and Mortimer (2017), and DeGraba, Greenlee and O'Brien (2017).

${ }^{15}$ Since there is a single upstream firm $(I=1)$, for notational simplicity we write $q_{j}$ and $t_{j}$ rather than $q_{1 j}$ and $t_{1 j}$.

${ }^{16}$ In Hart and Tirole (1990) contracts could take more general forms than the quantity-forcing contracts considered here, for example, specifying a non-linear tariff schedule $t_{j}\left(q_{j}\right)$ and allowing the retailer to decide how much to buy, or alternatively, allowing the manufacturer to choose how much to sell. Contracting externalities would generally be present for any retailer who is buying a positive quantity.
} 
Example 4. The Rasmusen, Ramseyer and Wiley (1991) / Segal and Whinston (2000) exclusive dealing model. Consider a setting with one incumbent monopolist manufacturer and $J$ retailers. The retailers each sell in distinct local markets, and hence do not compete with one another; consumer demand in each market is $D(p)$, while each retailer's marginal cost is (for simplicity) only the wholesale price of the product. The incumbent's cost per unit is $c_{I}$. There is also a potential manufacturer entrant, who has a random entry cost $\widetilde{f}$, with distribution function $G$, and who can produce at a cost per unit (not including the entry cost) of $c_{E}<c_{I}$.

Prior to possible entry, the incumbent manufacturer can negotiate with each retailer $j$ to sign an exclusive contract, in exchange for a payment $t_{j}$. We denote by $e_{j}=0$ if no exclusive is signed with retailer $j$, while $e_{j}=1$ if an exclusive is signed. So a contract between the incumbent and retailer $j$ is denoted by $\mathbb{C}_{j}=\left(e_{j}, t_{j}\right)$. The entrant observes how many retailers sign exclusives, and his entry cost $f$, and then decides whether to enter. If the entrant enters, for each free (i.e., non-exclusive) retailer the entrant and incumbent engage in Bertrand competition over per-unit wholesale prices, resulting in the entrant winning and charging a wholesale price of $w=c_{I}{ }^{17}$ The incumbent charges the monopoly wholesale price $w^{m}>c_{I}$ to any captive (signed) retailers, and to all retailers if entry does not occur. ${ }^{18}$

Thus, if $m=\sum_{j} e_{j}$ retailers sign exclusives, so that there are $J-m$ free retailers, the entrant can earn $(J-m)\left(c_{I}-c_{E}\right) D\left(c_{I}\right)$ by entering and so the probability of entry is $\bar{G}(m) \equiv G((J-$ $\left.m)\left(c_{I}-c_{E}\right) D\left(c_{I}\right)\right)$. Contracting externalities therefore exist: when an additional retailer signs, the likelihood of entry falls, and so the expected payoff of all retailers who are not signing is reduced. Specifically, the payoff of a free retailer when $m$ retailers sign exclusives is $\bar{G}(m) p^{m}\left(c_{I}\right)\left(p^{m}\left(c_{I}\right)-\right.$ $\left.c_{I}\right)+(1-\bar{G}(m)) p^{m}\left(w^{m}\right)\left(p^{m}\left(w^{m}\right)-w^{m}\right)$. The joint profit of the incumbent and all of the retailers equals $\bar{G}(m) p^{m}\left(c_{I}\right)\left(p^{m}\left(c_{I}\right)-c_{I}\right)+(1-\bar{G}(m)) p^{m}\left(w^{m}\right)\left(p^{m}\left(w^{m}\right)-c_{I}\right)$. It is maximized when $\bar{G}(m)=1$ (i.e., when entry is certain), since this prevents any double marginalization (the acquisition cost of the goods sold, from the joint perspective of the incumbent and the retailers, equals $c_{I}$ per unit regardless of whether there is entry).

The literature has taken two different approaches to determining the likely outcomes in these kinds of bilateral contracting settings. One models the contracting process as a non-cooperative game. This approach has the advantage of fully considering the strategic options available to the firms, but at the same time it has proven difficult to derive outcomes in very general settings and outcomes can be sensitive to fine details of the game. The other approach is what has come to be called the Nash-in-Nash solution, originally due to Horn and Wolinsky (1988). This approach has been used in a number of recent empirical papers. We discuss the non-cooperative approach first, which will also help make clearer the benefits and drawbacks of the Nash-in-Nash approach, as well as what non-cooperative bargaining processes might justify it.

\footnotetext{
${ }^{17}$ We assume that $c_{E}$ is not so much below $c_{I}$ that the entrant's monopoly price in selling to the retailer would be below $c_{I}$.

${ }^{18}$ The fact that initial contracting cannot specify terms of trade of the product, only an exclusivity provision, may reflect that at that stage future product specifications are unclear.
} 


\subsubsection{Non-cooperative bargaining models}

Many possible bargaining processes can be envisioned when specifying contract formation as a non-cooperative game. Vertical models in industrial organization have traditionally extended the successive monopoly model, by assuming that upstream sellers simultaneously set linear (per-unit) wholesale prices for downstream buyers. But contracts may be more complicated than this, as may be the bargaining process. Contracting parties may make take-it-or-leave-it offers with nonlinear pricing features, or they may go back and forth with offers and counteroffers as in the Rubinstein (1982) bargaining model. Another important issue when contracts involve more than simple wholesale prices concerns what a firm knows about the contracts that have been offered and/or agreed to by other parties in the market as that information may affect whether the firm should accept a contract that has been offered to it. ${ }^{19}$

The theoretical literature on the non-cooperative approach has made the most progress in focusing on settings in which only one side of the market has multiple parties, sometimes called a triangle structure, and lump-sum transfers are feasible. In some settings, such as in Example 3, the single party is an upstream firm who can sell to multiple downstream firms. In others, it may be a downstream firm who may buy from multiple upstream firms.

We begin by considering the simplest case, in which the single party on one side makes simultaneous take-it-or-leave-it offers to the other side, the so-called offer game. Our discussion follows the analysis in Segal (1999).

The Offer Game. Consider a setting with $J$ parties on one side and one party on the other. We will refer to the multiple parties as "agents" $j=1, \ldots, J$ and the single party as the "principal." 20 The principal can sign a bilateral contract $\mathbb{C}_{j}$ with each agent $j$ specifying $\boldsymbol{y}_{j} \in \mathcal{Y}_{j}$ and a lump-sum payment $t_{j}$ from the agent to the principal; i.e., $\mathbb{C}_{j}=\left(\mathbf{y}_{j}, t_{j}\right)$. To keep the presentation simple, we will restrict attention to the case in which $\boldsymbol{y}_{j}$ is one-dimensional, and henceforth denote it by $q_{j} \in \mathbb{R}$, which we refer to as the "trade" with agent $j .{ }^{21}$ Agent $j$ 's payoff is $\Pi_{j}\left(\left\{\mathbb{C}_{j}\right\}_{j=1}^{J}\right) \equiv \pi_{j}(\boldsymbol{q})-t_{j}$, where $\boldsymbol{q}=\left(q_{1}, \ldots, q_{J}\right)$, and the principal's payoff is $\Pi_{P}\left(\left\{\mathbb{C}_{j}\right\}_{j=1}^{J}\right) \equiv \pi_{P}(\boldsymbol{q})+\Sigma_{j} t_{j}$. The fact that each agent's payoff may depend upon the whole vector $\boldsymbol{q}$ rather than just $q_{j}$ is what can give rise to contracting externalities. Not reaching an agreement gives the same payoffs as reaching the "null" agreement with $\left(q_{j}, t_{j}\right)=(0,0) \equiv \mathbb{C}_{0}$.

In the Cournot retailer model of Example 3 where contracts were quantity-forcing contracts, the "trade" $q_{j}$ is simply the quantity sold to retailer $j$. However, our formulation here allows for other possibilities. For example, if contracts take the form of two-part tariffs that allow the downstream firm to choose how much to purchase, the "trade" $q_{j}$ in contract $\mathbb{C}_{j}=\left(q_{j}, t_{j}\right)$ would be the per-unit

\footnotetext{
${ }^{19} \mathrm{~A}$ further issue is whether the parties know each other's payoff functions. As in our discussion of bilateral contracting, we will assume here that they do as essentially all work on contracting with externalities, and empirical work on vertical contracting, has maintained this assumption. Relaxing this assumption is an important direction for future work.

${ }^{20}$ We follow Segal (1999) in this terminology to highlight that the single party making offers may be either an upstream or a downstream firm, depending on the application.

${ }^{21}$ See Segal (1999) for a more general treatment.
} 
wholesale price (and $t_{j}$ would be the fixed fee). In this case, the payoff functions $\pi(\cdot)$ are the payoffs taking account of the downstream equilibrium that arises given per-unit wholesale prices $\left(q_{1}, \ldots, q_{J}\right) .^{22}$

In the offer game, the principal makes simultaneous take-it-or-leave-it offers to the $J$ agents. A key distinction is whether offers are publicly observable, or instead, are private. We will discuss both cases.

In what follows, it will be convenient to define the set of jointly efficient contracts, i.e., the efficient trade profiles, which maximize the joint payoff $\Pi(\boldsymbol{q}) \equiv \pi_{P}(\boldsymbol{q})+\sum_{j} \pi_{j}(\boldsymbol{q})$ of the principal and $J$ agents. A trade profile $\boldsymbol{q}^{*}=\left(q_{1}^{*}, \ldots, q_{J}^{*}\right)$ is jointly efficient if it is in the set

$$
\mathcal{Q}^{*} \equiv \arg \max _{\boldsymbol{q} \in \mathbb{R}^{J}} \underbrace{\pi_{P}(\boldsymbol{q})+\sum_{j} \pi_{j}(\boldsymbol{q})}_{\Pi(\boldsymbol{q})} .
$$

In some cases, such as in both Examples 3 and 4, the joint payoff depends only on the aggregate trade $Q \equiv \sum_{j} q_{j}$, which Segal (1999) calls Condition $W$. When we assume Condition W holds below, we will also assume for convenience that all efficient trade profiles $\boldsymbol{q}^{*} \in \mathcal{Q}^{*}$ have the same aggregate trade $Q^{*}$ (this was true in Examples 3 and 4 ).

Public offers. Suppose, first, that when the principal makes her offers $\left\{\left(q_{j}, t_{j}\right)\right\}_{j=1}^{J}$ each agent observes the offers made to all of the agents prior to deciding whether to accept. Without loss of generality, we can focus on equilibria in which all agents accept. (Otherwise, there is an equivalent equilibrium in which all agents who are rejecting instead are offered the contract $(0,0)$ and accept. ${ }^{23}$ ) Agent $j$ will accept if and only if

$$
\pi_{j}(\boldsymbol{q})-t_{j} \geq \pi_{j}\left(0, \boldsymbol{q}_{-j}\right)
$$

Thus, if the principal offers $\boldsymbol{q}=\left(q_{1}, \ldots, q_{J}\right)$, she will set transfers

$$
t_{j}=\pi_{j}(\boldsymbol{q})-\pi_{j}\left(0, \boldsymbol{q}_{-j}\right)
$$

for $j=1, \ldots, J$. Given this, in equilibrium the principal will offer the trades $\widehat{\boldsymbol{q}}$ that solve

$$
\max _{\boldsymbol{q} \in \mathbb{R}^{J}} \pi_{P}(\boldsymbol{q})+\sum_{j}\left[\pi_{j}(\boldsymbol{q})-\pi_{j}\left(0, \boldsymbol{q}_{-j}\right)\right]
$$

\footnotetext{
${ }^{22}$ In some cases, some or all downstream competitive actions may be taken prior to or simultaneous with contract negotiations, a possibility that we discuss in more detail in Section 3. In that case, the payoff functions $\pi(\cdot)$ we consider here are conditional on those actions.

${ }^{23}$ Note that here we assume that the principal is able to induce her most desirable continuation equilibrium. For a treatment of the implications when this is not the case, see Segal (2003).
} 
or equivalently

$$
\widehat{\boldsymbol{q}} \in \max _{\boldsymbol{q} \in \mathbb{R}^{J}}\left\{\pi_{P}(\boldsymbol{q})+\sum_{j} \pi_{j}(\boldsymbol{q})\right\}-\sum_{j} \pi_{j}\left(0, \boldsymbol{q}_{-j}\right) .
$$

The term in curly braces is exactly the joint payoff of the principal and $J$ agents (the "vertical structure," "vertical chain," or "supply chain" profit), while the term $\sum_{j} \pi_{j}\left(0, \boldsymbol{q}_{-j}\right)$ is the sum of the agents' reservation payoffs, since $\pi_{j}\left(0, \boldsymbol{q}_{-j}\right)$ is agent $j$ 's payoff if $j$ rejects the offer (is a "nontrader") when all other agents accept. As (14) reveals, if there are no externalities on non-traders, the outcome will be efficient: ${ }^{24}$

Proposition 1. In the public-offer game with lump-sum transfers, absent externalities on nontraders, the equilibrium trade profile $\widehat{\boldsymbol{q}}$ is efficient, i.e., $\widehat{\boldsymbol{q}} \in \mathcal{Q}^{*}$.

However, when there are externalities on non-traders we expect the equilibrium trades to be distorted from those that maximize vertical structure profits. Examining condition (14) suggests that the bias comes because the principal has an incentive to distort trades in a direction that lowers agents' reservation payoffs, making them more willing to accept the principal's offers. Intuitively, this should lead trades to be too large when there are negative externalities on non-traders, and too low when those externalities are positive. ${ }^{25}$

Proposition 2. Assume Condition $W$ holds and suppose that the aggregate trade in an equilibrium trade profile of the public-offer game is $\widehat{Q}$. Then with positive [respectively, negative] externalities on non-traders, $\widehat{Q} \leq[$ respectively, $\geq] Q^{*}$.

Proof. Suppose that externalities on non-traders are negative. (The proof for positive externalities follows similarly.) Consider the principal's problem in two steps: (i) deciding on the aggregate trade $Q$, and (ii) allocating the aggregate trade among the $J$ agents. Under Condition $\mathrm{W}$, the second of these problems aims to minimize $\sum_{j} \pi_{j}\left(0, \boldsymbol{q}_{-j}\right)$. The minimized value is defined by:

$$
\begin{aligned}
R(Q) \equiv \min _{\boldsymbol{q} \in \mathbb{R}^{J}} & \sum_{j} \pi_{j}\left(0, \boldsymbol{q}_{-j}\right) \\
\text { s.t. } & \sum_{j} q_{j}=Q .
\end{aligned}
$$

Note that $R(\cdot)$ is a non-increasing function when there are negative externalities. Then the principal's overall problem can be written as

$$
\max _{Q} \Pi(Q)-R(Q)
$$

Suppose that $\widehat{Q}<Q^{*}$. Then by the definition of $Q^{*}$ and the fact that $R(\cdot)$ is a non-increasing function we would have $\Pi(\widehat{Q})-R(\widehat{Q})<\Pi\left(Q^{*}\right)-R\left(Q^{*}\right)$ - a contradiction to $\widehat{Q}$ solving (14). So we must have $\widehat{Q} \geq Q^{*}$.

\footnotetext{
${ }^{24} \mathrm{As}$ is evident from (14), Proposition 1 would continue to hold if we replace $q_{j} \in \mathbb{R}$ with the general $y_{j} \in \mathcal{Y}_{j}$.

${ }^{25}$ We say that there are "negative externalities" if there are weakly negative externalities for all agents. Similarly for our use of the term "positive externalities." Proposition 2 can be strengthened to yield strictly too small [respectively, too large] an aggregate trade if externalities are strictly positive [respectively, negative] and payoffs are smooth.
} 
In the Cournot retailer setting of Example 3, retailers who make no purchases are unaffected by how much other retailers purchase. As a result, Proposition 1 tells us that with public offers the outcome will maximize vertical structure profits (i.e., the vertically-integrated monopoly quantity is sold to consumers). In contrast, in the exclusive dealing setting of Example 4 non-traders (those who do not sign exclusive contracts) are negatively impacted when other retailers sign exclusives, as it reduces the probability that they will benefit from entry. Proposition 2 tells us that, in that case, with public offers too many exclusives will be signed from the perspective of vertical structure profits. Of course, in both cases there are parties who are affected but are not involved in the contracting process: consumers and, in the latter example, the potential entrant.

Private offers. Now consider, instead, the case in which the offer made to a particular agent $j$ is only observed by that agent. ${ }^{26}$ As in the public offers case, we can without loss of generality focus on equilibria in which all agents accept the principal's offers.

With private offers, a key issue concerns an agent's beliefs about the offers made to others when he receives an unexpected offer. In a pure strategy equilibrium, his beliefs when he receives his equilibrium offer are pinned down to be the other retailers' equilibrium offers. That is, suppose that in a perfect Bayesian equilibrium the principal is expected to make offers $\left\{\left(\widehat{q}_{j}, \widehat{t}_{j}\right)\right\}_{j=1}^{J}$. If agent $j$ receives offer $\left(\widehat{q}_{j}, \widehat{t}_{j}\right)$, his belief will be that the other agents have received the offers $\left\{\left(\widehat{q}_{k}, \widehat{t}_{k}\right)\right\}_{k \neq j}$. But if he receives instead some other offer, standard equilibrium concepts do not pin down what he should think. And, when there are externalities, what he thinks may be critical for determining whether he will accept the deviating offer and, hence, whether the principal should deviate in the first place.

Much of the literature resolves this problem by assuming that the agents hold passive beliefs. That is, they continue to believe that others have received their equilibrium offers $\left\{\left(\widehat{q}_{k}, \widehat{t}_{k}\right)\right\}_{k \neq j}$ (and will accept them) even when receiving an unexpected deviating offer. This assumption may be reasonable when players view deviations by the principal as independent low-probability random events (independent "trembling hands").

With passive beliefs, if $\left\{\left(\widehat{q}_{j}, \widehat{t}_{j}\right)\right\}_{j=1}^{J}$ are the expected equilibrium offers, agent $j$ will accept the (possibly deviating) offer $\left(q_{j}, t_{j}\right)$ if and only if

$$
\pi_{j}\left(q_{j}, \widehat{\boldsymbol{q}}_{-j}\right)-t_{j} \geq \pi_{j}\left(0, \widehat{\boldsymbol{q}}_{-j}\right)
$$

Thus, when offering $q_{j}$, the principal will set transfers

$$
t_{j}=\pi_{j}\left(q_{j}, \widehat{\boldsymbol{q}}_{-j}\right)-\pi_{j}\left(0, \widehat{\boldsymbol{q}}_{-j}\right)
$$

\footnotetext{
${ }^{26}$ Implicitly, our model that specifies profits as a function of $\left(q_{1}, \ldots, q_{J}\right)$ assumes that agreed-upon contracts become public prior to any later-chosen actions (e.g., downstream competitive actions), even if private at the contract negotiation stage. For simplicity, we will maintain that set up here. However, the equilibrium outcomes we focus on would remain unchanged were contracts to remain private. This assumption is, of course, fully without consequence when there is a single firm taking later-chosen actions (e.g., when the principal is a downstream monopolist).
} 
for $j=1, \ldots, J$. As a result, $\widehat{\boldsymbol{q}}=\left(\widehat{q}_{1}, \ldots, \widehat{q}_{J}\right)$ can arise in an equilibrium with passive beliefs if and only if

$$
\widehat{\boldsymbol{q}}=\arg \max _{\boldsymbol{q} \in \mathbb{R}^{J}} \pi_{P}(\boldsymbol{q})+\sum_{j}\left[\pi_{j}\left(q_{j}, \widehat{\boldsymbol{q}}_{-j}\right)-\pi_{j}\left(0, \widehat{\boldsymbol{q}}_{-j}\right)\right] .
$$

Simplifying, we see that equilibrium trades with passive beliefs must satisfy

$$
\widehat{\boldsymbol{q}}=\arg \max _{\boldsymbol{q} \in \mathbb{R}^{J}} \pi_{P}(\boldsymbol{q})+\sum_{j} \pi_{j}\left(q_{j}, \widehat{\boldsymbol{q}}_{-j}\right)
$$

Notice that (16) is a fixed point condition: given that agents believe the equilibrium offers to be $\widehat{\boldsymbol{q}}$, the principal actually wants to make those offers.

A necessary condition for (16) to hold is that the principal does not want to deviate to just a single retailer. Applying condition (16) to this case, we see that each $\widehat{q}_{j}$ must maximize the bilateral surplus between the principal and each agent $j$, that is, $\widehat{\boldsymbol{q}}$ must be what is called a pairwise-stable contract profile or (as Segal (1999) calls it) a pairwise-stable trade profile: ${ }^{27}$

$$
\widehat{q}_{j} \in \arg \max _{q_{j}} \pi_{P}\left(q_{j}, \widehat{\boldsymbol{q}}_{-j}\right)+\pi_{j}\left(q_{j}, \widehat{\boldsymbol{q}}_{-j}\right) \text { for } j=1, \ldots, J .
$$

The following example illustrates the implications of pairwise stability.

Example 5. The Cournot retailer model with private offers. Return to the setting of Example 3 , in which contracts are quantity-forcing contracts $\mathbb{C}_{j}=\left(q_{j}, t_{j}\right)$, but assume now that offers are private and retailers hold passive beliefs. Applying the bilateral surplus maximization condition (17) to this setting, the equilibrium quantities $\left(\widehat{q}_{1}, \ldots, \widehat{q}_{J}\right)$ must satisfy

$$
\widehat{q}_{j} \in \arg \max _{q_{j}} P\left(q_{j}+\sum_{k \neq j} \widehat{q}_{k}\right) q_{j}-c \cdot\left(q_{j}+\sum_{k \neq j} \widehat{q}_{k}\right)=\arg \max _{q_{j}} P\left(q_{j}+\sum_{k \neq j} \widehat{q}_{k}\right) q_{j}-c \cdot q_{j} \text { for } j=1, \ldots J,
$$

which are exactly the conditions for $\left(\widehat{q}_{1}, \ldots, \widehat{q}_{J}\right)$ to be the equilibrium of an J-firm Cournot game between competitors who can produce at cost c. Observe that, as a consequence, the equilibrium retail price converges to the competitive price $c$ as the number of retailers $J \rightarrow \infty$.

Thus, while with public offers the vertical structure sells the monopoly quantity to consumers, with private offers the equilibrium quantity exceeds this level. In effect, with private offers the upstream monopolist faces a commitment problem: given its trades with other retailers, the monopolist and agent $j$ have a joint incentive to trade too much from the perspective of overall vertical structure profits. This incentive wasn't present with public offers, because an increase in the trade with one agent would be observed by other agents, and would lower each other agent's willingness to pay for

\footnotetext{
27 Cremer and Riordan (1987) called this notion a contract equilibrium: no pair has joint incentive to change the terms of their contract given the contracts agreed to by every other pair. Note that this notion of pairwise stability applies to contracts, not quantities, although the two coincide when contracts take the form of quantityforcing contracts, where the "trade" $q_{j}$ is the quantity purchased. In some cases below we will refer to pairwise-stable quantity profiles, by which we mean the quantities that would arise in pairwise-stable quantity-forcing contracts. When contracts take more general forms than quantity-forcing contracts, pairwise-stable contract profiles may exist that do not result in pairwise-stable quantity profiles (see, e.g., footnote 36 in Example 7).
} 
the quantities they are purchasing. ${ }^{28}$

Example 5 illustrates that in the presence of contracting externalities pairwise-stable contracting stable outcomes will often be inefficient from the standpoint of the vertical structure. As Example 5 suggests, with private offers the relevant externalities for determining joint efficiency of the contracting outcome are no longer externalities on non-traders (no externalities on non-traders were present there). The following result establishes that with private offers and passive beliefs what is critical are now externalities on other agents at the efficient trade levels:

Proposition 3. In the private-offer game with lump-sum transfers:

(i) If there are no externalities on efficient traders (agents who agree to trade $q_{j}^{*}$ at some efficient trade profile $\left.\boldsymbol{q}^{*} \in \mathcal{Q}^{*}\right)$, then any passive beliefs equilibrium trade profile is efficient.

(ii) Assume Condition $W$ and let $\widehat{Q}$ be the aggregate trade in a passive beliefs equilibrium. If externalities on efficient traders are positive [respectively, negative], then $\widehat{Q} \leq[$ respectively, $\geq$ $1 Q^{*}$.

Proof. (i) Notice that for any passive beliefs equilibrium trade profile $\widehat{\boldsymbol{q}}$, and any efficient trade profile $\boldsymbol{q}^{*} \in Q^{*}$, we have

$$
\pi_{P}(\widehat{\boldsymbol{q}})+\sum_{j} \pi_{j}\left(\widehat{q}_{j}, \widehat{\boldsymbol{q}}_{-j}\right) \geq \pi_{P}\left(\boldsymbol{q}^{*}\right)+\sum_{j} \pi_{j}\left(q_{j}^{*}, \widehat{\boldsymbol{q}}_{-j}\right)=\pi_{P}\left(\boldsymbol{q}^{*}\right)+\sum_{j} \pi_{j}\left(q_{j}^{*}, \boldsymbol{q}_{-j}^{*}\right)
$$

where the inequality follows from (16), and the equality follows because there are no externalties on efficient traders. Together they imply that $\widehat{\boldsymbol{q}}$ is efficient. ${ }^{29}$

(ii) Suppose that there are negative externalities on efficient traders but that $\widehat{Q}<Q^{*}$. (The proof for positive externalities follows similarly.) Under Condition $\mathrm{W}$, there is some efficient trade profile $\boldsymbol{q}^{*}$ such that $\sum_{j} q_{j}^{*}=Q^{*}$ and $\widehat{q_{j}}<q_{j}^{*}$ for all $j$. In that case, with negative externalities on efficient traders the equality in (18) would become a strict inequality, so that

$$
\pi_{P}(\widehat{\boldsymbol{q}})+\sum_{j} \pi_{j}\left(\widehat{q}_{j}, \widehat{\boldsymbol{q}}_{-j}\right) \geq \pi_{P}\left(q^{*}\right)+\sum_{j} \pi_{j}\left(q_{j}^{*}, \widehat{\boldsymbol{q}}_{-j}\right)>\pi_{P}\left(\boldsymbol{q}^{*}\right)+\sum_{j} \pi_{j}\left(q_{j}^{*}, \boldsymbol{q}_{-j}^{*}\right)
$$

which contradicts $\boldsymbol{q}^{*}$ being efficient. Hence, we must have $\widehat{Q} \geq Q^{*}$.

The following example illustrates part (i) of Proposition 3 (Example 5 illustrates part (ii) of the proposition):

\footnotetext{
${ }^{28}$ The same pairwise-stable quantities must arise in any passive beliefs equilibrium of this Cournot retailer setting when fully general tariffs $t_{j}\left(q_{j}\right)$ are feasible provided that contracts remain private at the time of downstream competition so that rival retailers' quantities will not change if the manufacturer negotiates a deviating contract with retailer $j$. O'Brien and Shaffer (1992) show that a similar conclusion follows when the downstream retailers instead engage in differentiated-goods price competition: marginal prices to each retailer equal the upstream monopolist's marginal costs.

${ }^{29}$ This result continues to hold if we replace $q_{j} \in \mathbb{R}$ with the general $y_{j} \in \mathcal{Y}_{j}$.
} 
Example 6. The monopoly retailer model. Consider a setting with a local monopolist retailer who may sell the products of $J$ manufacturers, denoted $j=1, \ldots, J$. Each manufacturer $j$ can produce its product at unit cost $c_{j}$ and the retailer faces consumer demand given by inverse demand functions $P_{j}\left(q_{1}, \ldots, q_{J}\right)$ for $j=1, \ldots, J$. The products are substitutes for consumers, so that each $P_{j}(\cdot)$ is strictly decreasing in $q_{j}$ and $q_{-j}$. Bargaining takes the form of an offer game with private offers, with the retailer acting as principal.

Suppose at first that contracts specify a lump-sum payment and a quantity to trade; i.e., they are quantity-forcing contracts $\mathbb{C}_{j}=\left(q_{j}, t_{j}\right)$. In this case there are no contracting externalities: given the specified quantity $q_{j}$ and transfer $t_{j}$, manufacturer $j$ does not care how much the retailer buys from rival manufacturers. Thus, by Proposition 3, the vertical structure will achieve the joint monopoly profit.

Suppose, instead, that contracts specify a two-part tariff: i.e., $\mathbb{C}_{j}=\left(w_{j}, t_{j}\right) .{ }^{30}$ Now, contracting externalities are present whenever $w_{j}>c$ for some retailer $j$, since changes in prices agreed to with rival manufacturers will impact the amount the retailer buys from manufacturer $j$. Nonetheless, contracts that set all $w_{j}=c_{j}$ lead to an efficient outcome for the vertical structure (the retailer will set joint monopoly prices) and at such a contract profile there are no contracting externalities: when $w_{j}=c_{j}$ each manufacturer $j$ 's profit is unaffected by any changes in the amount the retailer buys from it. Hence, at that contract profile there are no externalities on efficient traders, and by Proposition 3 any passive beliefs equilibrium maximizes the joint profit of the $J$ manufacturers and the retailer.

Thus, with private offers, it is the absence of externalities on efficient traders that leads to efficiency, rather than a lack of externalities on non-traders. To understand this difference, consider again the transfer payment that the principal can extract from agent $j$ with public offers: $t_{j}=$ $\pi_{j}(\boldsymbol{q})-\pi_{j}\left(0, \boldsymbol{q}_{-j}\right)$. With public offers, if the principal changes the trade $q_{k}$ with another agent $k \neq j$, this changes the transfer that can be extracted from agent $j$ both by changing $\pi_{j}(\boldsymbol{q})$ and by changing $\pi_{j}\left(0, \boldsymbol{q}_{-j}\right)$. The former effect incents the principal to promote efficiency as changes in $\pi_{j}(\boldsymbol{q})$ reflect how a change in $q_{k}$ will actually change agent $j$ 's payoff, leading the principal to internalize this externality. The latter effect, however, reflects the change in $j$ 's non-trader payoff, which does not reflect an actual (on the equilibrium continuation path) payoff change, and creates incentives for the principal to undermine efficiency. In contrast, with private offers, there is no effect of a change in $q_{k}$ on agent $j$ 's perceived payoff when he doesn't trade, so that cause of inefficiency is eliminated. However, $j$ also does not perceive the effect the change in $q_{k}$ will have on his actual payoff from accepting, which creates a new source of inefficiency, as the principal no longer internalizes this effect.

A second point to note about Proposition 3 is how the fact that the principal can engage in multilateral deviations rules out inefficient outcomes when externalities on efficient traders are absent. Pairwise stability alone does not ensure this; indeed, pairwise-stable trade profiles need not be jointly efficient even when there are no externalities at all. For instance, if in Example 6

\footnotetext{
${ }^{30}$ Here $w_{j}$ is the one-dimensional trade variable (denoted $q_{j}$ earlier).
} 
the monopoly retailer had a fixed cost, with quantity-forcing contracts we might get $\boldsymbol{q}=0$ as a pairwise-stable outcome even when there is a trade profile $\boldsymbol{q}^{*}$ that generates strictly positive profits for the vertical structure. The retailer's ability to deviate to all manufacturers at once rules out this possibility. ${ }^{31}$

Finally, the inefficiencies for the vertical structure that Proposition 3 identifies can lead firms to adopt contract provisions that avoid these externalities when feasible. In some cases, these provisions may be anti-competitive. For example, suppose that in the Cournot retailer setting of Example 5 the manufacturer can offer a contract to a retailer that commits the manufacturer to dealing exclusively with that retailer. Formally, we now have $\mathbb{C}_{j}=\left(q_{j}, e_{j}, t_{j}\right)$, where $e_{j}=1$ if the contract is exclusive and $e_{j}=0$ if it is non-exclusive. Now there is an efficient trade profile that involves no externalities, in which the manufacturer offers an exclusive contract to retailer 1 with the monopoly quantity and a transfer that captures all of retailer 1's profits, and offers no contract (or equivalently, a trade of zero) to all other retailers. Thus, according to Proposition 3, allowing exclusive contracts restores the monopoly outcome. Hart and Tirole (1990) instead focus on vertical integration with retailer 1 as a response that can restore the monopoly outcome. ${ }^{32}$

Proposition 3 assumes that agents hold passive beliefs. Absent this assumption, many other equilibrium outcomes can arise when offers are private. For example, in the Cournot retailer setting of Example 5, the joint monopoly outcome can be sustained if retailers always believe that the manufacturer has offered all retailers the same contract (see McAfee and Schwartz (1994) who refer to this as symmetry beliefs). Alternatively, any outcome that gives every firm a non-negative profit is sustainable by having retailers who receive a deviating offer believe that the manufacturer has made offers to other retailers that will result in total sales exceeding the competitive quantity, $Q^{c} \equiv P^{-1}(c)$ : with these beliefs, retailers will reject any deviating offer.

Moreover, passive beliefs is not always a reasonable assumption. For example, imagine an equilibrium in which a manufacturer with 10 units of capacity is selling 4 units to each of two retailers. If the manufacturer deviates and offers 7 units to one of them, that retailer cannot sensibly think that the manufacturer is still offering 4 units to the other retailer. More generally, if the manufacturer's cost function is not additive, selling additional units to one retailer changes the incremental cost of selling to other retailers, so when a retailer receives an unexpected offer he may reasonably think that the manufacturer may have changed her offers to other retailers. (Notably, Hart and Tirole (1990) assumed that the manufacturer had a constant cost per unit, so this issue did not arise in their model.)

One response to this observation is to focus on forms of beliefs that seem compelling. McAfee and Schwartz (1994) introduce what they call "wary beliefs" in which an agent who receives a deviating contract offer assumes the principal will make optimal offers to the other agents given

\footnotetext{
${ }^{31}$ See Rey and Vergé (2004) for more on multilateral deviations. They show that, in some cases, the possibility of multilateral deviations can undermine the existence of a passive beliefs equilibrium in an offer game.

${ }^{32}$ Rey and Tirole (2007) and Whinston (2006) provide general overviews of exclusive contracts and vertical integration as anti-competitive devices. O'Brien and Shaffer (1992) and Rey and Vergé (2004) observe that, in settings of downstream differentiated-goods price competition, resale price maintenance can also restore the monopoly outcome.
} 


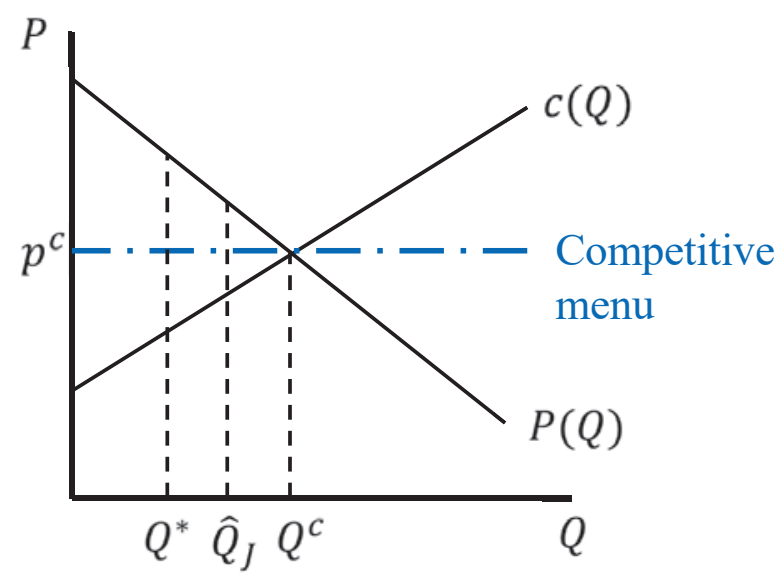

Figure 2

the deviating offers. ${ }^{33}$ Segal and Whinston (2003) instead observe that if the principal can make certain types of richer offers, which allow the principal to choose from a menu after contract acceptance, then there are offers that induce agents to accept regardless of their beliefs and this fact can restrict the set of possible equilibrium outcomes, as the next example illustrates.

Example 7. Linear Cournot retailer example with increasing manufacturer marginal cost. Consider the setting of Example 3, but suppose now that the manufacturer's marginal cost is increasing. Specifically let inverse demand be $P(Q)=a-b Q$, where $(a, b) \gg 0$, and let the manufacturer's marginal cost be $c(Q)=c+d Q$, where $(c, d) \geq 0$. The jointly efficient (joint monopoly) aggregate trade is

$$
Q^{*}=\frac{a-c}{2 b+d},
$$

the passive beliefs equilibrium aggregate trade is

$$
\widehat{Q}_{J}=\frac{a-c}{\frac{J+1}{J} b+d},
$$

and the "competitive" aggregate trade (where price equals marginal cost) is

$$
Q^{c}=\frac{a-c}{b+d}
$$

Figure 2 depicts these quantities as well as the corresponding competitive price $p^{c}=a-b Q^{c}$. The figure also depicts what Segal and Whinston call the "competitive menu": a menu that allows the principal to choose the amount $q_{j}$ to sell to retailer $j$ at a price of $p^{c}$ per unit. Observe that if the agent accepts a contract with this menu, and the manufacturer is selling $Q<Q^{c}$ units to other retailers, she will choose to sell $Q^{c}-Q$ units to retailer $j$, resulting in a retail price of $p^{c}$. If, instead, the manufacturer is selling $Q \geq Q^{c}$ units to other retailers, she will choose to sell nothing

\footnotetext{
${ }^{33}$ See also Rey and Vergé (2004) for additional analysis of the implications of wary beliefs.
} 
to retailer $j$. In either case, retailer $j$ is assured of a zero profit. So an offer of the competitive menu plus a small positive transfer to a retailer will lead the retailer to accept regardless of his beliefs. ${ }^{34}$ Segal and Whinston (2003) show that the ability to offer such contracts implies that the set of equilibrium aggregate trades in the offer game is $\left[\underline{Q}_{J}, Q^{c}\right]$ where ${ }^{35}$

$$
\underline{Q}_{J}=\frac{a-c}{\left(1+\frac{2 b}{d J}\right)(b+d)}
$$

Thus, as the number of agents $J$ gets large, the ability to write such a contract implies that the equilibrium aggregate trade must converge to the competitive level $Q^{c}$, as in any passive beliefs equilibrium. ${ }^{36}$

Consideration of these menus from which the principal chooses also highlights how passive beliefs concerning contract offers need not imply that agents have passive beliefs about quantities that will arise under the contracts with other agents. In particular, if in equilibrium other agents are being offered contracts involving menus from which the principal can then choose, then when the principal makes agent $j$ a deviating offer and agent $j$ holds passive beliefs about offers to other agents, agent $j$ will anticipate that the principal may change her choice from these menus.

The Bidding Game. A different possible bargaining protocol in triangle structures is that the multiple parties make simultaneous offers to the single party, who then decides whether to accept or reject each offer. This framework, which we refer to as the bidding game, has been studied in the literature on "common agency" initiated by Bernheim and Whinston (1986). We will follow that literature and now refer to the single party as the "agent" and the $J$ multiple parties as "principals" (the consistency with the offer-game terminology is that principals make take-it-or-leave-it offers to agents). To ease comparisons, we maintain the same setting as in our offer-game analysis, where $\mathbb{C}_{j}=\left(q_{j}, t_{j}\right)$ so lump-sum transfers are possible and the non-lump-sum term is the "trade" $q_{j} \in \mathbb{R} .{ }^{37}$

Because the principals make simultaneous offers, in any pure-strategy equilibrium of the bidding game they each take as given the equilibrium contract offers being made by rival principals, so with these beliefs pinned down it is similar to how agents in the offer game who have passive beliefs take as given the contracts that rival agents are agreeing to. However, there are two differences from offer games with passive beliefs. First, because each principal offers only their individual contract $\mathbb{C}_{j}$, only unilateral contract deviations are possible in a bidding game. Second, in the bidding game,

\footnotetext{
${ }^{34}$ In essence, these types of menus allow the manufacturer to propose a contract that screens her own types, thus reassuring the agent. The manufacturer in this case acts much like an informed principal in the language of Maskin and Tirole (1992).

${ }^{35}$ Segal and Whinston (2003) show that, when such menus can be offered, this set is in fact a "robust prediction" in the sense that the aggregate trade in every equilibrium in a wide class of bilateral contracting processes must lie in this set.

${ }^{36}$ Note that, for any number of retailers $J \geq 2$, the competitive aggregate trade $Q^{c}$ can in fact be sustained here as an equilibrium outcome with passive beliefs where the manufacturer offers the competitive menu to every retailer.

${ }^{37}$ Bernheim and Whinston (1986) assume instead that offers are tariffs that condition on the entire trade profile $\boldsymbol{q}$. As a result, contracting externalities are eliminated when agents offer sell-out contracts.
} 
it is possible for a deviating contract offer to induce the agent to reject the offer of a rival principal. The following example illustrates both issues.

Example 8. Bidding game version of the monopoly retailer model of Example 6. Suppose that in the setting of Example 6 the $J$ manufacturers make simultaneous quantity-forcing contract offers to the monopoly retailer. In that case, the equilibrium quantities $\widehat{\boldsymbol{q}}$ must be pairwise stable. To see why, suppose that there was a deviating quantity $q_{j}^{\prime} \neq \widehat{q}_{j}$ that increased the bilateral surplus of manufacturer $j$ and the retailer given whatever quantities $\boldsymbol{q}_{-j}$ the retailer is buying from other manufacturers. Then manufacturer $j$ could instead offer a quantity-forcing contract $\mathbb{C}^{\prime}=\left(q_{j}^{\prime}, t_{j}\right)$ with $t_{j}$ chosen to keep the retailer's payoff unchanged if he continues to accept the rivals' contract offers, and that would therefore strictly increase manufacturer $j$ 's payoff if it did not induce the retailer to reject any rival's offer. However, because externalities on manufacturer $j$ from the retailer's trades with others are absent with this quantity-forcing contract, any induced changes in the quantities the retailer makes with other manufacturers (including rejecting their offers) have no effect on manufacturer $j$. They also weakly raise the retailer's payoff and so the retailer will accept this deviating contract offer, which is therefore a profitable deviation for manufacturer $j$. Hence, the quantity profile $\widehat{\boldsymbol{q}}$ must be pairwise stable. As in our discussion after Example 7, however, an inefficient quantity profile could be pairwise stable here because of the lack of multilateral deviations. However, if the vertical structure payoff is concave, pairwise-stable quantities are jointly efficient for the vertical structure. ${ }^{38}$

Suppose then that the vertical structure profit is concave. Even so, the efficient quantity profile need not be an equilibrium. To see why, suppose for simplicity that there are just two manufacturers. In that case, each manufacturer $j$ must earn exactly her marginal contribution to the joint monopoly profit given the trade with the other manufacturer:

$$
t_{j}-c_{j} q_{j}^{*}=\left[P\left(q_{1}^{*}+q_{2}^{*}\right)\left(q_{1}^{*}+q_{2}^{*}\right)-c_{1} q_{1}^{*}-c_{2} q_{2}^{*}\right]-\left[P\left(q_{j}^{*}, 0\right) q_{j}^{*}-c_{j} q_{j}^{*}\right] .
$$

Any payoff lower than that and manufacturer $j$ would be able to increase the payment $t_{j}$; any higher, and the retailer would not accept. Notice, however, that the payoffs of both the retailer and manufacturer $k \neq j$ are therefore unchanged if the retailer rejects manufacturer $j$ 's contract offer. As a result, manufacturer $k$ has a profitable deviation in which she offers the retailer to trade the best quantity for an exclusive relationship

$$
q_{k}^{e}=\arg \max _{q_{k}} P\left(q_{k}, 0\right) q_{k}-c_{k} q_{k}
$$

while setting $t_{k}$ to keep the retailer's profit unchanged (or slightly higher to ensure acceptance and rejection of retailer $j$ 's offer). ${ }^{39}$ Thus, the possibility of inducing rejection of rivals' offers undermines existence of an equilibrium. Bernheim and Whinston (1998) and O'Brien and Shaffer

\footnotetext{
${ }^{38}$ Bernheim and Whinston (1986) and Bernheim and Whinston (1998) focus on equilibrium refinements that ensure efficiency regardless of concavity conditions.

${ }^{39}$ We assume here that $q_{k}^{e} \neq q_{k}^{*}$, which holds under very general conditions.
} 
(1997) nonetheless show that an efficient equilibrium does exist if the manufacturers can instead offer nonlinear tariff contracts that give the retailer the option of whether to buy quantity $q_{j}^{*}$ or $q_{j}^{e} \cdot 40$

More generally, less is known about equilibrium outcomes in settings with contracting externalities for bidding games than for offer games. Segal and Whinston (2003) compare offer and bidding game outcomes in the linear Cournot retailer model of Example 7, in which the manufacturer's marginal cost is increasing and very general contracts (such as the competitive menu discussed in Example 7) are feasible. They show that the equilibrium bidding-game aggregate quantity in that setting must be at least the offer-game passive beliefs aggregate quantity $\widehat{Q}_{J}$ and no greater than the competitive aggregate quantity $Q^{c}$, and that bidding-game aggregate quantities are a subset of offer-game aggregate quantities.

\section{Other Non-cooperative Bargaining Processes and More General Vertical Structures.}

The non-cooperative models discussed above are very special in (at least) two regards. First, they are restricted to "triangle" vertical structures with only one upstream or one downstream firm. In most applied settings, there are multiple upstream and downstream firms that can contract with one another. Second, either upstream firms or downstream firms made take-it-or-leave-it offers. Often, though, bargaining power is more evenly split. ${ }^{41}$ Extending the above analysis to these more general settings with contracting externalities has posed challenges. Because each party can both make and receive multiple offers, the issues that arise in both offer and bidding games are present. $^{42}$

Nocke and Rey (2018) consider a vertical setting with two differentiated upstream manufacturers selling to two undifferentiated downstream retailers who compete in a Cournot fashion. All firms have constant returns to scale and manufacturer-retailer pairs negotiate privately-observed contracts. In that setting, equilibrium outcomes with either wary or passive beliefs coincide and involve quantities that are pairwise stable, resulting in an outcome equivalent to that were two multi-product Cournot retail competitors each able to procure their products at cost. Nocke and Rey assume that with some probability manufacturers make take-it-or-leave-it offers and with the complementary probability retailers do, thereby generating an intermediate split of (expected) sur-

\footnotetext{
40 Such offers, which include out-of-equilibrium trade-transfer pairs, lead to multiple equilibria that all involve the efficient trades but with differing payoffs: the lower the transfer in each manufacturer $j$ 's offer for quantity $q_{j}^{e}$, the lower the equilibrium transfer is for quantity $q_{j}^{*}$. Bernheim and Whinston (1998), for example, focus on the equilibrium with the highest manufacturer payoffs.

${ }^{41} \mathrm{~A}$ separate issue is that the precise bargaining process may be unknown to an analyst. Segal and Whinston (2003) analyze "robust predictions" that would hold across a range of bargaining processes, albeit in a model with a triangle structure.

${ }^{42}$ In addition to the papers we discuss here, there are many papers that consider formation of agreements in other, non-vertical settings with externalities, including network formation (e.g., Jackson and Wolinsky, 1996), coalition formation games (e.g., Yi, 1997; Gomes, 2005; Gomes and Jehiel, 2005), bargaining with externalities (e.g., Jehiel and Moldovanu, 1995), auctions with externalities (e.g., Jehiel and Moldovanu, 2000), and bargaining in networks (e.g., Abreu and Manea, 2012). There is also work that we do not discuss here studying settings in which there are parallel vertical structures; see, e.g., Rey and Stiglitz (1995) and Bonanno and Vickers (1988). Contracting equilibria in such parallel vertical structure settings are much simpler to analyze.
} 
plus. However, multiple equilibria with differing payoffs exist due to off-equilibrium path quantitypayment pairs necessarily being offered (as in Example 8 and the discussion in footnote 40).

de Fontenay and Gans (2014) consider a general structure with arbitrary numbers of upstream and downstream firms. As in the triangle-structure models we discussed above, each upstream firm $i$ and downstream firm $j$ can agree privately to contracts specifying a one-dimensional "trade" $q_{i j}$ and transfers $t_{i j} .{ }^{43}$ However, each agreement specifies these terms conditional on each possible collection of bilateral agreements that may be reached between upstream-downstream pairs. In addition, each firm is assumed to assign a distinct agent to conduct the bargaining of each of its agreements, and these distinct agents hold passive beliefs. As a result of the distinct bargaining agents, there are no issues of multilateral deviations, nor of a firm inducing a party it is bargaining with to reject an offer from a rival firm. Bargaining in each pair takes place in an alternating-offer form, with the proposer chosen randomly in each bargaining period with equal probability and there being a (vanishingly) small probability of a permanent breakdown following a rejected offer. de Fontenay and Gans establish that there is an equilibrium in which (i) the equilibrium $\boldsymbol{q}$ are pairwise stable, and (ii) payoffs are described by the Shapley Value, but applied to the inefficient payoffs generated by the pairwise-stable $\boldsymbol{q} \cdot{ }^{44}$

The Shapley Value payoffs in this equilibrium may be an unattractive prediction in some cases. For example, in a monopoly retailer setting in which two upstream firms produce identical homogeneous goods the Shapley Value gives the two upstream firms strictly positive profits. In the non-cooperative model of de Fontenay and Gans (2014) this payoff outcome arises because the downstream monopoly retailer recognizes that if an upstream firm rejects its offer, and there is a subsequent bargaining breakdown, it will be left in a one-on-one situation with the other upstream supplier and will end up with only half of the surplus.

Finally, one feature of all of the non-cooperative contracting with externalities models considered above is that they assumed that lump-sum transfers are possible. In applied settings, it is sometimes (but by no means always!) the case that pricing takes a very simple price-per-unit form. The empirical work that has used the Nash-in-Nash approach, to which we next turn, has most often done so assuming that contracts involve simple per-unit prices. With per-unit prices, many of the complications considered above (such as beliefs about rivals' contracts determining whether to accept a contract offer, or the possibility of inducing rejection of rivals' offers) would not arise: for example, contracting in offer or bidding games looks much like traditional IO vertical models. ${ }^{45}$

\footnotetext{
${ }^{43}$ Strictly speaking, de Fontenay and Gans (2014) describe these contracts as forcing contracts specifying actions $q_{i j}$. However, as in our discussion above, $q_{i j}$ can be given a broader interpretation, such as a per-unit price in a two-part tariff.

${ }^{44}$ We also conjecture that this conclusion can be strengthened to hold in any equilibrium. The Shapley Value result builds on the literatures on fair allocation (Myerson, 1977; Navarro, 2007) and related analysis by Inderst and Wey (2003) and on alternating offer bargaining (Binmore, Rubinstein and Wolinsky, 1986). The result is also related to the analyses in Stole and Zweibel (1996) and Brügemann, Gautier and Menzio (2018). Both assume that agreements are non-binding and hence are renegotiated if any pair fails to contract, which has a similar effect on equilibrium payoffs as the contingent contracting in de Fontenay and Gans (2014).

${ }^{45}$ Understanding why and when contracts will take these simpler forms is an important open question.
} 


\subsubsection{Nash-in-Nash Bargaining}

An alternative approach to modeling vertical contract formation in these types of multilateral settings is the Nash-in-Nash approach, originally due to Horn and Wolinsky (1988). Consider a setting with $I$ sellers and $J$ buyers. Each pair $i j$ may agree to a contract $\mathbb{C}_{i j} \in \mathcal{C}_{i j}$; as before no agreement is represented by the null contract $\mathbb{C}_{0}$. Given a collection of contracts between all pairs $i$ and $j, \mathbb{C} \equiv\left\{\mathbb{C}_{i j}\right\}$, downstream firm $j$ 's payoff is $\Pi_{D j}(\mathbb{C})$ and upstream firm $i$ 's payoff is $\Pi_{U i}(\mathbb{C})$.

Formally, define the set of contracts that give non-negative gains from trade to both $i$ and $j$, given contracts $\mathbb{C}_{-i j} \equiv\left\{\mathbb{C} \backslash \mathbb{C}_{i j}\right\}$, as

$$
\begin{aligned}
\mathcal{C}_{i j}^{+}\left(\mathbb{C}_{-i j}\right) \equiv\left\{\mathbb{C}_{i j} \in \mathcal{C}_{i j}:\left[\Pi_{D j}\left(\left\{\mathbb{C}_{i j}, \mathbb{C}_{-i j}\right\}\right)-\Pi_{D j}\left(\left\{\mathbb{C}_{0}, \mathbb{C}_{-i j}\right\}\right)\right] \geq 0\right. \text { and } \\
\\
{\left.\left[\Pi_{U i}\left(\left\{\mathbb{C}_{i j}, \mathbb{C}_{-i j}\right\}\right)-\Pi_{U i}\left(\left\{\mathbb{C}_{0}, \mathbb{C}_{-i j}\right\}\right)\right] \geq 0\right\} . }
\end{aligned}
$$

Then we have:

Definition 1. Contracts $\widehat{\mathbb{C}} \equiv\left\{\widehat{\mathbb{C}}_{i j}\right\}$ constitute a Nash-in-Nash equilibrium if:

(i) For all ij such that $\widehat{\mathbb{C}}_{i j} \neq \mathbb{C}_{0}$,

$$
\begin{aligned}
\widehat{\mathbb{C}}_{i j} \in \arg \max _{\mathbb{C}_{i j} \in \mathcal{C}_{i j}^{+}\left(\widehat{\mathbb{C}}_{-i j}\right)}\left[\Pi_{D j}\left(\left\{\mathbb{C}_{i j}, \widehat{\mathbb{C}}_{-i j}\right\}\right)-\Pi_{D j}\left(\left\{\mathbb{C}_{0}, \widehat{\mathbb{C}}_{-i j}\right\}\right)\right]^{b_{i j}} \\
\times\left[\Pi_{U i}\left(\left\{\mathbb{C}_{i j}, \widehat{\mathbb{C}}_{-i j}\right\}\right)-\Pi_{U i}\left(\left\{\mathbb{C}_{0}, \widehat{\mathbb{C}}_{-i j}\right\}\right)\right]^{1-b_{i j}} .
\end{aligned}
$$

(ii) For all ij such that $\widehat{\mathbb{C}}_{i j}=\mathbb{C}_{0}$, there is no contract in $\mathcal{C}_{i j}^{+}\left(\widehat{\mathbb{C}}_{-i j}\right)$ that gives strictly positive gains from trade to both $i$ and $j$.

In words, a collection of contracts is a Nash-in-Nash equilibrium if each pair's contract solves the bilateral Nash bargaining problem taking the contracts agreed to by all other pairs as given. ${ }^{46}$

Taking all other contracts as given has much of the same flavor as passive beliefs. Indeed, by the same logic as in the offer game with passive beliefs, if a lump-sum transfer is possible, each pair $i j$ 's contract must maximize the pair's bilateral surplus given the contracts agreed to by all other pairs. So, for example, the quantities q that arise in Nash-in-Nash equilibria of the Cournot retailer setting of Example 5 must be the same as in the passive beliefs equilibrium that arose there. Likewise, the Nash-in-Nash equilibria in the monopoly retailer setting of Example 6 when vertical structure profits are concave must involve the joint (multi-product) monopoly sales levels of the $J$ manufacturers' products. However, unlike in the offer game where multi-lateral deviations are possible, inefficient outcomes for the vertical structure are possible in the monopoly retailer

\footnotetext{
${ }^{46}$ Strictly speaking, part (i) of Definition 1 allows for Pareto-inefficient contracts when one of the parties receives zero gains from trade. The definition can be strengthened to require Pareto efficiency in those cases. Part (ii) differs slightly from our earlier discussion of Nash bargaining in bilateral settings. Earlier, we assumed that parties would contract if and only if there was a contract in which each party did at least as well as their disagreement payoff. Here, we allow that parties may not contract absent both parties getting strictly positive gains from trade. The definition here allows for a greater set of equilibrium outcomes.
} 
setting when vertical structure profits are not concave. Of course, payoffs to the various parties will generally differ from offer and bidding game payoffs with Nash-in-Nash bargaining.

One way to formalize the Nash-in-Nash solution is as the equilibrium of an alternating offer or random proposer Rubinstein (1982)-style bargaining game in which the firms send distinct agents to bargain for each pairwise negotiation and these agents hold passive beliefs (see Rey and Vergé, 2020, for a formulation). As we noted above, with delegated bargaining agents it is not possible for a deviating offer to a firm to induce that firm to reject rival firms' offers. As well, multilateral deviations are not possible.

Collard-Wexler, Gowrisankaran and Lee (2019) study when the Nash-in-Nash solution may arise without making the delegated bargaining agent assumption. To do so, they examine settings in which contracts involve only lump-sum payments and there is an exogenously-specified set of feasible agreements that each generate positive gains from trade given that all other agreements in the set form. They show that the Nash-in-Nash equilibrium outcome must arise in any equilibrium as the time between bargaining periods shrinks provided that products satisfy certain substitutability conditions and firms do not impose too large negative externalities on others from signing additional contracts. $^{47}$

In some circumstances, however, Nash-in-Nash equilibria may involve unreasonable payoff predictions, as illustrated in the following example.

Example 9. Consider the monopoly retailer setting of Example 6 with two manufacturers $i=1,2$ who produce a homogeneous good. Let $Q^{m}$ denote the joint monopoly sales level for the vertical structure. Suppose that bargaining is described by the Nash-in-Nash concept over quantity-forcing contracts consisting of a quantity and a lump-sum payment $\left(\right.$ so $\left.\mathbb{C}_{i}=\left(q_{i}, t_{i}\right)\right)$, with equal bargaining powers for manufacturers and the retailer; i.e., $b_{i}=1 / 2$ for $i=1,2$.

In this case, there are a continuum of Nash-in-Nash equilibria. In all of them the total quantity traded is $Q^{m}$. We would expect that in such a setting all of the profit would be earned by the retailer since the manufacturers produce perfect substitutes - this is true, for example in both the bidding game and the offer game. However, this is not the case in any of the Nash-in-Nash outcomes. For example, there is a Nash-in-Nash equilibrium in which $q_{1}=Q^{m}, q_{2}=0$, and manufacturer 1 earns half of the joint monopoly profits. (Given that the retailer buys nothing from manufacturer 2, Nash bargaining gives half of the profit to manufacturer 1.) One would expect that in that case, manufacturer 2 would make the retailer a better offer for the quantity $Q^{m}$, inducing the retailer to drop manufacturer 1, but the Nash-in-Nash concept does not allow for this possibility. (Note that if, instead, contracts are two-part tariffs, then there is a Nash-in-Nash equilibrium in which both manufacturers offer contract $\left(p_{i}, t_{i}\right)=(c, 0)$ and the retailer gets the entire joint monopoly profit. $\left.{ }^{48}\right)$

\footnotetext{
${ }^{47}$ Collard-Wexler, Gowrisankaran and Lee (2019) also provide weaker conditions, which include limited forms of complementarities, under which there exists an equilibrium of their game that coincides with the Nash-in-Nash solution.

${ }^{48}$ This contrasts with the Shapley Value prediction of de Fontenay and Gans (2014) which yields positive payoffs for the upstream firms in this example even with two-part tariffs.
} 
Extensions of the Nash-in-Nash concept. A key issue in the Nash-in-Nash approach concerns the specification of the parties' disagreement points. Ho and Lee (2019) define and explore an extension of the Nash-in-Nash concept that aims to correct the problem identified in Example 9 by introducing the idea that a bargaining party may possess an outside option to adjust its contracts with other parties. ${ }^{49}$ Under this alternative solution concept, which Ho and Lee refer to as Nash-inNash with Threat of Replacement (NNTR), a firm that bargains with a counterparty can threaten to replace that counterparty with an alternative partner the firm is not currently bargaining with. Such a threat is credible in their model - and hence affects the negotiated contract - only if the alternative partner generates more surplus for the firm than what Nash bargaining achieves with the original counterparty (that is, the outside option is "binding") ${ }^{50}$ In Example 9, the NNTR protocol predicts that in an equilibrium where $q_{1}=Q^{m}$ and trade occurs only with manufacturer 1 , the retailer retains all monopoly profits: the retailer in a sense plays the manufacturers off against one another, and hence holds each to its reservation payoff. ${ }^{51}$

Contracting Dynamics. The models we have considered above were all static: contracts were simultaneously negotiated, and when contracts were privately negotiated a firm could find itself with a permanently lower payoff as a result of an unexpected change in contracts by other firms. This could lead to some striking results, such as in the Cournot retailer example in which an upstream monopolist was unable to fully exploit its monopoly position due to its temptation to contract secretly with one retailer at the expense of others.

A reasonable question is whether these static models with private contracting overstate the extent of this opportunism. The fact that contracting actually takes place in a dynamic world might limit these temptations if, as seems reasonable, some or all aspects of negotiated agreements (including, perhaps, just their existence) become known to other parties over time. One reason is that a firm might develop a reputation for not behaving opportunistically. ${ }^{52}$

Another reason is that if contracts eventually become observed, contracts might be structured in ways that curbs opportunism. For example, Rey and Whinston (2013), building on an insight of Marx and Shaffer (2007), show that three-part tariff contracts in which a retailer pays a fixed fee at the signing of the contract and then faces a further two-part tariff in which the retailer pays a fixed fee only if he purchases a positive quantity after seeing the contracts signed with other retailers, can sustain a joint monopoly solution in the Cournot retailer setting. Given the results when contract offers are public, this shouldn't be too surprising: if contract execution can be delayed until offers

\footnotetext{
${ }^{49}$ Ho and Lee (2019) were motivated in part by the desire to rationalize the presence of narrow hospital networks as a means for inducing competition among hospitals.

${ }^{50}$ This is a version of what Binmore, Shaked and Sutton (1989) refer to as the "deal-me-out" outside option principle in the bilateral Nash bargaining problem with an outside option, and obtains from an adaptation of the extensive form bargaining protocol developed in Manea (2016) between one seller and multiple buyers. Bolton and Whinston (1993) derive a similar result (using a different bargaining protocol) when an upstream firm with a single unit to sell bargains with two downstream firms.

${ }^{51}$ See also the related analyses of Ghili (2021) and Liebman (2016), who formalize different approaches to this issue.

${ }^{52}$ For one vertical model in which reputation-like dynamic responses feature, albeit in a different setting, see Asker and Bar-Isaac (2014).
} 
become public, it is much like having offers be public.

A third reason why dynamics might matter arises because contracts may be renegotiated in response to observed changes in rivals' contracts. In that case, a firm contemplating making or accepting a contract offer needs to consider how the other contracts in the market will evolve in response to its own contracting outcomes. Lee and Fong (2013) provide one approach to this question, introducing a dynamic network formation game to rationalize both which contracts form and how surplus is divided when contract renegotiation is costly. In each period of their game, firms simultaneously announce the set of counterparties with whom they wish to negotiate; all pairs that wish to jointly negotiate then engage in Nash-in-Nash bargaining. In any period, negotiating a contract that did not exist in previous periods is more costly than negotiating existing contracts. As a result, when bargaining firms internalize that the outcome of their negotiations - either agreement or disagreement - will affect the dynamic state, and hence contracting in future periods. ${ }^{53}$

Further exploration of contracting in dynamic settings seems a useful direction for research.

\section{An Empirical Framework}

Researchers have incorporated many of the theoretical insights described in the previous section into increasingly sophisticated industry models of vertical contracting with externalities. These models often adopt the following two-stage framework:

1. (Supply) In Stage 1, firms negotiate contracting terms. Firms may also take additional payoff-relevant actions not explicitly governed by contracts, such as determining product availability, characteristics, and prices; or choosing investment and effort levels. Researchers have employed a variety of assumptions regarding the timing of these action choices vis-à-vis contract formation.

2. (Demand) In Stage 2, consumers purchase products or services provided by upstream and downstream firms. Depending on the setting, researchers have taken various approaches to modeling how contracting between upstream and downstream firms affects consumer demand.

As is common in structural work, this framework is interpreted as governing firm actions and market outcomes for a single time period (for instance, a year). Behavior over multiple time periods, though not necessarily modeled, can be captured by repeated play of these two stages.

This section is organized as follows. First, we discuss common approaches to specifying and estimating models of firm behavior in Stage 1 (Sections 3.1-3.2). We then discuss approaches to specifying and estimating models of consumer demand in Stage 2 (Section 3.3).

\footnotetext{
${ }^{53}$ Formally, continuation values, as a function of the set of agreements, enter into payoffs used in each pairs' Nash bargaining problem. Applying this model to a setting similar to Example 9, Lee and Fong show that as firms become patient, the monopoly retailer's profits converge to those of a vertically-integrated monopolist and the retailer trades only with a single manufacturer in each period.
} 


\subsection{Supply: Modeling Vertical Contracting}

This subsection discusses common approaches to building contracting models that are "taken to data." We defer discussing the econometric parameterization of these models, and topics related to the estimation and identification of unknown parameters, until Section 3.2.

\subsubsection{Preliminaries: Contracts, Actions, and Payoffs}

Contracts. Let there be $I$ upstream firms and $J$ downstream firms, represented by the sets $\mathcal{I}$ and $\mathcal{J}$. Following notation from the previous section, a contract $\mathbb{C}_{i j}$ between upstream firm $i$ and downstream firm $j$ is an element of some predefined set of feasible contracts $\mathcal{C}_{i j}$. Contracts may or may not include a lump-sum transfer: for example, in the case that contracts are two-part tariffs, $\mathcal{C}_{i j}=\mathbb{R}^{2}$ for all $i j$ pairs, and each contract $\mathbb{C}_{i j}=\left(w_{i j}, t_{i j}\right)$ consists of a linear price $w_{i j}$ and lumpsum transfer $t_{i j}$. For all pairs $i j$, we denote by $\mathbb{C}_{0}$ the "null contract," representing the outcome when parties fail to agree. Let $\mathbb{C}=\left\{\mathbb{C}_{i j}\right\}_{i \in \mathcal{I}, j \in \mathcal{J}}$ represent the profile of contracts signed by all firms.

Payoff-Relevant Actions. Denote by $\boldsymbol{a}$ the profile of payoff-relevant actions taken by upstream and downstream firms that are not explicitly specified by contract terms. The actions that are modeled and contained within $\boldsymbol{a}$ will vary across applications. In many cases, $\boldsymbol{a}$ includes consumer-facing prices chosen by downstream firms. It may also include decisions related to product availability (as in Crawford et al., 2018 and Fan and Yang, 2020) and effort provision (as in Conlon and Mortimer, 2019).

Denote by $\boldsymbol{a}_{0}$ those actions determined simultaneously with contracts; and by $\boldsymbol{a}_{1}\left(\mathbb{C}, \boldsymbol{a}_{0}\right)$ those actions taken after contracts $\mathbb{C}$ and actions in $\boldsymbol{a}_{0}$ are determined. ${ }^{54}$ Hence, $\boldsymbol{a}=\left\{\boldsymbol{a}_{0}, \boldsymbol{a}_{1}(\cdot)\right\}$. (All observable payoff-relevant actions taken by firms prior to contracting are conditioned upon in this analysis.) This distinction between which payoff-relevant actions are taken after contracting concludes, and which are chosen simultaneously with contracting, is important. If contracts are publicly observable once agreed to, and signed prior to such actions being taken, then actions can adjust if contracts change. In contrast, if certain actions are taken contemporaneously with contracting, then these actions would not adjust if contracts were to (unexpectedly) change. Different timing assumptions thus provide different contracting incentives to firms and, for a given set of parameters and economic primitives, may lead to different equilibrium predictions..$^{55}$

Payoffs. The theoretical models described in the previous section treat as primitives firms' payoffs arising from any arbitrary profile of contracts signed between upstream and downstream firms. To

\footnotetext{
${ }^{54}$ Implicit in our notation is the assumption that actions $\boldsymbol{a}_{1}(\cdot)$ are chosen in a well-defined, potentially noncooperative, manner: for example, Nash equilibrium in a differentiated-goods pricing game when $\boldsymbol{a}_{1}(\cdot)$ represents downstream pricing.

${ }^{55}$ In applied work, unknown model parameters are estimated for a given model in order to rationalize observed moments in data. As discussed in Crawford et al. (2018), even though different modeling assumptions may give rise to different parameter estimates, this does not preclude them from nonetheless generating similar predictions for other quantities of interest (for example, the welfare effects of a market structure or policy change).
} 
adapt these models for use in empirical work - and to construct measures of payoffs for any profile of contracting terms, including for those never observed in the data-researchers often specify payoffs as functions of contract terms, other Stage-1 actions taken by firms (potentially determined via a model of product-market competition), consumer behavior in Stage 2, and additional unknown parameters that govern firm revenue and cost functions.

We represent payoffs for each upstream firm $i$ and downstream firm $j$ by $\Pi_{U i}\left(\mathbb{C}, \boldsymbol{a}_{0}\right)$ and $\Pi_{D j}\left(\mathbb{C}, \boldsymbol{a}_{0}\right) .{ }^{56}$ These payoffs implicitly depend on any subsequent actions taken by firms $\left(\boldsymbol{a}_{1}(\cdot)\right)$. They will also depend on actions taken by final consumers, typically captured by demand functions (derived from models we discuss further in Section 3.3). When relevant, we will represent demand by $\bar{D}(\cdot)$ for "upstream" and $\underline{D}(\cdot)$ for "downstream" demand. What comprises upstream or downstream demand will depend on the application: for instance, in the successive monopoly (with per-unit pricing) example from the previous section (Example 1), $\mathbb{C}=\{w\}, a_{0}=\emptyset, a_{1}=\{p\}$, and $\bar{D}(w)=\underline{D}(w)=D\left(p^{m}\left(w+c_{R}\right)\right)$ (upstream and downstream demand coincide in this single-retailermanufacturer setting). When there are multiple upstream firms or when consumers do not always purchase upstream products, upstream and downstream demand objects will typically differ.

We now provide examples of payoffs used in recent applied work.

Example 10. Medical devices. Grennan (2013) studies the procurement of coronary stents by hospitals in the US. Contracts $\mathbb{C}$ between (upstream) stent manufacturers and (downstream) hospitals, indexed by $i$ and $j$, specify linear prices $\boldsymbol{w} \equiv\left\{w_{i j}\right\}$, where the null contract $\mathbb{C}_{0}$ is represented by $w_{i j}=\infty$. Payoffs for each upstream stent manufacturer $i$ are

$$
\Pi_{U i}(\mathbb{C})=\sum_{j: \mathbb{C}_{i j} \neq \mathbb{C}_{0}}\left(w_{i j}-c_{i}\right) \bar{D}_{i j}\left(\left\{w_{k j}\right\}_{k \in \mathcal{I}}\right)
$$

where $c_{i}$ is the marginal cost for stent $i$, and $\bar{D}_{i j}(\cdot)$ is the quantity of stent $i$ used at hospital $j$. This quantity depends on the preferences of doctors and patients at hospital $j$, and the contracts for all stents signed by hospital $j$. Grennan assumes that each downstream hospital $j$, when negotiating with stent manufacturers, contemplates the following payoffs

$$
\Pi_{D j}(\mathbb{C})=W_{j}\left(\left\{w_{k j}\right\}_{k \in \mathcal{I}}\right)
$$

where $W_{j}(\cdot)$ is a measure of doctor and patient welfare at hospital $j$ that depends again on the preferences of doctors and patients at hospital $j$ and all contracts signed by hospital $j$. Since Grennan assumes that hospitals do not compete with one another on the basis of stent availability or pricing, each hospital's demand for stents and its welfare measure $W_{j}(\cdot)$ do not depend on the contracts that are signed by other hospitals.

\footnotetext{
${ }^{56}$ Components of payoffs that are invariant to contract terms (which may include fixed or sunk costs) are typically omitted from notation as they do not affect contracting outcomes. Such fixed components of payoffs may affect other firm actions such as entry and exit, and be required for welfare evaluation.
} 
Example 11. Commercial health insurers and hospitals. Ho and Lee (2017) study negotiations between (upstream) hospitals and (downstream) insurers in the US commercial health care industry. Contracts $\mathbb{C}$ between hospitals and insurers, indexed by $i$ and $j$, specify a linear payment for each inpatient hospital admission $\boldsymbol{w} \equiv\left\{w_{i j}\right\}$. Insurers' premiums are denoted $\boldsymbol{p} \equiv\left\{p_{j}\right\}$, and assumed to be chosen simultaneously with contracting (i.e., $\left.\boldsymbol{a}_{0}=\{\boldsymbol{p}\}\right)$. Let $\underline{D}_{j}(\boldsymbol{p}, \boldsymbol{N})$ represent the number of households enrolled in insurer $j$, and $\bar{D}_{i j}(\boldsymbol{p}, \boldsymbol{N})$ the number of insurer $j$ 's enrollees admitted to hospital $i$, where $\boldsymbol{N}=\left\{i j: \mathbb{C}_{i j} \neq \mathbb{C}_{0}\right\}$ is the set (or "network") of all pairs of firms that have reached an agreement under contracts $\mathbb{C}{ }^{57}$

Simplified versions of payoffs are as follows (see [Chapter by Handel and Ho] for more details). Payoffs for each hospital $i$ are

$$
\Pi_{U i}(\mathbb{C}, \boldsymbol{p})=\sum_{j: \mathbb{C}_{i j} \neq \mathbb{C}_{0}}\left(w_{i j}-c_{i}\right) \bar{D}_{i j}(\boldsymbol{p}, \boldsymbol{N})
$$

where $c_{i}$ are hospital i's per-admission costs; and payoffs for each insurer $j$ are

$$
\Pi_{D j}(\mathbb{C}, \boldsymbol{p})=\left(p_{j}-\eta_{j}\right) \underline{D}_{j}(\boldsymbol{p}, \boldsymbol{N})-\sum_{i: \mathbb{C}_{i j} \neq \mathbb{C}_{0}} w_{i j} \bar{D}_{i j}(\boldsymbol{p}, \boldsymbol{N}),
$$

where $\eta_{j}$ represent marginal costs from non-hospital services, such as physician and drug payments.

This setup has two main differences with Example 10. First, firm payoffs depend on the choice of an additional supply-side action (here, premiums). Second, downstream insurers compete for enrollees with one another, and maximize profits. Hence, both downstream-insurer and upstreamhospital demand, and hence firms' payoffs, depend on the contracting decisions and actions of all firms. In contrast, in the previous example both upstream-stent demand at a given hospital and payoffs for that downstream hospital, represented by doctor and patient welfare, are not affected by the contracts signed by other downstream firms. ${ }^{58}$

Example 12. Multichannel television and vertical integration. Crawford and Yurukoglu (2012) and Crawford et al. (2018) model negotiations between (upstream) television channels and (downstream) multichannel video programming distributors (MVPDs), which include cable and satellite television firms. Here, contracts $\mathbb{C}$ between channels and distributors specify linear "affiliate fees" $\boldsymbol{w} \equiv\left\{w_{i j}\right\}$, where $w_{i j}$ is the amount each distributor $j$ pays channel $i$ per subscriber that receives the channel; and distributors choose consumer subscription prices $\boldsymbol{p} \equiv\left\{p_{j}\right\}$. In Crawford and Yurukoglu (2012), subscription prices are chosen after contracting, whereas in Crawford et al. (2018), they are chosen simultaneously with contracting. Denote by $\underline{D}_{j}(\boldsymbol{p}, \boldsymbol{N})$ the number

\footnotetext{
${ }^{57}$ In Ho and Lee (2017), consumer demand responds to insurance plan premiums $\boldsymbol{p}$ and the set of hospitals in each insurer's network $\boldsymbol{N}$, but not to negotiated per-admission prices $\boldsymbol{w}$.

${ }^{58}$ Gowrisankaran, Nevo and Town (2015) model negotiations between hospitals and insurers over hospital prices following an approach similar to Grennan (2013), and assume that insurers maximize a weighted sum of the consumer surplus of their enrollees net of hospital payments. Their main empirical analysis does not model insurer-premium setting, and assumes that each insurer's enrollees do not switch insurance plans if hospital-insurer contracts change. In both Grennan (2013) and Gowrisankaran, Nevo and Town (2015), negotiated linear prices $\boldsymbol{w}$ affect consumer demand for upstream products (stents, hospitals).
} 
of households that subscribe to distributor $j$, where $\boldsymbol{N}=\left\{i j: \mathbb{C}_{i j} \neq \mathbb{C}_{0}\right\}$ represents the set of all channel-distributor agreements. ${ }^{59}$

A simplified version of payoffs used in both papers is as follows. Payoffs for each channel $i$ are

$$
\Pi_{U i}(\mathbb{C}, \boldsymbol{p})=\sum_{j: \mathbb{C}_{i j} \neq \mathbb{C}_{0}}\left(w_{i j} \underline{D}_{j}(\boldsymbol{p}, \boldsymbol{N})+a d_{i j}(\boldsymbol{p}, \boldsymbol{N})\right),
$$

where $a d_{i j}(\cdot)$ represents total advertising revenues earned by the channel for subscribers at distributor $j$, and channels have zero marginal costs. ${ }^{60}$ Payoffs for each distributor $j$ are

$$
\Pi_{D j}(\mathbb{C}, \boldsymbol{p})=\left(p_{j}-\sum_{i: \mathbb{C}_{i j} \neq \mathbb{C}_{0}} w_{i j}\right) \underline{D}_{j}(\boldsymbol{p}, \boldsymbol{N})
$$

Note the similarities and differences between these payoffs and those used in Example 11. In both cases, payoffs depend on contracts $\mathbb{C}$ and downstream prices $\boldsymbol{p}$ (both directly and indirectly through the effects of these objects on demand). The main difference between the two examples is that here, contracted linear fees $w_{i j}$ are paid by distributor $j$ to channel $i$ for all of distributor $j$ 's subscribers (i.e., $\left.\underline{D}_{j}(\cdot)\right)$, whereas in the previous hospital-insurer example, such fees are only paid for a subset of insurer $j$ 's patients (i.e., $\left.\bar{D}_{i j}(\cdot)\right)$. Consequently, setting aside the advertising term ad $d_{i j}(\cdot)$, both upstream and downstream payoffs can be computed in this example without using a measure of upstream demand as an input. ${ }^{61}$

Crawford et al. (2018) also examines the behavior of vertically integrated firms. Assume that distributor $j$ is integrated with channel $i$, and no other firms are integrated. When channel $i$ negotiates with a rival distributor, payoffs contemplated by channel $i$ are

$$
\Pi_{U i}^{V I}(\mathbb{C}, \boldsymbol{p})=\Pi_{U i}(\mathbb{C}, \boldsymbol{p})+\mu \lambda \Pi_{D j}(\mathbb{C}, \boldsymbol{p})
$$

and when distributor $j$ negotiates with a rival channel, it considers payoffs:

$$
\Pi_{D j}^{V I}(\mathbb{C}, \boldsymbol{p})=\Pi_{D j}(\mathbb{C}, \boldsymbol{p})+\mu \Pi_{U i}(\mathbb{C}, \boldsymbol{p})
$$

Both expressions are equal to a weighted sum of upstream and downstream payoffs given by (31)

\footnotetext{
${ }^{59}$ To simplify exposition, we omit market subscripts, and we assume that if a distributor $j$ and channel $i$ have a contract $\left(\mathbb{C}_{i j} \neq \mathbb{C}_{0}\right)$, then channel $i$ is included by distributor $j$ in the bundle of channels that $j$ offers consumers in all markets. In both Crawford and Yurukoglu (2012) and Crawford et al. (2018), there is an additional "bundling" supply-side action not discussed here: i.e., even if there is a contract signed between a distributor and channel, the distributor may choose not to carry the channel in its bundle in certain markets. Since a distributor's payments to a channel are only made for those households that receive the channel, a distributor may find it profitable to exclude a channel in certain markets but not in others.

${ }^{60}$ Crawford and Yurukoglu (2012) uses per-hour advertising measures to construct $a d_{i j}(\cdot)$, thus requiring a prediction of hourly viewership for each channel to compute total advertising revenues. Crawford et al. (2018) uses per-subscriber advertising measures, and can compute total advertising revenues by multiplying these measures with downstream distributor demand $\underline{D}_{j}(\cdot)$.

${ }^{61}$ As discussed later, both Crawford and Yurukoglu (2012) and Crawford et al. (2018) still specify and estimate a model of upstream-channel viewership to assist with the identification of parameters in their downstream-distributordemand model.
} 
and (32). The parameter $\mu \geq 0$ allows for each unit of the integrated firm (either the downstream distributor or upstream channel) to place a different weight on its own profits relative to those of the other whenever $\mu \neq 1$. The parameter $\lambda \geq 0$, present in the integrated channel's payoffs in (33), represents an additional "rival-foreclosure" parameter, and-along with $\mu$-captures how much an integrated channel considers the benefits to its integrated-downstream distributor when deciding whether to supply a rival distributor. By including these additional parameters, the model estimates rather than imposes the extent to which firms internalize the profits of integrated units when making pricing and bundling decisions, or when deciding whether to supply or foreclose rival distributors. (See further discussion in Section 4.2.)

\subsubsection{Modeling Contract Formation}

Much of the recent empirical literature has modeled contracting between upstream and downstream firms using versions of approaches discussed in Section 2.1. These include variants of the non-cooperative "offer game" and procedures such as "Nash-in-Nash" bargaining. Furthermore, empirical work has broadly maintained the assumptions of symmetric information, and that contracts - or at least, the set of firms who have reached an agreement - are publicly observable once signed (even if not observable at the contract formation stage). We maintain these assumptions here.

Offer Games. One of the simplest versions of a contracting game between upstream and downstream firms is one in which upstream firms make take-it-or-leave-it (TIOLI) contract offers to downstream firms. ${ }^{62}$ This is the approach taken by Villas-Boas (2007) to model contracting between manufacturers (yogurt producers) and retailers (supermarkets). ${ }^{63}$ Villas-Boas models contracting and supply-side decisions in two sub-stages. First, all manufacturers, indexed by $i$, simultaneously choose contract terms governing trade for all retailers, indexed by $j$. Next, given these contracts, retailers simultaneously set downstream prices for manufacturers' products carried in their stores. Villas-Boas allows for contracts to consist of both linear and two-part tariffs, and also explores the implications of a variety of conduct assumptions, including firm-level profit maximization or industry-wide collusion.

To show how this sequential pricing model generates contract predictions, assume for simplicity that each manufacturer $i$ produces only a single product, each retailer $j$ stocks all products, and contracts consist of linear wholesale prices $\boldsymbol{w} \equiv\left\{w_{i j}\right\}$; this environment is then a multi-firm generalization of the successive monopoly problem discussed in Example 1. With linear wholesale prices, a retailer will always accept any contract offer from a manufacturer. Each retailer $j$ 's profits

\footnotetext{
${ }^{62}$ Another variant is one in which upstream firms offer a menu of contracts from which downstream firms choose (Mortimer, 2008).

${ }^{63}$ Other manufacturer-retailer examples include Brenkers and Verboven (2006), Bonnet and Dubois (2010), Asker (2016) and Fan and Yang (2020).
} 
are given by

$$
\Pi_{D j}(\boldsymbol{w}, \boldsymbol{p})=\sum_{i}\left(p_{i j}-w_{i j}-c_{D j}\right) D_{i j}(\boldsymbol{p}),
$$

where $\boldsymbol{p} \equiv\left\{p_{i j}\right\}$ are retail prices for each product $i$ at store $j, c_{D j}$ are retailer marginal costs, and $D_{i j}(\cdot)$ is the quantity of yogurt $i$ sold at store $j$ given retail prices. Under Nash-Bertrand price setting by multi-product retailers, Villas-Boas shows that retail prices, taking wholesale prices and costs as given, satisfy

$$
\boldsymbol{p}=\boldsymbol{w}+\boldsymbol{c}_{D}-\left(\boldsymbol{T} * \Lambda_{D}\right)^{-1} \times \boldsymbol{D}(\boldsymbol{p}),
$$

where $\boldsymbol{p}, \boldsymbol{w}, \boldsymbol{c}_{D}, \boldsymbol{D}(\cdot)$ are vectors of retail prices, wholesale prices, retailer marginal costs, and demand for all $(I \times J)$ product-retailer combinations; $\boldsymbol{T}$ is an $(I \times J) \times(I \times J)$ matrix with element $\boldsymbol{T}(m, n)$ equal to 1 if $m$ and $n$ share the same retailer (where $m$ and $n$ each correspond to a particular $(i, j)$ product-retailer combination); $\Lambda_{D}$ is a matrix with element $\Lambda_{D}(m, n)=\frac{\partial D_{n}}{\partial p_{m}}$; and $*$ is the element-by-element multiplication operator. Next, each manufacturer $i$ 's profits are given by

$$
\Pi_{U i}(\boldsymbol{w})=\sum_{j}\left(w_{i j}-c_{U i}\right) \times D_{i j}(\boldsymbol{p}(\boldsymbol{w}))
$$

where $c_{U i}$ are upstream marginal costs, and $\boldsymbol{p}(\boldsymbol{w})$ are the implied equilibrium downstream prices given by (35). ${ }^{64}$ Villas-Boas shows that, under appropriate conditions, equilibrium wholesale prices - i.e., contract terms - satisfy

$$
\boldsymbol{w}=\boldsymbol{c}_{U}-\left(I_{I \times J} *\left(\left(\Lambda_{P}\right)^{\prime} \times \Lambda_{D}\right)\right)^{-1} \times \boldsymbol{D}(\boldsymbol{p}(\boldsymbol{w})),
$$

where $I_{I \times J}$ is an $(I \times J)$ identity matrix, and $\Lambda_{P}$ is a "pass through" matrix with element $\Lambda_{P}(m, n)=$ $\frac{\partial p_{n}}{\partial w_{m}}$. Villas-Boas shows how to use similar calculations to derive price-cost margins implied by different contractual forms and conduct assumptions, such as industry-wide collusion. ${ }^{65}$

Ho (2009) also employs a version of an offer game to analyze hospital-insurer negotiations in US commercial health care settings. As in Villas-Boas (2007), Ho assumes firms on one side of the market (hospitals) make take-it-or-leave-it offers to the other side (insurers). Ho models contracting as follows: hospitals make simultaneous, privately-observed offers comprising two-part tariffs to insurers; next, insurers who have passive beliefs simultaneously decide which contracts to accept or reject, thereby determining the set of hospitals included in each insurer's network. Following these contracting decisions, insurers choose premiums, and then consumers choose which insurance plans to enroll in, and then which hospitals (if any) to visit; these actions then determine payoffs to firms.

By incorporating the accept-reject decisions of insurers into the industry model, Ho (2009) derives conditions that unobserved hospital-insurer contracts must satisfy to be consistent with the set of hospital-insurer networks observed in the data. Under the assumption that the observed

\footnotetext{
${ }^{64}$ Note that, in the notation we introduced earlier, $\underline{D}_{i j}(w)=D_{i j}(p(w))$.

${ }^{65}$ Bonnet and Dubois (2010) also use an offer game to study contracting between bottled water manufacturers and retailers, examining equilibria characterized in Rey and Vergé (2010).
} 
hospital networks are equilibrium outcomes when firms hold passive beliefs, Ho derives two sets of inequalities. The first set is based on insurers' decisions. Since insurers act simultaneously after hospitals have made offers, the model requires that insurers must earn higher payoffs from their observed hospital network than from any alternative hospital network that their own rejections could induce (i.e., holding fixed the networks of other insurers). ${ }^{66}$ For instance, any insurer cannot improve its profits by unilaterally dropping a single hospital from its network. The second set of inequalities involves hospitals' decisions. Here - since contract offers are privately observed, hospitals act simultaneously, and insurers hold passive beliefs - if hospital $i$ deviates only in its contract offer to insurer $j$, both $i$ and $j$ believe that the hospital networks of other insurers $-j$ do not adjust. However, insurer $j$ may nonetheless adjust its acceptance decisions with respect to offers received from other hospitals - for instance, $j$ can reject contracts it otherwise would have accepted upon receipt of the deviant offer from $i$. As Ho notes, in an equilibrium it still must be the case that any hospital $i$ earns higher payoffs from their observed contracts than from eliminating a contract with some insurer $j$ assuming insurer $j$ then chooses its hospital network to minimize hospital $i$ 's payoffs (holding fixed the hospital networks of all other insurers $-j$ ), and Ho employs this necessary condition in estimation. ${ }^{67}$

Nash-in-Nash bargaining. Although TIOLI models of vertical contracting are appealing given their tractability, they have important limitations. First, these models inherently assume that one set of firms makes all contract offers. It may not be clear which set to choose, particularly since firms often engage in back-and-forth negotiations in reality. Second, predictions of such models may be at odds with observed market outcomes, or generate economically implausible predictions. For example, when upstream firms simultaneously make TIOLI offers to downstream firms over linear wholesale prices, there is an implied relationship between demand elasticities, marginal costs, and equilibrium prices (e.g., see equation (35)). Given this relationship, certain observed pricing and demand patterns may only be rationalizable under such a model if products have negative marginal costs (Grennan, 2013; Gowrisankaran, Nevo and Town, 2015).

Partly in response to these concerns, recent empirical work has adopted alternative contracting approaches that involve some form of bargaining. One approach that has gained traction is the Nash-in-Nash solution, which has been used to examine manufacturer-retail environments (Draganska, Klapper and Villas-Boas, 2010), content distribution markets (Crawford and Yurukoglu, 2012; Crawford et al., 2018), healthcare settings (Grennan, 2013; Gowrisankaran, Nevo and Town, 2015; Ho and Lee, 2017), and pharmaceutical sales (Dubois and Sæthre, 2020). This particular approach, as well as others based on bargaining, avoids the need to specify ex-ante which "side" of the market possesses greater bargaining power, and by allowing for flexible bargaining weights, can rationalize empirical relationships that otherwise might be at odds with predictions from contracting games

\footnotetext{
${ }^{66}$ Given the timing assumptions made in Ho (2009), firms anticipate premium and demand responses to any changes in hospital networks.

${ }^{67}$ See also Demirer and Olssen (2021), who use a similar moment-inequalities approach to estimate negotiated drug rebates for U.S. Medicare Part D plans.
} 
relying on TIOLI offers.

A typical implementation of the Nash-in-Nash solution is as follows. Assume first that there are no other payoff-relevant actions $\boldsymbol{a}$ taken by firms. Then, from the first part of Definition 1 in Section 2.1.2, a necessary condition for contracts $\widehat{\mathbb{C}} \equiv\left\{\widehat{\mathbb{C}}_{i j}\right\}$ to comprise a Nash-in-Nash equilibrium is that, for all firm pairs $i j$ such that $\widehat{\mathbb{C}}_{i j} \neq \mathbb{C}_{0}$,

$$
\begin{aligned}
\widehat{\mathbb{C}}_{i j} \in \arg \max _{\mathbb{C}_{i j} \in \mathcal{C}_{i j}^{+}\left(\widehat{\mathbb{C}}_{-i j}\right)}[\underbrace{\left(\left\{\mathbb{C}_{i j}, \widehat{\mathbb{C}}_{-i j}\right\}\right)-\Pi_{D j}\left(\left\{\mathbb{C}_{0}, \widehat{\mathbb{C}}_{-i j}\right\}\right)}_{\Delta_{i j} \Pi_{U i}\left(\left\{\mathbb{C}_{i j}, \widehat{\mathbb{C}}_{-i j}\right\}\right)}]^{b_{i j}\left(\left\{\mathbb{C}_{i j}, \widehat{\mathbb{C}}_{-i j}\right\}\right)} \\
\times \underbrace{\left[\prod_{U i}\left(\left\{\mathbb{C}_{i j}, \widehat{\mathbb{C}}_{-i j}\right\}\right)-\Pi_{U i}\left(\left\{\mathbb{C}_{0}, \widehat{\mathbb{C}}_{-i j}\right\}\right)\right.}_{\Delta_{i j}}]^{\left(1-b_{i j}\right)},
\end{aligned}
$$

where $\mathcal{C}_{i j}^{+}\left(\mathbb{C}_{-i j}\right)$ represents the set of contracts that give non-negative gains from trade to both $i$ and $j$, defined in $(25)$, and $b_{i j} \in[0,1]$ represents a pair-specific Nash-bargaining parameter. The terms $\Delta_{i j} \Pi_{D j}(\cdot)$ and $\Delta_{i j} \Pi_{U i}(\cdot)$ represent the gains from trade realized by firms $i$ and $j$ from the contract $\mathbb{C}_{i j}$ relative to disagreement $\mathbb{C}_{0}$. As noted in the previous section, the key assumption that underlies the Nash-in-Nash solution is that, for each pair of firms $i$ and $j$, the payoffs used to evaluate the Nash product hold fixed the contracts of all other pairs $\widehat{\mathbb{C}}_{-i j} .{ }^{68}$

In many applications, only the necessary condition given by (36) is imposed for firm pairs that form contracts $\left(\left\{i j: \mathbb{C}_{i j} \neq \mathbb{C}_{0}\right\}\right)$. The second set of necessary conditions, provided by the second part of Definition 1 and mirroring pairwise stability conditions from the two-sided matching literature, is that for pairs that do not contract $\left(\left\{i j: \mathbb{C}_{i j}=\mathbb{C}_{0}\right\}\right)$, there does not exist a contract that gives strictly positive gains from trade to both parties.

Extending the Nash-in-Nash solution to environments with other payoff-relevant supply-side actions $\boldsymbol{a}$ is straightforward. Consider first actions $\boldsymbol{a}_{0}$ that are simultaneously determined with contract terms $\mathbb{C}$. In equilibrium, contracts $\widehat{\mathbb{C}}$ must satisfy the Nash-in-Nash conditions described above taking equilibrium actions $\widehat{\boldsymbol{a}}_{0}$ as given; and equilibrium actions $\widehat{\boldsymbol{a}}_{0}$ must not admit any strictly profitable unilateral deviations in actions for any firm, taking equilibrium contracts $\widehat{\mathbb{C}}$ as given. For example, for each downstream firm $j$ and simultaneously determined actions $\widehat{\boldsymbol{a}}_{0 j}$, it must be that $\Pi_{D j}\left(\widehat{\mathbb{C}}, \widehat{\boldsymbol{a}}_{0}\right) \geq \Pi_{D j}\left(\widehat{\mathbb{C}},\left\{\boldsymbol{a}_{0 j}^{\prime}, \widehat{\boldsymbol{a}}_{0,-j}\right\}\right)$ for any alternative set of actions $\boldsymbol{a}_{0 j}^{\prime}$ that $j$ could have taken. An equivalent condition holds for actions $\widehat{\boldsymbol{a}}_{0 i}$ taken by each upstream firm $i$.

Consider next any payoff-relevant actions $\boldsymbol{a}_{1}(\cdot)$ that are chosen after contracting. ${ }^{69}$ Actions in $\boldsymbol{a}_{1}(\cdot)$ affect the computation of payoffs in each firm's gains from trade in two places. First, in "agreement payoffs" (e.g., $\Pi_{D j}\left(\left\{\mathbb{C}_{i j}, \widehat{\mathbb{C}}_{-i j}\right\}\right)$ ), actions in $\boldsymbol{a}_{1}(\cdot)$ respond to any changes in contract terms. For example, in the successive monopoly case examined in Example 1 of Section 2, firms anticipate that downstream prices respond to any adjustments in upstream wholesale prices. Second, in "disagreement payoffs" (e.g., $\left.\Pi_{D j}\left(\left\{\mathbb{C}_{0}, \widehat{\mathbb{C}}_{-i j}\right\}\right)\right)$, actions in $\boldsymbol{a}_{1}(\cdot)$ respond to potential

\footnotetext{
${ }^{68}$ For this reason, the solution has been referred to as a "Nash equilibrium in Nash bargains."

${ }^{69}$ Since consumers act in Stage 2 following all supply-side decisions, firms anticipate the responses of consumer demand when contracting in a similar manner to how they anticipate responses in $\boldsymbol{a}_{1}(\cdot)$.
} 
disagreements or breakdowns between pairs. ${ }^{70}$

Example 13. Health insurer-hospital negotiations. In Ho and Lee (2017), health insurers negotiate consumer-facing premiums $\boldsymbol{p}$ with a large employer simultaneously with contracts $\mathbb{C}$ specifying per-admission hospital payments $\boldsymbol{w}$. Given payoffs defined in (29)-(30) from Example 11, the first-order conditions for the Nash-in-Nash conditions in (36) for hospital payments $\boldsymbol{w}$ (adapted to include supply-side actions $\boldsymbol{a}_{0}=\{\boldsymbol{p}\}$ ) are

$$
\begin{aligned}
\widehat{w}_{i j} \times \underline{D}_{i j}(\cdot)=\left(1-b_{i j}\right) & \times \Delta_{i j} \Pi_{D j}\left(\left\{\left(w_{i j}=0\right), \widehat{\mathbb{C}}_{-i j}\right\}, \widehat{\boldsymbol{p}}\right) \\
-b_{i j} & \times \Delta_{i j} \Pi_{U i}\left(\left\{\left(w_{i j}=0\right), \widehat{\mathbb{C}}_{-i j}\right\}, \widehat{\boldsymbol{p}}\right) \quad \text { for all } i j: \mathbb{C}_{i j} \neq \mathbb{C}_{0},
\end{aligned}
$$

where $\widehat{\boldsymbol{p}}$ are equilibrium premiums. Equation (37) relates the total payments made to hospital $i$ by insurer $j$ to a weighted sum of components of the insurer's gains from trade and the hospital's gains from trade, where each of these gains-from-trade terms are evaluated as if the negotiated per-admission payment between the parties is equal to zero. ${ }^{71}$ The equilibrium premium $\widehat{p}_{j}$ for each insurer $j$ solves each insurer's Nash bargaining problem with the employer (where the employer is assumed to maximize the total welfare of its employees, minus premium payments to insurers), holding fixed the premiums of other insurers $\widehat{\boldsymbol{p}}_{-j}$ and hospital payments $\widehat{\boldsymbol{w}}$.

Example 14. Multichannel television negotiations. Crawford et al. (2018) assume that negotiations over contracts $\mathbb{C}$ that specify per-subscriber affiliate fees $\boldsymbol{w}$ are conducted simultaneously with downstream distributor pricing. As in Example 13, this means that distributor prices are contained in action-set $\boldsymbol{a}_{0}$, and are held fixed at their equilibrium values when evaluating contracting outcomes. With this assumption, and with payoffs given by (33)-(34) from Example 12, it turns out that the same Nash-in-Nash first-order conditions from Example 13 characterize equilibrium affiliate fee contracts (albeit now in a different setting). In this context, equation (37) relates the total payments made by distributor $j$ to channel $i$, on the left-hand-side, to the weighted sum of their gains-from-trade when their negotiated affliate fee $w_{i j}$ is zero.

\footnotetext{
${ }^{70}$ This implementation is consistent with the assumption that contracts are observable. The analysis can be modified if certain contracting outcomes are instead not observed. For example, Horn and Wolinsky (1988) and Iozzi and Valletti (2014) examine models where agreed-upon contract terms are observable, but off-equilibrium disagreements are not.

${ }^{71}$ As shown in [Chapter by Handel and Ho], the first-order conditions given by (37) can be rewritten in terms of underlying primitives:

$$
\begin{aligned}
\widehat{w}_{i j} \times \underline{D}_{i j}(\cdot)= & \left(1-b_{i j}\right) \times\left(\left[\Delta_{i j} \underline{D}_{j}(\cdot)\right]\left(\widehat{p}_{j}-\eta_{j}\right)-\left(\sum_{h \in\left(\boldsymbol{N}_{\left.D_{j} \backslash\{i\}\right)}\right.} \widehat{w}_{h j}\left[\Delta_{i j} \bar{D}_{h j}(\cdot)\right]\right)\right) \\
& \left.+b_{i j} \times\left(c_{i} \times \bar{D}_{i j}(\cdot)-\sum_{k \in\left(\boldsymbol{N}_{U i} \backslash\{j\}\right)}\left[\Delta_{i j} \bar{D}_{i k}(\cdot)\right]\left(\widehat{w}_{i k}-c_{i}\right)\right]\right),
\end{aligned}
$$

where the demand objects $\left[\Delta_{i j} \bar{D}_{h k}(\cdot)\right]$ and $\left[\Delta_{i j} \underline{D}_{k}(\cdot)\right]$ represent changes in hospital $h$ demand from insurer $k$ 's enrollees, and insurer $k$ 's demand, when hospital $i$ and insurer $j$ disagree (i.e., when contracts adjust from $\widehat{\mathbb{C}}$ to $\left.\left\{\mathbb{C}_{0}, \widehat{\mathbb{C}}_{-i j}\right\}\right)$.
} 
In contrast, Crawford and Yurukoglu (2012) assumes that contracts are negotiated before distributor prices $\boldsymbol{p}$ are set. ${ }^{72}$ This implies that distributor prices are in the set of actions $\boldsymbol{a}_{1}(\mathbb{C})$, and respond to any changes in contracts. With this alternative assumption, the Nash-in-Nash firstorder conditions differ from those in (37) in two important ways. First, agreement and disagreement payoffs for each channel $i$-distributor $j$ pair condition on different sets of downstream prices (i.e., $\boldsymbol{p}(\widehat{\mathbb{C}})$ and $\left.\boldsymbol{p}\left(\left\{\mathbb{C}_{0}, \widehat{\mathbb{C}}_{-i j}\right\}\right)\right)$. Second, agreement payoffs account for changes in distributor prices when affiliate fees adjust from their equilibrium levels. For example, with a single channel and single distributor, the first-order condition contains a term analogous to $\bar{D}^{\prime}(w)$ in (11) from Example 2 , which accounts for the effect of upstream wholesale prices on downstream prices, and hence demand. When there are multiple distributors, the first-order conditions account for adjustments in equilibrium prices from the downstream-pricing game (as in Villas-Boas (2007)).

Remarks on Timing. In the previous two examples, Ho and Lee (2017) and Crawford et al. (2018) assume that contracting occurs at the same time as downstream pricing. Though firms' disagreement points do account for the potential responses of consumers to contracting breakdowns, there is no adjustment in downstream demand when wholesale prices change in equation (37), as downstream prices are held fixed when wholesale prices adjust. This is in contrast to Example 2, which discusses the Nash bargaining solution in a successive monopoly setting, and Crawford and Yurukoglu (2012), which assumes that downstream pricing occurs after contracting concludes.

As noted at the beginning of this Section, researchers have adopted different timing assumptions for various reasons. One reason for assuming simultaneous contracting and pricing is that it provides meaningful computational advantages: in both Ho and Lee (2017) and Crawford et al. (2018), the Nash-in-Nash first-order conditions given by (37) express wholesale prices as a system of linear equations, allowing these prices to be solved for directly from cost objects, downstream prices, and bargaining parameters. For instance, Ho and Lee show that the Nash-in-Nash conditions for all contracting pairs can be written as $\boldsymbol{w}=(\boldsymbol{X})^{-1} \times \boldsymbol{Y}$, where $\boldsymbol{X}$ is a square matrix, $\boldsymbol{Y}$ is a vector, and elements of each contain only non-wholesale price terms on the right-hand side of (38); Crawford et al. provide a similar derivation. In contrast, under sequential contracting and pricing as in Crawford and Yurukoglu (2012), maximizing a single pair's Nash product (holding fixed other pairs' contracts) requires solving for different downstream pricing equilibria as contract terms vary, and upon bargaining disagreement.

While simultaneous actions have been assumed for computational reasons, it should be noted that there are somewhat different incentives under sequential versus simultaneous contracting and downstream pricing. For example, consider the cable television setting of Crawford et al. (2018), and assume that upstream channel $i$ is owned by downstream distributor $j$. When bargaining and downstream pricing are simultaneous, channel $i$ perceives that all downstream distributors' prices are fixed at equilibrium levels when negotiating affiliate fees; this means that channel $i$ does not

\footnotetext{
${ }^{72}$ Crawford and Yurukoglu (2012) also consider an alternative bargaining model under which disagreement between any pair results in all other pairs renegotiating, with the disagreeing pair no longer able to negotiate (recall the related discussion in Section 2.1.2).
} 
anticipate any direct benefits to its integrated distributor $j$ from an increase in its affiliate fee to some rival distributor $k$. Nonetheless, channel $i$ does internalize the benefit to its integrated distributor $j$ if it forecloses distributor $k$ altogether: this is because consumers are assumed to act after all supply decisions are made, and hence can respond to observed bargaining breakdowns that affect the channels that are available in a distributor's bundle. This reduction in channel $i$ and rival $k$ 's gains from trade (by increasing the integrated channel's disagreement payoff) alters equilibrium affiliate fees (see (37)), and can lead to increases in negotiated affiliate fees with rival distributors due to vertical integration, even with simultaneous contracting and pricing. ${ }^{73}$

Similarly, even with simultaneous contracting and downstream pricing, double marginalization may still be present in equilibrium:

Example 15. Double marginalization under Nash bargaining with simultaneous contracting and pricing. Consider again the successive monopoly setting from Example 2 where a manufacturer and retailer Nash bargain over a wholesale price w. Assume now that bargaining over $w$ occurs simultaneously and separately from the retailer setting its price $p$. In this case, firms take retail prices $\widehat{p}$ as given when bargaining, and the retailer takes the wholesale price $\widehat{w}$ as given when setting prices. In equilibrium, the Nash bargaining condition given by (8) implies that $\widehat{w}=(1-b)\left(\widehat{p}-c_{R}\right)+b c_{M}$, and retailer profit maximization implies that $\widehat{p}=\widehat{w}+c_{R}-D(\widehat{p}) / D^{\prime}(\widehat{p})$. Whenever $b<1$ so that the retailer does not have all the bargaining power, the wholesale price exceeds the manufacturer's marginal cost $\left(\widehat{w}>c_{M}\right)$, and the retailer and manufacturer do not maximize joint profits. ${ }^{74}$

In the end, different timing assumptions represent different static approximations to real-world dynamics, and hence none will be completely accurate. ${ }^{75}$ Absent compelling institutional evidence or other reasons pointing in one direction or another, researchers' decisions will typically be influenced by theoretical as well as tractability or computational considerations.

\subsection{Supply: Estimation and Identification}

We now turn to the estimation and identification of these vertical contracting models. On the supply side, objects to be estimated can include marginal costs, contract terms, and bargaining

\footnotetext{
${ }^{73}$ As noted in Crawford et al., this "raising-rivals' costs" effect under simultaneous bargaining and downstream pricing differs from that identified in Salop and Scheffman (1983) and Krattenmaker and Salop (1986). In those papers, the upstream supplier has all the bargaining power, and input prices are determined before downstream prices are set; in such a setting, the integrated firm's motive to increase a rival's input price arises from the anticipated effect of a higher input price on downstream consumer prices.

${ }^{74}$ With simultaneous pricing and bargaining, there may not exist an equilibrium with positive demand when the retailer's bargaining weight $b$ is sufficiently low.

${ }^{75}$ For example, consider contracts that specify upstream wholesale prices, and the only other supply-side actions are pricing decisions by downstream firms. Assuming that downstream pricing takes place after contracting concludes, and that downstream prices immediately adjust to wholesale price adjustments before consumers act, ignores the possibility that downstream prices may be fixed for some length of time (e.g., monthly service prices for television services, annual health insurance premiums). However, assuming that downstream prices are determined at the same time as contracts implies that downstream prices do not adjust to potentially large unanticipated contracting adjustments, including disagreements and breakdowns. Depending on the length of time being represented by a period in the model - e.g., months or years - this may or may not be plausible.
} 
parameters. Restrictions from the supply side can also help to estimate demand parameters in certain cases, which we discuss in Section 3.3. What is assumed as opposed to estimated is often determined by a combination of institutional details, ancillary information, or variation in the underlying data that enables the identification of underlying primitives or conduct.

In Example 2, Nash bargaining in successive monopoly with linear prices, equation (12) describes an equilibrium relationship between negotiated wholesale prices, manufacturer marginal cost, retailer additional marginal cost, bargaining parameters, and demand. We repeat the equation here:

$$
\left(w-c_{M}\right) \bar{D}^{\prime}(w)+\bar{D}(w)=\left(\frac{b}{1-b}\right)\left(\frac{w-c_{M}}{p^{m}\left(w+c_{R}\right)-\left(w+c_{R}\right)}\right) \bar{D}(w) .
$$

When $b=0$, so the upstream firm is making a TIOLI offer, this simplifies to equation (5) from Example 1, repeated here:

$$
\left(w-c_{M}\right) \bar{D}^{\prime}(w)+\bar{D}(w)=0 .
$$

When $b=1$, the downstream firm's TIOLI offer sets $w=c_{M}$ resulting in vertical efficiency. Papers that assume $b=0$ or $b=1$ seek to estimate objects such as unobserved contractual terms or unobserved marginal costs of production. In what follows, we primarily focus on bargaining models where the goal is to estimate $b$.

In the ideal data scenario for estimating $b$, the researcher has estimated a demand system using standard techniques (e.g. Berry, Levinsohn and Pakes (1995)) and observes wholesale prices $w$, downstream marginal cost $c_{R}$, and upstream marginal costs $c_{M}$. In this case, the bargaining parameter $b$ can be recovered to satisfy equation (39). This is similar in spirit to inferring marginal costs in a differentiated goods oligopoly price competition model using firms' first-order conditions and an estimated demand system. Here, additional data on marginal costs allows the researcher to relax this pricing assumption and estimate a bargaining parameter $b \in[0,1]$. If no bargaining parameter can be found to satisfy equation (39), the model is rejected unless it is adjusted in some way (for example, by allowing for an error term to reflect measurement error in one of the observable components). Under the Nash-in-Nash model, expanding this example to multiple upstream and multiple downstream firms is straightforward. Conditional on all other pairs, the bargaining problem for each pair satisfies an equation like (39). As discussed in Section 3.1, one can solve for pair-specific bargaining parameters which can then be held constant for counterfactual analysis, or projected on firm characteristics for analysis.

However, when one deviates from the idealized data scenario, additional assumptions are often necessary. We continue to assume a demand system is available. ${ }^{76}$ We focus on two cases: unobserved marginal costs and unobserved wholesale prices.

Unobserved marginal costs. In the bilateral monopoly case, when the manufacturer's marginal costs are not observed, there is an identification problem regarding separating its marginal costs from the bargaining parameter. If one observes a high wholesale price, this could be either because

\footnotetext{
${ }^{76}$ In Section 3.3.4, we discuss how a supply model can be used in demand estimation.
} 
the upstream marginal cost is high, and the upstream firm is a weak bargaining party, or because the upstream marginal cost is low, and the upstream firm is a strong bargaining party. Essentially, there is one equation and two unknowns.

Identification is possible if one observes multiple instances of bargaining and an observable component of surplus, and further assumes that the bargaining parameters are uncorrelated with the observable component of surplus (for example, equal to constant plus an i.i.d. shock) across observed instances. In this case, how the negotiated price moves with changes in surplus identifies the bargaining parameter. To see this in the bilateral monopoly case, consider observations of tuples of $\left\{w_{t}, c_{R t}, z_{t}\right\}$ where $w_{t}$ are generated by equation (39), $D$ is known, $z$ shifts the surplus available to split at a known rate (for example through $c_{M}$ ), and $t$ represents separate instances of bargaining such as different geographic markets or time periods. Assume that $c_{M t}=\lambda+z_{t}$, and $b_{t}=\bar{b}+\epsilon_{t}$ with $\operatorname{cov}\left(z_{t}, \epsilon_{t}\right)=0$. For candidate values of $(\bar{b}, \lambda),\left\{\epsilon_{t}\right\}$ can be recovered from (39). Since $z$ is assumed orthogonal to $\epsilon_{t}$, one can then estimate $(\bar{b}, \lambda)$ from the associated moment conditions $E\left[Z_{t} \epsilon_{t}\right]=0$ for $Z_{t}=\left[1, z_{t}\right] \cdot{ }^{77}$

As one example, in Crawford et al. (2018), advertising revenue per subscriber (earned by the upstream firm) is observed and enters as a negative marginal cost, and $\bar{b}$ is estimated by assuming advertising revenue is uncorrelated with $\epsilon$, and thus from how $w$ correlates with advertising revenue per subscriber. Were $w$ to move exactly one to one with advertising revenue per subscriber, then one would estimate a bargaining parameter $b=1$ as the downstream firm sets $w=c_{M}$. Otherwise, pass-through is incomplete and the degree to which advertising revenue per subscriber affects $w$ identifies $b$.

The above discussion assumes that the contract space consists of linear wholesale prices. Under the assumption of two-part tariffs with Nash-in-Nash bargaining and with observed contracts, the bargaining parameter can be inferred from the lump-sum transfer. The linear part of the tariff is chosen to maximize bilateral surplus, thus for an observed linear tariff, one can infer the upstream marginal cost and implied bilateral surplus. The bargaining parameter is the share of surplus accruing to each party which is equal to the transfer divided by the bilateral surplus.

An analogous strategy could be used if there was an unobserved error term in retailer marginal costs, or shocks to demand. The fundamental logic is to measure how the negotiated fee $w$ varies with shocks to surplus. If the downstream firm has all the bargaining power, then they will drive the fee down to the upstream firm's marginal cost, and shocks to demand will not induce any change the negotiated fee. If the upstream firm has all the bargaining power and sets linear prices, however, shocks to demand would lead to changes in the optimal $w$ according to equation (40). With constant $c_{m}$, level shifts in demand are sufficient to distinguish between these cases. If, instead, there are returns to scale in production, then rotations of the demand curve would be necessary as in Bresnahan (1982) and Lau (1982). Villas-Boas (2007) and Bonnet and Dubois (2010) extend these arguments to multiple upstream and downstream firms in the context of offer games.

\footnotetext{
${ }^{77}$ As an alternative formulation, the error term could enter just as well into the cost structure. One could assume $c_{M t}=\lambda+z_{t}+\epsilon_{t}$, and $b_{t}=\bar{b}$ with $\operatorname{cov}\left(z_{t}, \epsilon_{t}\right)=0$. Again, candidate values of $(\bar{b}, \lambda)$ imply values of $\left\{\epsilon_{t}\right\}$, and one can estimate $(\bar{b}, \lambda)$ from the associated moment conditions $E\left[Z_{t} \epsilon_{t}\right]=0$ for $Z_{t}=\left[1, z_{t}\right]$.
} 
With linear fees, generalization to the multiple upstream and multiple downstream firm case is straightforward under Nash-in-Nash as the first-order conditions hold fixed all other pairs' outcomes. Depending on the data set, other parameterizations of bargaining parameters might be possible with multiple upstream and downstream firms in lieu of observing the same exact pair

multiple times. For example, one could parameterize $b_{i j}=\frac{b_{i}}{b_{i}+b_{j}}+\epsilon_{i j}$ and proceed analogously to the bilateral monopoly case.

Grennan (2013) and Gowrisankaran, Nevo and Town (2015) each provide versions of this identification argument in the case where downstream firms do not compete with each other and negotiated wholesale prices $w_{t}$ do not feed into a successive pricing problem. Both papers use data on wholesale prices but not upstream marginal costs. In these applications, the error term can often be backed out analytically from data allowing for computationally simpler estimation. When downstream firms compete, computational difficulty depends partially on the timing of bargaining relative to downstream pricing as discussed in Section 3.1.

Unobserved contract payments. Next, consider the case of unobserved negotiated wholesale prices. One can estimate per-unit wholesale prices from downstream firm behavior. For example, in the bilateral monopoly case, if one is willing to assume optimal pricing by the downstream firm, one can invert to get downstream marginal costs. Then, variation in input usage across products can inform estimates about negotiated fees. For example, having inverted to get the total downstream marginal cost of various packages of television content, one can regress these costs on indicator variables for the inclusion of different channels to estimate their negotiated fees. In this case, identification is achieved because asymptotically one recovers the negotiated prices and is back in the ideal data scenario. Similarly, if the downstream firm chooses product characteristics after negotiations, then optimal choice of product characteristics can inform estimates of input costs. This approach is taken in Crawford and Yurukoglu (2012) and Crawford et al. (2018) who combine optimal pricing and product assortment assumptions with aggregated data on negotiated wholesale prices. Crawford and Yurukoglu (2012) impose additional parametric restrictions on negotiated wholesale prices as a function of observable characteristics of the negotiating parties to aid in estimation. These papers then proceed with estimation in the ideal data scenario with observed upstream marginal costs of delivering produced content to additional households equal to zero.

Alternatively, without data on negotiated payments but knowledge of costs and demand, the researcher may infer components of payments based on the observed pattern of agreements as in Но (2009).

\subsection{Demand}

A key input into estimating supply side parameters for models of vertical relationships is a demand system. While demand estimation is covered in detail elsewhere in this volume [Chapters by Berry and Haile, and Gandhi and Nevo], the consumer choice segment of industry models 
featuring vertical relationships usually does not nest perfectly within standard demand models because of the existence of multiple interacting choices and data constraints. To calculate payoffs, the researcher often must be able to predict the quantity of each product demanded for both upstream and downstream firms as a function of prices and product characteristics, which may be affected by negotiated contracts. Upstream or downstream quantities can potentially be a function of all upstream and downstream prices and characteristics. For example, in the healthcare example involving upstream hospitals and downstream insurers, if consumers must pay a co-payment upon visiting a hospital, then consumer demand for insurers will depend on the prices negotiated between the insurer and hospital in addition to other insurer product characteristics, such as its premiums and hospital network (which in turn depends on the characteristics of hospitals that the insurer has a contract with, such as location and quality).

It would thus be sufficient to estimate upstream and downstream demand objects $\bar{D}(\boldsymbol{p}, \boldsymbol{x}, \boldsymbol{w})$ and $\underline{D}(\boldsymbol{p}, \boldsymbol{x}, \boldsymbol{w})$, where $\boldsymbol{x}$ denotes upstream and downstream product characteristics, and $\boldsymbol{w}$ allows for the possibility that demand responds to negotiated contract terms (or potentially just the set of agreements $\left\{i j: \mathbb{C}_{i j} \neq \mathbb{C}_{0}\right\}$ ). If one observes upstream and downstream quantities, then with exogenous variation in prices and characteristics, these demand functions can be estimated using standard regression techniques. In some cases, the relevant $\bar{D}$ may be a simple transformation of $\underline{D}$. For example, in Crawford et al. (2018), downstream demand is determined by the set of upstream content channels offered in each subscription package. Knowing downstream demand, upstream quantities of subscribers to each content channel are equal to the total quantities of downstream products that include each content channel. Given the contractual form of wholesale payments being per subscriber (instead of, for example, based on usage) this quantity is all that is necessary to compute the relevant payoffs for the negotiations. However, in other settings, downstream demands do not necessarily fully determine upstream demands. For example, in the insurer and hospital case, hospitals might be paid only when a consumer visits the hospital to receive care. In this case, knowing how many consumers purchase insurance plans including each hospital does not provide the relevant notion of demand for modelling negotiations.

Many applications add additional structure to this estimation problem in light of known institutional details or because data constraints necessitate further assumptions. As examples of the former case, upstream prices might be considered irrelevant to downstream consumers conditional on downstream prices. For example, a consumer's behavior at a grocery store is naturally assumed to be unaffected by the wholesale price the store pays its suppliers, conditional on the final consumer price. As an example of the latter case of data constraints, which we describe in more detail below, in Crawford and Yurukoglu (2012) and Crawford et al. (2018) the authors add additional assumptions relating viewership behavior to demand because there is not enough variation in channel offerings to estimate $\underline{D}$ using classical techniques.

Papers in this literature typically build up demand functions from models of heterogeneous individual consumers who have preferences over product characteristics as in Berry, Levinsohn and Pakes (1995). With single-unit demand by consumers and when the researcher observes market 
shares for combinations of upstream and downstream products, standard demand estimation techniques are typically sufficient for estimating the necessary inputs to model supply negotiations. This is the case in Villas-Boas (2007) for combinations of grocery store and yogurt products, and Fan and Yang (2020) for combinations of wireless carrier and smartphone purchases.

One important case is where final consumers purchase access to a package of upstream options from which they can choose what quantities to consume different components of the bundle. For example, in media, consumers may buy access from a downstream firm to a bundle of content produced by different upstream creators, and then choose which pieces of content to consume. Negotiations occur between the content creators and downstream distributors over the terms of supply. Downstream distributors then compete with each other by setting prices for the bundle of content to consumers. In health care, downstream insurers offer a network of upstream providers to consumers. Consumers choose which providers to visit. Insurers and providers negotiate over terms of supply, and insurers compete with each other by choosing prices for access to their network. We discuss these models next.

\subsubsection{Bundles and Usage Models}

When downstream firms offer packages of upstream products or services to consumers, the choice model determining consumption of both upstream and downstream products can be a crucial input into the supply side empirical analysis (e.g., determining the gains from trade when two firms sign a contract). As previously mentioned, with enough exogenous variation in which upstream products are available through downstream distributors, a researcher could estimate valuations over access to upstream products using only downstream choice data. In this case, the upstream products offered are characteristics of downstream products, and valuations can be estimated using standard demand estimation techniques. However, in many important cases, there is not enough variation in upstream products offered to have any hope of separately estimating valuations solely from downstream choices. For example, in the television example, there are pieces of content that are available in nearly all television packages. Furthermore, upstream products could be substitutes or complements with each other, requiring interaction terms of characteristics in the downstream choice equation, and thus even more variation in offered packages. In typically-sized data sets, downstream purchase decisions alone will not suffice to get precise estimates on the valuations of this content. Without valuations of the content, the researcher is hamstrung in modelling negotiations over supply terms. The supply-side identification arguments above relied on demand being known or estimated separately. With unknown demand, a negotiated price could be high because valuations are high or because the bargaining parameter of the upstream firm is high.

Researchers have therefore estimated demand models that impose a particular structure on the linkage between upstream and downstream choices. Often, consumers are assumed to have indirect utility over downstream firms or products given by a function analogous to:

$$
u_{c j m}=\beta_{c}^{v} v_{c j m}^{*}\left(\mathbb{C}_{j}, \boldsymbol{a}\right)+\boldsymbol{x}_{j m}^{\prime} \boldsymbol{\beta}_{c}^{x}+\xi_{j m}+\varepsilon_{c j t},
$$


where consumers are indexed by $c$, downstream firms by $j$, and markets by $m ; \boldsymbol{x}_{j m}$ are observable characteristics of firm $j$ (including its price), and $\xi_{j m}$ and $\varepsilon_{c j t}$ are demand or preference shocks. The term $v_{c j m}^{*}(\cdot)$ represents the utility that a consumer obtains from upstream products through downstream firm $j$ as a function of its contracts $\mathbb{C}_{j}=\left\{\mathbb{C}_{i j}\right\}_{i \in \mathcal{I}}$ (and potentially other actions $\boldsymbol{a}$ taken by firms). The specification of this upstream product utilization term varies depending on the specific setting.

Example 16. Demand for health insurers and hospitals. In Ho and Lee (2017) (see also $H o$, 2006), the term $v_{c j m}^{*}(\cdot)$ in a consumer's utility for a downstream health insurer represents the consumer's willingness-to-pay (WTP) for access to insurer j's hospital network. A closed-form expression can be obtained when a consumer's choice of hospitals is governed by a logit demand system (see also Town and Vistnes (2001); Capps, Dranove and Satterthwaite (2003)): $v_{\text {cjm }}^{*}(\cdot)=$ $\sum_{d \in \mathcal{D}} \gamma_{c, d} \log \left(\sum_{i: \mathbb{C}_{i j} \neq \mathbb{C}_{0}} \exp \left(v_{c d i}\right)\right)$ where $\gamma_{c, d}$ is the probability of consumer $c$ requiring hospital admission for some diagnosis $d$ contained in the set of diagnoses $\mathcal{D}$, and $v_{c d i}$ is the utility (net of an idiosyncratic logit preference shock) that the consumer receives from being able to visit hospital $i$ for that diagnosis.

Example 17. Demand for multichannel television services. In Crawford and Yurukoglu (2012) and Crawford et al. (2018), the term $v_{c j m}^{*}(\cdot)$ in a consumers' utility for a downstream television distributor $j$ represents the consumer's viewership utility from the optimal solution to a time-allocation problem across channels contained in firm $j$ 's bundle in market $m$.

Example 18. Demand in hardware-software markets. Lee (2013) models demand for video game hardware platforms and software titles. The term $v_{c j m}^{*}(\cdot)$ in a consumer's utility for a downstream hardware platform represents the expected option value of being able to purchase any software title $i$ on platform $j$ that is either currently available or may be potentially available in the future.

Under this structure, the usage and consumption decisions of the upstream products made available by the downstream firm's contracts are informative about consumer valuations for upstream products. In some cases, this works even when consumers do not directly pay or exchange money with upstream firms. This approach is reminiscent of the distinction between estimating demand in product space versus in characteristic space. The usage model transforms the vector of available upstream products on a downstream product into a single dimensional usage utility $v^{*}$. The researcher thus reduces the data requirement from sufficient exogenous variation combinations of upstream products offered to requiring only sufficient exogenous variation in $v^{*}$.

As an example, consider an environment where the same two hospitals, A and B, are part of every insurer's network. However, some insurers had a third hospital $\mathrm{C}$ in their network asgood-as-randomly. Suppose the researcher's goal involves predicting demand for an insurance plan which only included hospital A. If a consumer's utility for an insurance plan is additive over the inclusion of each hospital in the plan, demand for a plan with only A would not be identified. As one alternative, the researcher could specify consumer's utility for insurance plans to be a function of a "coarser" set of characteristics than the exact set of hospitals offered. For example, the utility 
could be a function of a consumer's distance to the nearest hospital in the plan, the total number of hospitals in the plan, and an dummy variable indicating whether a pediatric hospital is in the insurer's hospital network. A researcher could estimate demand for insurance plans in this manner without utilizing data on observed choices of which hospitals to visit after a plan has been selected.

Another alternative would be use to an upstream-usage model and " $v^{*}$ " formulation, as above, to inform downstream demand. This allows the researcher to predict demand for an insurer whose network only includes A by adding functional assumptions on the usage choice and its link to downstream choice with data on usage choice. Suppose in this example, we observed that whenever $\mathrm{A}$ and $\mathrm{B}$ were equidistant and had equal out-of-pocket cost to a patient, the choice probability of A was higher than for B. The usage model would, under reasonable assumptions, generate a higher contribution to $v^{*}$ from including A than including B. The exogenous variation due to some plans also including $\mathrm{C}$ allows for identification of the coefficient on $v^{*}$ in the plan choice equation. These two ingredients together would generate a prediction that a plan consisting solely of A would have higher demand than a plan consisting solely of B, all else equal, despite never observing $\mathrm{A}$ and B separately. The benefit relative to specifying utility over a coarse set of characteristics is that the usage formulation allows for the incorporation of additional data. For example, the researcher might infer that pediatric hospitals are desirable to consumers if they see heavy usage of pediatric hospitals whenever available. Without usage data, such an inference would be based solely on observing higher market shares for insurance plans which include more pediatric hospitals, all else equal.

The functional forms that researchers have specified for the usage model depend on the application and data availability. Ho (2006), Gowrisankaran, Nevo and Town (2015), and Ho and Lee (2017) use a logit model of hospital usage based on Capps, Dranove and Satterthwaite (2003) to estimate willingness-to-pay for inclusion of hospital in an insurance plan's network. Crawford and Yurukoglu (2012) use a Cobb-Douglas model of time allocation to estimate usage of television channels. Lee (2013) employs a model of dynamic choice under uncertainty in modelling video game hardware choice to account for the possibility of new game software being released after a consumer purchases the hardware. ${ }^{78}$

In addition to aiding in the estimation of demand parameters, the usage model might itself be a necessary component for calculating firm payoffs to the extent that payoffs depend directly on usage. This occurs when wholesale payments depend on usage, such as pay-per-service contracts between hospitals and insurers. It also occurs in some two-sided market models where advertising revenue is a function of usage rather than subscriptions. As we noted earlier, Crawford and Yurukoglu (2012) and Crawford et al. (2018) present different modelling strategies related to this point. In Crawford and Yurukoglu (2012), advertising revenue is assumed to be a function of viewership of each channel. Therefore, to compute payoffs, the researcher must necessarily have a model of

\footnotetext{
${ }^{78}$ Usage data often, though not always, is available at levels of aggregation that may aid in adding heterogeneity to a model. For example, viewership data for television channels is often available at the demographic, geographic, or individual level which makes it easier to estimate a usage model with agent heterogeneity similar to the use of individual level data in Berry, Levinsohn and Pakes (2004).
} 
viewership. In Crawford et al. (2018), advertising revenue is assumed to be a function of the number of subscribers of each channel. Therefore, the viewership model's role is solely to help estimate valuations for content given limited variation in the observed set of packages offered to consumers.

\subsubsection{Upstream Choice Only}

Another separate simplification that some papers have made is to focus only on demand for upstream products. For example, in Grennan (2013), hospitals negotiate and purchase medical devices from manufacturers. A choice model takes preferences, prices, and product characteristics and produces a decision of the device a doctor and patient at the hospital utilize. However, the decision of doctors and patients over which hospital to use is outside of the specified model. In Gowrisankaran, Nevo and Town (2015), health insurers negotiate with hospitals to provide access to hospital services for consumers. The choice model determines which hospitals consumers attend given the prices and networks negotiated by their insurance plan, but the choice of insurance plan by consumers is outside of the model. In many cases, this is a reasonable modelling assumption that substantially simplifies the computational burden of the model. It is also commonly used in industry models that do not focus on determination of supply relationships. For example, in Berry, Levinsohn and Pakes (1995), consumers directly choose car models and the decision of which dealership to purchase from is not modeled.

Embedding such an upstream choice-only model of demand into a bargaining model over supply terms can however limit the set of economic forces that determine the outcome of a negotiation. For example, in the case of a hospital-insurer relationship, if an insurer does not have a hospital on its network, such a model will not predict any loss of final customers for the insurer. To model a cost to the insurer of losing a hospital, Gowrisankaran, Nevo and Town (2015) specify that the objective function of the insurer is the indirect utility of its final customers from choosing among the hospitals on its network minus total payments to hospitals. In this formulation, a disagreement

between a hospital and insurer does not impact other insurers' relationships with hospitals. ${ }^{79}$ The interaction between negotiations is limited to those negotiations that involve the same downstream firm. Such an assumption may be reasonable in the case of an insurer who has long-term contracts with its final customers, but may be less attractive in markets where final customers can and do switch in response to changes in portfolio of products offered by the downstream firm.

\subsubsection{Consumer Selection}

An important selection problem can arise when estimating downstream and upstream demand models when there is unobservable heterogeneity in consumer preferences for upstream products. Specifically, because consumers choose a downstream firm based on the upstream products the downstream firm makes available, consumption of particular upstream products may only be observed for consumers who have unobservably high valuations for those products. Ignoring this

\footnotetext{
${ }^{79}$ This assumes a constant marginal cost for hospitals, including, for example, that there are no binding capacity constraints.
} 
sample selection issue can lead to estimates of willingness-to-pay for upstream products that are upward biased. ${ }^{80}$ Crawford and Yurukoglu (2012), Crawford et al. (2018), and Lee (2013), for example, estimate the upstream and downstream choice models jointly to control for potential "selection on unobservables." Joint estimation ensures that the consumption decisions of upstream products that are being compared to the data are made by consumers in the model who selected into the downstream product that featured the upstream products they desire. Specifically, joint estimation entails simultaneously searching for combinations of parameters at both the upstream and downstream choice levels and ensuring that the choices are mutually consistent with each other. For example, in the case of media, consumers can only watch channels which they have purchased access to. Therefore, the upstream viewership choice is conditional on liking the package of available channels enough to have purchased it. If a researcher were to separately estimate upstream and downstream choice, this would lead to overestimating consumer valuations for content because the observed set of consumers choosing among that content is selected to have higher average valuations for that package of content. The joint modelling of upstream and downstream choice is in the spirit of Heckman (1979), and a similar point is made by Dubin and McFadden (1984) in the context of discrete-continuous choice models.

A brief overview of the procedures used in Crawford and Yurukoglu (2012), Crawford et al. (2018), and Lee (2013) follows. These specify consumer utility for downstream products as in $(41)$, and allow the term $v_{c j m}^{*}\left(\mathbb{C}_{j}, \boldsymbol{a}\right)=v_{j m}^{*}\left(\mathbb{C}_{j}, \boldsymbol{a} ; \boldsymbol{\gamma}_{c}\right)$ to vary across consumers based on a vector of unobserved preferences $\gamma_{c}$ for upstream products (that are known to consumers prior to the purchase of any downstream good). Let $\theta$ represent the parameters of the model, which include those that govern the distribution of both upstream $\left(\boldsymbol{\gamma}_{c}\right)$ and downstream $\left(\boldsymbol{\beta}_{c}^{x}\right)$ preferences. These papers estimate $\theta$ via generalized methods of moments.

In Crawford and Yurukoglu (2012) and Crawford et al. (2018), one set of moment conditions interacts downstream product-market demand shocks $\left\{\xi_{j m}\right\}$ for distributor bundles with a set of instruments; another set is the distance between channel ratings data and the model's predicted viewership of channels (which is a function of the preferences of consumers who choose to subscribe to each distributor bundle). ${ }^{81}$ For each evaluation of parameter vector $\theta$, Crawford et al. compute these moments by: (i) drawing a set of household preferences $\left\{\boldsymbol{\gamma}_{c}, \boldsymbol{\beta}_{c}^{x}\right\}$ from the parameterized distribution; (ii) solving each household's optimal viewership program, thereby generating a value of $v_{c j m}^{*}(\cdot)$ for each household-bundle-market; and (iii) solving for each consumer's optimal bundle choice given $v_{c j m}^{*}(\cdot)$, and using the contraction mapping technique from Berry, Levinsohn and Pakes (1995) (BLP) to recover the values of downstream demand shocks $\left\{\xi_{j m}(\theta)\right\}$ that match observed to predicted downstream product market shares.

Lee (2013) also interacts downstream demand shocks $\left\{\xi_{j m}\right\}$ for hardware platforms with a set of

\footnotetext{
${ }^{80}$ This selection issue will not be present if consumers do not know the realization of such preferences for upstream products prior to purchasing the downstream product (as is typically assumed for upstream idiosyncratic preference shocks in logit-based demand models). In addition, controlling for selection when consumer preferences depend only observable consumer characteristics is more straightforward (see, e.g., Ho, 2006).

${ }^{81}$ There are also additional moments derived from the supply side of the model; see Section 3.3.4.
} 
instruments as one set of moment conditions. As opposed to using a measure of upstream product (software) usage as a second set of moments, Lee instead, in a manner analogous to the estimation of downstream product demand, recovers upstream product demand shocks, denoted $\left\{\zeta_{k m}\right\}$, for each upstream product market and interacts these with another set of instruments. For each evaluation of parameter vector $\theta$, Lee recovers both downstream and upstream product demand shocks by: (i) drawing a set of household preferences $\left\{\boldsymbol{\gamma}_{c}, \boldsymbol{\beta}_{c}^{x}\right\}$ from the parameterized distribution; (ii) for given values of $\left\{v_{c j m}^{*}(\cdot)\right\}$ for each consumer-hardware product market (starting with arbitrary values), using techniques from BLP to recover downstream product-market demand shocks to match observed and predicted downstream market shares, and generate predictions for which households choose which downstream products; (iii) given the predicted downstream hardware product choices of each household, using techniques from BLP to recover upstream software product market demand shocks that match observed and predicted upstream market shares, and generate updated measures of $\left\{v_{c j m}^{*}(\cdot)\right\}$ (which represents the expected option-value of purchasing software products available both in the present and in the future, and depends on updated upstream-product preferences); (iv) iterating between steps (ii)-(iii) until convergence on $\left\{v_{c j m}^{*}(\cdot)\right\}$, at which point the converged values for $\left\{\xi_{j m}(\theta), \zeta_{k m}(\theta)\right\}$ are used to construct moments.

\subsubsection{Joint Estimation of Demand with Supply}

Just as in the case of joint estimation of demand and oligopoly pricing, there are potential efficiencies in jointly estimating demand and a supply model of vertical relationships. Intuitively, a high wholesale price might indicate a high valuation of an input. As mentioned above, this intuition breaks down if demand and bargaining parameters are fully flexible. However, under certain parametric restrictions, observing wholesale prices and specifying a model of vertical relationships can provide information to help estimate consumer valuations. Crawford et al. (2018) provides an example from the media sector. The motivating observation for this approach in that setting is that certain types of upstream content that consumers view for similar amounts of time commanded vastly different wholesale prices. Specifically, sports content has higher wholesale prices than nonsports content for the same amount of usage by consumers. This pattern could be explained by sports content having higher bargaining parameters, or by a richer demand system that can predict different valuations for pieces of content that have the same amount of usage. Crawford et al. (2018) specify the model so that all content has the same bargaining parameter, and rationalize the higher prices by estimating a richer demand model that allows sports content to be valued differently than non-sports content.

\section{Recent Applications}

We now provide an overview of recent empirical work that employs structural models of vertical contracting and bargaining. The applications that we cover include the competitive and welfare

effects of horizontal and vertical mergers, price discrimination, and non-linear and exclusionary 
contracts. $^{82}$ Of course, our discussion here is by no means comprehensive. For example, researchers have used variants of the models described in this chapter to study other topics, including the market for financial advice and the relationships between mortgage brokers and originating banks (Robles-Garcia, 2019), the arrangements between Apple, Amazon, and book publishers (De los Santos, O'Brien and Wildenbeest, 2021), and the effect of buying alliances in grocery procurement (Molina, 2019). Moreover, the modeling framework has been used to examine settings outside of IO that are still characterized by market power and contracting externalities, including bilateral tariff negotiations between countries (Bagwell, Staiger and Yurukoglu, 2020, 2021). Our aim here is to provide the reader with an introduction to this broader literature, and a sense for the variety of topics that have been studied.

\subsection{Horizontal Mergers in Vertical Markets}

Analysis of proposed horizontal mergers is a central mission of competition agencies around the world. Modern developments in the industrial organization literature have introduced new tools, such as merger simulation, for forecasting their effects (see, for example, Whinston, 2007). ${ }^{83}$ These merger simulation tools have typically assumed that sellers simultaneously name simple linear prices for buyers, regardless of whether the buyers are final consumers or large downstream firms. Moreover, in many cases the downstream industry is not even considered; for example, manufacturers may be modeled as choosing the retail prices consumers face, implicitly treating downstream distribution as a competitively supplied input. ${ }^{84}$

However, in many cases downstream buyers or upstream suppliers are significant players in the vertical chain of production and distribution and this can matter for the effects of horizontal mergers at a given level of the vertical structure. For example, if downstream buyers have significant bargaining power this may limit the ability of merging firms to exercise market power post merger. The methods we have surveyed here have been used to address such issues.

Gowrisankaran, Nevo and Town (2015) study a proposed 2006 merger of hospitals in Virginia. The buyers of hospital services they focus on are large insurers. Gowrisankaran, Nevo and Town (2015) begin by estimating consumers' demand for hospital services. One initial striking finding is that hospitals' prices for procedures (observed in claims data from four insurers) are much lower than what could be explained by standard differentiated-goods Nash-equilibrium pricing by hospitals given hospital's marginal costs and the very low price elasticity consumers exhibit for hospital services as a result of their insurance coverage. Gowrisankaran, Nevo and Town (2015) therefore adopt a Nash-in-Nash bargaining framework both to be consistent with these observed prices and to simulate the effects of the merger. They find that the merger (which was blocked by the FTC) would have led to significant hospital price increases and a reduction in consumer welfare despite insurers' bargaining leverage.

\footnotetext{
${ }^{82}$ See also [Chapter by Asker and Nocke].

${ }^{83}$ Merger simulation has focused on what are known as "unilateral effects." Forecasting the effects of mergers on tacit coordination ("coordinated effects") remains largely undeveloped.

${ }^{84}$ See, for example, Nevo (2001).
} 
Another possibility that may limit consumer harm from mergers is that by improving the merging firms' negotiating power with suppliers, input costs may fall enough that downstream prices fall rather than rise. Ho and Lee (2017) study this issue, again with a focus on the bargaining between insurers and hospitals. In this case, however, the issue is the effect of a reduction in competition among insurers. ${ }^{85}$ The merger of firms that compete against one another both in selling to consumers and in procuring inputs has ambiguous effects on the prices that they can negotiate with suppliers. ${ }^{86}$ On one hand, if downstream prices increase, this will increase the value that the downstream buyers have for the input, which will tend to increase negotiated input prices. On the other hand, the downstream merger will give the merging firms more bargaining leverage. To see why, consider a merger between insurers $j$ and $k$. Before the merger, when one of the insurers, say $j$, negotiated with a hospital, failure to strike a deal would shift some consumers to insurer $k$, and some of those consumers would end up going to the hospital. After the merger, however, if the hospital fails to strike a deal with the merged insurer it will lose these consumers. So the hospital faces greater harm from a failure to strike a deal. Likewise, a merged insurer is less likely to lose consumers' business if it fails to strike a deal than prior to the merger (for example, consumers who like the hospital no longer have the option to shift to insurer $k$ if insurer $j$ does not have the hospital in its network). In general, negotiated input prices could rise or fall, and Ho and Lee (2017) identify factors that push in each direction. If hospital prices do fall enough, this can lead the merged insurer to reduce its premium, despite the fact that competition for consumers between the merging insurers has been eliminated.

\subsection{Effects of Vertical Integration and Mergers}

Over the past several decades, a large theoretical literature has developed potential pro- and anticompetitive theories of vertical mergers and integration (surveys include Perry, 1990; Rey and Tirole, 2007; Riordan, 2008; Bresnahan and Levin, 2013). Such theories include efficiencies arising from the elimination of double marginalization (Spengler, 1950) and alignment of investment incentives (Willamson, 1985; Grossman and Hart, 1986), as well as welfare losses arising from incentives to foreclose rivals and raise their costs (Salop and Scheffman, 1983; Ordover, Saloner and Salop, 1990). Relatively less has been written about which incentives are economically meaningful, whether firms act upon them, and the circumstances under which vertical mergers are likely to generate, on net, harm or benefit. The answers to these ultimately empirical questions are at the heart of vertical merger policy, which historically in many countries has been more permissive than policy towards horizontal mergers. ${ }^{87}$

One recent paper that addresses such questions is Crawford et al. (2018), which does so in

\footnotetext{
${ }^{85}$ Ho and Lee (2017) look at the impact of removing an insurer from the market, rather than a merger, but the analysis is directly relevant for mergers as well.

${ }^{86}$ The consideration of competition between insurers also distinguishes Ho and Lee (2017) from Gowrisankaran, Nevo and Town (2015), who assume that insurers are monopolists for their customers.

${ }^{87}$ For instance, prior to the 2017 AT\&T/Time Warner merger, neither the US Department of Justice nor Federal Trade Commission had litigated a vertical merger case in 40 years.
} 
the context of integration between regional sports networks (RSNs) and multichannel (cable and satellite) television distributors in the US. The authors' focus on this market is driven in part by the significant variation in ownership patterns of RSNs by television distributors across local markets and over time, and the reach and scale of the multichannel television industry and sports programming. Complementing reduced-form work examining vertical integration in this industry (Waterman and Weiss, 1996; Chipty, 2001; Chen and Waterman, 2007; Suzuki, 2009), Crawford et al. quantify merger efficiencies (modeled as reduced double marginalization and increased carriage of integrated channels) separately from foreclosure incentives (a firm's desire to deny rivals access to integrated inputs), and also provide estimates of overall welfare effects. ${ }^{88}$

Crawford et al. (2018) conduct their exercise as follows. They first assemble a data set on the US multichannel television market from 2000-2010, containing aggregate and individual level data on both consumer behavior, such as viewership and subscription patterns, as well as firm-level pricing, quantities, and channel bundles at the local market level. Second, they build and estimate a structural model of consumer viewership and subscription decisions, distributor pricing and carriage decisions, and bargaining between distributors and channel providers (portions briefly described earlier in this chapter). Importantly, the model does not assume that incentives are perfectly aligned within an integrated firm, but rather estimates the extent to which firms internalize the profits of integrated units when making pricing, carriage, or supply decisions. The model also allows the authors to estimate the degree to which RSNs recognize and act on incentives to foreclose rivals of their downstream distribution divisions. This flexibility is found to be economically important, as the authors estimate that an integrated distributor internalizes 79 cents of each dollar earned by an integrated RSN when making pricing and carriage decisions. However, the authors find that integrated RSNs fully internalize their distributor's profits when choosing to supply or foreclose a rival distributor. These estimates are primarily informed by the extent to which integrated distributors are more likely to carry their own channels than predicted by the channel's profitability to the distributor alone, and the extent to which integrated channels are less likely to be supplied to rival distributors in markets where such exclusion is permitted.

Using estimates from their structural model, the authors simulate vertical mergers and divestitures for $26 \mathrm{RSNs}$ that were active in 2007. They find that, on average across channels, the overall net effect of integration on total and consumer welfare is positive, and is on the order of approximately $15-16 \%$ of the average consumer willingness to pay for an RSN. However, there is considerable heterogeneity across markets: in four markets where a rival distributor is predicted to be denied access to an integrated channel, estimated consumer welfare gains are negative (although statistically indistinguishable from zero). Rival distributors, moreover, are on average significantly harmed. These findings suggest that both efficiency and foreclosure effects of vertical mergers can meaningful affect welfare, and-given the variation in magnitudes across markets - that effective vertical merger analysis is likely to require a highly industry- and fact-specific inquiry. The paper's

\footnotetext{
${ }^{88}$ See also Hastings and Gilbert (2005), Hortaçsu and Syverson (2007), Atalay, Hortaçsu and Syverson (2014), and Luco and Marshall (2020) for work examining the efficiency and foreclosure effects of vertical integration in other industries.
} 
analysis also is silent on some other possible welfare effects of vertical integration, most notably on investment and entry behavior (Grossman and Hart, 1986; Hart and Moore, 1990).

Adopting a similar approach, Cuesta, Noton and Vatter (2019) examine vertical integration between hospitals and insurers in the private Chilean health care market. Building upon the hospital-insurer industry model developed in Ho and Lee (2017), they explore the extent to which integrated hospitals and insurers reduce double marginalization, and act to foreclose rival insurers from their hospital services. As in Gowrisankaran, Nevo and Town (2015), the authors assume consumers' hospital choices are affected by negotiated prices. Cuesta, Noton and Vatter use their model's estimates to simulate the effects of eliminating vertical integration between private insurers and hospitals in the city of Santiago, and find that eliminating vertical integration, assuming no cost efficiencies from integration, would lower negotiated hospital prices and benefit consumers on average. As the authors discuss, both the direction and magnitude of the net welfare impact is sensitive to consumer responsiveness to hospital prices and insurance premiums.

Ellickson, Kong and Lovett (2018) examine how retailers can use private-label products to increase their bargaining leverage with non-integrated suppliers. They focus on the "Single-cup" coffee pod market, which was pioneered and successfuly marketed by Keurig and Green Mountain Coffee Roasters in the mid-2000s. In 2012, the patent for the technology expired, allowing retailers to enter the market with their own private-label products. Ellickson, Kong and Lovett develop and estimate a demand system and supply-side model with Nash-in-Nash bargaining between manufacturers of coffee pods and retailers (similiar to Draganska, Klapper and Villas-Boas, 2010) to recover wholesale prices both prior to and following patent expiration. The authors estimate that a fifth of the profits generated from the introduction of private labels were attributable to being able to negotiate better wholesale prices for non-integrated, branded products.

Last, Yang (2020) expands upon the previous analyses by measuring the impact of integration on investment and R\&D incentives. ${ }^{89}$ The author focuses on the smartphone industry, and models the interactions between a dominant "system-on-chip" (SoC) manufacturer (Qualcomm) and three major smartphone manufacturers (Apple, HTC, and Samsung) by adding a Nash-in-Nash bargaining stage to a dynamic investment game developed in Igami (2017). Yang (2020) assumes that upstream investments by Qualcomm and downstream investments by smartphone manufacturers are complementary, and simulates industry outcomes if Qualcomm hypothetically merged with HTC. In the analysis, the divisions of the vertically integrated firm jointly make investment decisions and fully internalize benefits across units, but vertical integration also creates incentives for the merged firm to raise input prices for rival smartphone manufacturers. On net, Yang finds that this hypothetical vertical merger would increase investment activity and innovation for all firms, and benefit consumers.

\footnotetext{
${ }^{89}$ Related is Eizenberg (2014) which models the product availability and pricing response in the downstream personal computer market to an exogeneous change in the set of upstream products offered by CPU manufacturers.
} 


\subsection{Price Discrimination}

A series of theoretical papers examine the effects of third degree price discrimination on social welfare (Schmalensee, 1981; Varian, 1985; Katz, 1987) finding generally that the effects of price discrimination are theoretically ambiguous. In response, an empirical literature has emerged in which authors specify and estimate specific industry models in order to simulate counterfactual environments with alternative regulations on price discrimination. Several papers in this literature incorporate a vertical market model into their analysis.

Crawford and Yurukoglu (2012) study multichannel television where downstream firms price discriminate by bundling. Bundling of content by multichannel video program distributors (MVPDs) for sale to consumers attracted significant regulatory scrutiny in the mid 2000s. The chair of the FCC at the time professed his belief that "all consumers would benefit from cable channels being sold in a more à la carte manner", ${ }^{90}$ while in 2006 and 2013 Congress considered bills that would mandate à la carte pricing for cable channels. Since all US markets exhibited various forms of bundling, and because theoretically the effects of bundling on consumer and social welfare are ambiguous, Crawford and Yurukoglu (2012) approach the question by specifying and estimating a model of the industry under bundling which was rich enough to predict outcomes in a counterfactual unbundled world. Modelling the reaction of the wholesale market to banning downstream firms from bundling turns out to be crucial for the predicted welfare effects.

The model consists of four stages. In the first stage, upstream content conglomerates and downstream MVPDs negotiate over the wholesale prices of content. In the second stage, MVPDs compete by setting prices to consumers. In the third stage, consumers choose which package to purchase from which MVPD. In the fourth stage, consumers allocate their time to viewing the channels to which they have access through their purchase.

The consumer model of viewership and subscription decisions play an important role in the analysis. Simulating unbundling requires estimates of valuations on individual channels, and the theoretical literature has shown further that the correlation in valuation across channels is important for understanding the effects of bundling (Stigler, 1963; Adams and Yellen, 1976). Inferring a multidimensional distribution of valuations from bundle choice was infeasible with the observed degree of variation in the offered bundles. In the viewership decision, however, the authors can observe choices made at the individual channel level. Furthermore, viewership data was available at the individual consumer level. Therefore, through the model's assumptions linking viewership and subscription choice, the authors are able to estimate a multidimensional distribution of valuations for channels.

On the supply side, the authors do not observe pair-specific wholesale prices for content. They do observe aggregated data on wholesale prices. Specifically, for each channel, they observe how much revenue accrues to the channel from fee payments by MVPDs as well as the total number of subscribers. The ratio of these is the average per-subscriber linear fee the channel receives. The authors model the contract space as featuring only a constant linear fee per subscriber, a choice

\footnotetext{
${ }^{90}$ See https://docs.fcc.gov/public/attachments/DOC-276771A1.pdf.
} 
based on institutional knowledge about the industry's operation gleaned from various court proceedings, regulatory reports, the trade press, and discussions with industry analysts. To estimate pair-specific wholesale prices, the authors combine the observed average fees with inferences about MVPD-specific costs from the MVPDs' pricing and bundling behavior. The authors search for a parameterized function of pair-specific wholesale prices which best fits the assumed Nash equilibrium in price and bundle setting by MVPDs together with the observed channel average wholesale prices.

With the estimated wholesale prices, the authors fit the bargaining parameters in a Nash-inNash bargaining model for two synthetic markets. ${ }^{91}$ Marginal costs of serving additional content by the upstream channels are assumed to be zero. Channels also receive revenue from advertising which is observed in the data. The authors fit a channel-specific relationship between viewership and advertising revenue using multiple years of data. All together, the authors are in the ideal data scenario case discussed earlier in the chapter: a single bargaining parameter can be backed out for each pair to rationalize the estimated pair-specific wholesale prices.

The counterfactual analysis focuses on a scenario where downstream firms are forced to price channels individually and cannot offer bundles. They also consider intermediate schemes such as themed tiers and bundle-size pricing (Chu, Leslie and Sorensen, 2011). Given the combinatorial difficulty of examining a full à la carte scenario, the authors make a number of simplifying assumptions in the counterfactual scenario to render the analysis feasible. Average consumer welfare is essentially unaffected by counterfactual unbundling, though the distribution of consumer welfare is affected. Consumers who watch many channels benefit from a bundled world, whereas consumers who watch few channels would benefit from unbundling.

The findings of the paper rely heavily on modelling the equilibrium in the wholesale market. Ignoring the re-equilibration of contract terms in the upstream content market makes unbundling appear heavily consumer welfare enhancing. This may explain some of the enthusiasm in policy circles for mandating unbundling. Once the reactions of the upstream market are accounted for, however, average consumer benefits are mostly eliminated. The authors point out that unbundling may have welfare effects which are unmodeled. These include the effects on the quantity and type of content that is created, and on the discovery of content by consumers.

Villas-Boas (2009) and Grennan (2013) study third-degree price discrimination. Villas-Boas (2009) investigates banning wholesale price discrimination by coffee manufacturers to grocery stores. Villas-Boas estimates a demand model with choices over combinations of grocery store and coffee product, and models the vertical relationships using an offer game with simple linear (per-unit) pricing. Villas-Boas simulates a counterfactual scenario where manufacturers must offer the same prices for specific products to grocery stores and finds that total welfare increases from eliminating price discrimination. Most of the increase accrues to producers while consumers benefit by a smaller

\footnotetext{
${ }^{91}$ These markets were constructed so that their demographics and taste parameters match the estimated national distribution, and both markets were served by a single cable MVPD and two satellite MVPDs. The cable wholesale prices were chosen in one market to match those of a small cable MVPD and in the other market to match those of a large cable MVPD.
} 
amount. While the industry as a whole would like to commit to not price discriminate, this would not constitute a Nash equilibrium as firms would deviate to discrimination.

Grennan (2013) considers the effects of third-degree price discrimination in the market for coronary stents, and simulates counterfactual scenarios that require stent manufacturers to charge all hospitals the same price for a given stent. Grennan observes hospital-stent-specific wholesale prices together with a panel of stent-specific quantities sold to individual hospitals, and estimates a bargaining model between stent manufacturers and individual hospitals. Since he assumes that doctor-patient flow is invariant to stent prices, the disagreement payoffs for each stent manufacturer in a single hospital negotiation are zero, while hospitals can potentially increase purchases from other stent manufacturers if they don't reach agreeable terms with a specific manufacturer. The counterfactual analysis is complicated by the question of how to model nondiscrimination in prices in a bargaining model where prices are not directly controlled by a single party. To do so, Grennan assumes hospitals bargaining collectively. Grennan finds that unless the hospitals are able to collectively bargain with the maximum of their bargaining parameters, prices for stents rise on average. Thus, price discrimination has ambiguous effects on welfare in the study, with the final results depending on what bargaining parameter the collective of hospitals would enjoy in such a setting. ${ }^{92}$

Dubois and Sæthre (2020) and Dubois, Gandhi and Vasserman (2020) use bargaining models to study price discrimination in the market for pharmaceuticals. Dubois and Sæthre (2020) consider the effects of banning parallel trade, whereby a EU member imports drugs that whose prices were negotiated by another EU member, thereby diminishing the ability of a pharmaceutical company to price discriminate based on demand conditions. In the atorvastatin market, they find that banning parallel trade, and thereby increasing the ability to price discriminate, increases the manufacturer's profit significantly, and raises expenses in the destination country while decreasing expenses in the source country. Dubois, Gandhi and Vasserman (2020) consider the effects of a potential reference pricing policy whereby the US would cap pharmaceutical prices at those negotiated by other countries. The authors quantify predictions on how much prices would rise in other countries and fall in the US as a result.

\subsection{Nonlinear Contracts}

Interfirm contracts in practice often involve various forms of non-linear pricing, such as quantity discounts and bundle discounts. These forms of pricing have the potential to improve efficiency, for example by encouraging greater levels of trade or creating incentives for effort provision. At the same time, they could lead to foreclosure of rivals. A few papers have used structural methods to

\footnotetext{
${ }^{92}$ Grennan and Swanson (2020) delve further into hospital supply procurement and document what happens to wholesale prices when hospitals receive benchmarking information about other hospitals' prices. They find savings ranging from 2 to $4 \%$ after hospitals gain access to the benchmarking data. This paper thus confronts some of the issues raised by considering asymmetric information in wholesale price negotiations, which most of the empirical literature sidesteps in the Nash-in-Nash framework. Bargaining with asymmetric information has been studied empirically more in settings where individual bargaining outcomes are not strongly linked, such as on eBay (Backus et al., 2020) or in certain wholesale auto transactions (Larsen, 2021).
} 
investigate the effects of such contracts, albeit focusing on only some aspects of the approach we have outlined here.

For example, Conlon and Mortimer (2019) examine a contractual term known as all units discount (AUD). In this arrangement, the retailer pays a higher wholesale price if its volume is below a specified threshold, and a lower wholesale price if its volume exceeds that threshold. Importantly, the lower wholesale price applies to all units, including the quantity purchased below the threshold, and thus provides strong, discontinuous incentives to exceed the volume threshold. Their model allows for the possibility that AUD contracts can be used to enhance efficiency by aligning incentives for the downstream retailer to exert effort to increase downstream sales. However, the AUD contract can also serve to block out rival manufacturers from space in the retailer's product assortment.

The specific retailing technology in Conlon and Mortimer (2019) is through vending machines. In this setting, consumer prices are assumed fixed and exogenous. The retailer's main decision is to determine how often to restock inventory in the machine. Restocking increases sales because some consumers decide not to purchase anything if their preferred product is stocked out of the machine. Because the retailer pays the cost of restocking and the manufacturer shares in the benefit, restocking occurs too infrequently if the manufacturer utilizes a simple per-unit wholesale price above its marginal cost. The AUD contract can incentivize the retailer to exert a high level of effort to hit the discount's quantity threshold. However, the machine can only carry so many products, and thus the desire to meet a manufacturer's threshold may lead to stocking more of that manufacturer's product at the expense of consumers who would prefer other manufacturers' products.

The authors quantify the effects of AUD contracts using the estimated model and simulating the removal of the AUD provision of Mars, the largest firm in this product category. A key input into this quantification is the substitution patterns of consumers: if a manufacturer's products are stocked out, what alternative products do consumers purchase, and how does overall quantity change? The authors run a field experiment with a vending machine company in which they randomly change the product assortment available to observe how consumers substitute between products during stock outs. Utilizing a demand system estimated from the observed substitution patterns from both the experiment and other variation in product assortment, the authors use the restocking model to infer how the retailer's and manufacturer's profits vary with different product portfolio and restocking effort choices by the retailer, and under different contracts.

The estimated demand system and retailer model allow the authors to simulate outcomes under alternative contracts between the manufacturer and retailer. The simulations indicate that while the AUD does increase the frequency of restocking towards the socially optimal level, the observed assortment of products features too many Mars products and not enough from rival manufacturers. On net, the loss of variety effect on consumers is larger than the efficiency benefits from increased restocking.

One point to note about this counterfactual analysis, however, is that when the authors explore the effect of banning the use of the AUD contract they do not predict what the new equilibrium 
contract (within the set of allowed contracts) would be. That is, while they use structural methods to analyze and predict the retailer's optimal behavior under various actual and counterfactual contracts, they do not include any model of contract formation. Other structural papers in this area, such as Mortimer (2008)'s study of revenue sharing contracts and Ho, Ho and Mortimer (2012) on full-line forcing contracts, share this feature.

\subsection{Exclusive Vertical Contracts}

Although nonlinear contract terms such as AUD can have exclusionary effects, there are also contracts that explicitly condition terms of trade on exclusivity. Such exclusive contracts have attracted a significant amount of attention from policymakers and academics alike due to their theoretical potential to both reduce competition through foreclosure and enhance efficiency through increasing effort provision and investment. Though for much of the twentieth century, such agreements have been viewed by the U.S. courts with considerable skepticism, they are currently evaluated according to the rule of reason.

In one of the earliest structural empirical papers to examine the potential pro- and anticompetitive effects of exclusive arrangements, Asker (2016) proposes a test for whether exclusive distribution contracts may have been used to foreclose rivals and harm competition. ${ }^{93}$ Asker's setting is the Chicago beer market, which has the feature that firms which operate in any one of the three tiers of the supply chain-brewing, distribution, or retail-cannot operate in another tier. As a result, brewers have to rely on a system of distributors to get their beer to market. During Asker's period of study, Anheuser Busch (AB) relied solely on exclusive distribution: any distributor of $\mathrm{AB}$ beer could not distribute beer for another brewer. Miller, however, relied on both exclusive distributors in certain geographic markets, and non-exclusive distributors in others.

Similar to papers discussed in Section 4.4, Asker explores the effects of exclusive distribution contracts, but does not use a model of contract formation to predict what contracts might be signed if exclusive contracts, for example, were prohibited. Rather, to test whether or not such exclusive arrangements improved or harmed efficiency, Asker compares estimated measures of distribution costs and demand for non-AB and non-Miller beers between markets where Miller used an exclusive distributor, and markets where Miller did not use an exclusive distributor. The idea is that if exclusive distribution led to "cost-based" foreclosure whereby rival brewers were denied access to lower-cost distributors, distribution costs for other brewers should be higher whenever Miller used an exclusive; and similarly, if exclusive distribution led to "service-based" foreclosure preventing access to distributors who are able to increase sales (through, for example, assisting retailers with promotions and inventory management), sales for other brewers should be lower. ${ }^{94}$

\footnotetext{
${ }^{93}$ See also Brenkers and Verboven (2006), who examines the removal of an exclusive distribution system in the European car market.

${ }^{94}$ As Asker notes, the test is not a necessary condition for there to be foreclosure effects. For example, even if Miller forecloses other brewers from accessing a low-cost distributor through an exclusive contract, if other brewers re-contract with the remaining distributors so that their average costs fall relative to markets where Miller is not exclusive, then the test will not detect cost-based foreclosure even when it exists.
} 
In this difference-in-difference research design, the markets without Miller-exclusive distributors are used as a control for those markets with Miller-exclusives. To implement his diagnostic test, Asker estimates distribution costs and product-demand shifters across different markets using a consumer demand system for beer, and a supply-side model in which each tier, starting with the brewers, sequentially sets prices to the next tier. Asker assumes that distributors are non-strategic and obtain fixed payments from manufacturers, and hence the analysis is conceptually similar to modeling only a two-tier supply chain with manufacturer-retailer interactions as in Villas-Boas (2007) and Bonnet and Dubois (2010). Given the similarities in distribution costs and sales for other brewers across markets with and without Miller-exclusive distributor, Asker concludes that foreclosure effects were not significant in his setting.

In the setting studied by Asker (2016), exclusive distribution contracts did not ultimately affect the choice sets that consumers faced: consumers could essentially purchase all major beer products at any retailer regardless of whether exclusive distribution contracts were used. In contrast, in two different settings studied by Lee (2013) and Sinkinson (2020), the use of exclusive contracts by certain firms altered what products consumers could purchase depending on which hardware platform or mobile carrier they adopted, and raised concerns due to the associated consumer welfare losses from restricted choice. ${ }^{95}$

Lee (2013) studies the welfare and competitive effects of software exclusivity in the videogame industry, and examines whether an incumbent hardware platform's use of exclusive and integrated software was anti-competitive. During the period of analysis (2000-2005), there were three primary hardware manufacturers who each had a partially overlapping set of software products (games). Software that was exclusive to one platform - due to integration, contract, or choice by the software developer - was not accessible to users of rival platforms. Because exclusive software, as one of the primary means of differentiation between platforms, could lead to greater adoption of a platform by consumers, which in turn could lead to greater software variety and further consumer adoption due to the presence of indirect network effects, an incumbent platform could potentially leverage exclusivity early on in a particular hardware generation to "tip" the market and stymie competition.

To determine whether exclusive software was more beneficial to incumbent rather than entrant hardware platforms, Lee estimates a dynamic model of consumer demand for both hardware and software products and software developer decisions for which platforms to support, and uses it to simulate market outcomes had hardware providers been unable to integrate or acquire exclusive software titles. By incorporating a model of software developer decisions, Lee is one of the first in the literature to account for re-matching between contracting partners in counterfactual regimes; this is important since, when exclusive and integrated software are prohibited, the analysis still allows for software products to voluntarily develop for only a subset of available hardware platforms (as opposed to, for example, assuming that all software products develop for all platforms).

Lee finds that consumers would have benefited from greater compatibility of software prod-

\footnotetext{
${ }^{95}$ See also Ho (2006), who quantified the consumer welfare loss from restricted hospital choice due to selective, but not exclusive, insurer-hospital contracting.
} 
ucts absent exclusive contracts or integrated software, holding fixed hardware prices and product availability. However, Lee also shows that exclusive arrangements between hardware and software products strengthened smaller, entrant platforms: without exclusive arrangements, high quality software would typically have been released on all platforms; lower quality titles, constrained by the costs of developing for multiple systems, would likely have developed first for the larger incumbent platform due to its larger user base, and only later, if at all, developed a version for others. With exclusivity, entrants could overcome early disadvantages from smaller scale in order to gain a foothold in this networked industry. ${ }^{96}$

Sinkinson (2020) studies exclusive arrangements between mobile carriers and handset manufacturers, focusing on the exclusive contract between AT\&T and Apple for the iPhone which lasted between 2007 and 2011. The question that Sinkinson poses is whether AT\&T would have been able to pay Apple enough to offset what Apple might have been able to earn had it been exclusive with Verizon, or multihomed on both carriers. When deciding whether or not to be exclusive with a carrier, a handset manufacturer faces the following trade-off. On one hand, an exclusive contract with one carrier foregoes sales to customers of rival carriers. On the other hand, exclusivity can increase carrier differentiation through handset offerings and soften carrier price competition (Rey and Stiglitz, 1995; Hagiu and Lee, 2011), and this may allow the manufacturer to extract higher payments from carriers for exclusivity. When gains from higher prices are sufficient to offset the handset manufacturer's losses from fewer sales, and the vertical structure's joint profit thereby increases, then an exclusive contract can be an equilibrium outcome. Sinkinson estimates a dynamic model of carrier-handset choices for consumers in order to determine if this was indeed true. Sinkinson finds that even though consumers had a higher willingness-to-pay for Verizon's network than AT\&T's, AT\&T stood to gain more from exclusivity than Verizon and hence would have have been willing to pay more to Apple for the contract; and that exclusivity was in fact jointly profitable for the two parties. Though the Apple-AT\&T exclusive relationship harmed consumers due to increased prices and restricted choice, Sinkinson also finds that the exclusive arrangement nonetheless increased the incentives for new handsets - in particular, those running Google's Android operating system - to enter, generating a positive counterweight for consumer welfare.

\section{Concluding Remarks}

The recent structural empirical literature on vertical markets has embraced a close relationship between theoretical models of contracting and the empirical realities of specific markets. Much of this has been out of necessity: pressing policy and regulatory questions related to industries with oligopolistic supply chains persist and continue to emerge, fueling demand for more credible quantitative guidance on the likely equilibrium effects of particular contracting practices or market

\footnotetext{
${ }^{96}$ Lee also finds that integrated and contractually exclusive games were, on average, higher quality than those that "multi-homed" and were developed for multiple platforms. Though this finding is consistent with exclusivity better aligning investment incentives and hence game quality, it is also consistent with an alternative selection story: that is, only higher quality games were acquired or offered exclusive deals.
} 
interventions. This has motivated the development of quite sophisticated econometric models that are tailored to the idiosyncrasies of various industries, account for rich strategic interactions among firms with market power, and remain tractable, computable, and estimable. In this sense, the structural empirical literature on vertical markets continues to further the "new empirical industrial organization" paradigm described three decades ago in an earlier volume of this handbook (Bresnahan, 1989).

Despite significant progress, room for advancement remains. We highlight three directions that we believe to be valuable. First, expanding the analyses in this chapter to allow for richer contracts, and understanding and potentially modeling when they will be employed, are natural next steps to take. Second, with few exceptions, most of the applications described in Section 4 do not endogenize the set of contracting partners. Counterfactual simulations without this margin of adjustment are inherently limited, and may benefit from relaxing this restriction. Third, researchers may find it necessary for certain applications to extend the static, complete-information framework presented in Section 3 to incorporate incomplete information and dynamics. Allowing for incomplete information about valuations or costs (or about types, as in reputational bargaining models) can help to explain negotiation breakdowns and disagreements, and provide yet another potentially important source of interdependencies across negotiations. Dynamics may be necessary to understand and model the duration of contracts and timing of (re-)negotiations, as well as to realistically capture investment and R\&D behavior. They can also inform the use of time-series and panel data on firm interactions to estimate unobserved primitives. For these and related efforts, we do not believe that either a theory-only or empirics-only approach pursued in isolation will be most fruitful. Rather, a vibrant dialogue between the two should exist: theoretical models for these applications should be guided by the institutional features of markets they are meant to represent, and econometric models that are developed should be consistent with a coherent theoretical framework and suited for the types of data that are available.

We conclude with an appeal for further empirical work that takes the methods developed here, and ideas behind them, to study other (not necessarily vertical) industries and applications. As we noted at the beginning of Section 4, the approaches described in this chapter have been used to study settings where agents strategically negotiate over terms of trade, both within and outside of traditional IO settings. Pursuing these studies will tend to identify additional shortcomings of existing methods and thus the next set of issues to tackle. 


\section{References}

Abreu, Dilip, and Mihai Manea. 2012. "Bargaining and efficiency in networks." Journal of Economic Theory, 147(1): 43-70.

Adams, William James, and Janet L Yellen. 1976. "Commodity bundling and the burden of monopoly." The quarterly journal of economics, 475-498.

Akkus-Clemens, Selvin, and John Asker. 2014. "Tomorrow's Antitrust Rulings on Conditional Pricing: How the Lastest Economic Research May Show the Way." Monopoly Matters, 12(1): 8-12.

Asker, John. 2016. "Diagnosing Foreclosure due to Exclusive Dealing." Journal of Industrial Economics, 64(3): 375410 .

Asker, John, and Heski Bar-Isaac. 2014. "Raising Retailers' Profits: On Vertical Practices and the Exclusion of Rivals." American Economic Review, 104(2): 672-86.

Atalay, Enghin, Ali Hortaçsu, and Chad Syverson. 2014. "Vertical Integration and Input Flows." American Economic Review, 104(4): 1120-1148.

Backus, Matthew, Thomas Blake, Brad Larsen, and Steven Tadelis. 2020. "Sequential bargaining in the field: Evidence from millions of online bargaining interactions." The Quarterly Journal of Economics, 135(3): 13191361.

Bagwell, Kyle, Robert W Staiger, and Ali Yurukoglu. 2020. "Nash-in-Nash" tariff bargaining." Journal of International Economics, 122: 103263.

Bagwell, Kyle, Robert W. Staiger, and Ali Yurukoglu. 2021. "Quantitative Analysis of Multiparty Tariff Negotiations." Econometrica, 89(4): 1595-1631.

Bernheim, B. Douglas, and Michael D. Whinston. 1986. "Menu Auctions, Resource Allocation, and Economic Influence." Quarterly Journal of Economics, 51(1): 1-32.

Bernheim, B. Douglas, and Michael D. Whinston. 1998. "Exclusive Dealing." Journal of Political Economy, 106(1): 64-103.

Berry, Steve, James Levinsohn, and Ariel Pakes. 1995. "Automobile Prices in Market Equilibrium." Econometrica, 63(4): 841-890.

Berry, Steven, James Levinsohn, and Ariel Pakes. 2004. "Differentiated products demand systems from a combination of micro and macro data: The new car market." Journal of Political Economy, 112(1): 68-105.

Binmore, Ken, Ariel Rubinstein, and Asher Wolinsky. 1986. "The Nash Bargaining Solution in Economic Modelling." RAND Journal of Economics, 17(2): 176-188.

Binmore, Ken, Avner Shaked, and John Sutton. 1989. "An Outside Option Experiment." Quarterly Journal of Economics, 104(4): 753-770.

Bolton, Patrick, and Michael D. Whinston. 1993. "Incomplete Contracts, Vertical Integration, and Supply Assurance." Review of Economic Studies, 60(1): 121-148.

Bonanno, Giacomo, and John Vickers. 1988. "Vertical Separation." The Journal of Industrial Economics, 36(3): 257-265.

Bonnet, Céline, and Pierre Dubois. 2010. "Inference on vertical contracts between manufacturers and retailers allowing for nonlinear pricing and resale price maintenance." The RAND Journal of Economics, 41(1): 139-164.

Brenkers, Randy, and Frank Verboven. 2006. "Liberalizing a distribution system: the European car market." Journal of the European Economic Association, 4(1): 216-251.

Bresnahan, Timothy, and Jonathan Levin. 2013. "Vertical Integration and Market Structure." In Handbook of Organizational Economics., ed. Robert Gibbons and John Roberts. Princeton, NJ:Princeton University Press. 
Bresnahan, Timothy F. 1982. "The oligopoly solution concept is identified." Economics Letters, 10(1-2): 87-92.

Bresnahan, Timothy F. 1989. "Empirical studies of industries with market power." In Handbook of Industrial Organization. Vol. 2, Chapter 17, 1011-1057. Elsevier.

Brügemann, Björn, Pieter Gautier, and Guido Menzio. 2018. "Intra Firm Bargaining and Shapley Values." The Review of Economic Studies, 86(2): 564-592.

Capps, Cory, David Dranove, and Mark Satterthwaite. 2003. "Competiton and Market Power in Option Demand Markets." RAND Journal of Economics, 34(4): 737-763.

Chen, Dong, and David Waterman. 2007. "Vertical Ownership, Program Network Carriage, and Tier Positioning in Cable Television: An Empirical Study." Review of Industrial Organization, 30(3): 227-251.

Chipty, Tasneem. 2001. "Vertical Integration, Market Foreclosure, and Consumer Welfare in the Cable Television Industry." American Economic Review, 91(3): 428-453.

Chipty, Tasneem, and Christopher M Snyder. 1999. "The role of firm size in bilateral bargaining: A study of the cable television industry." Review of Economics and Statistics, 81(2): 326-340.

Chu, Chenghuan Sean, Phillip Leslie, and Alan Sorensen. 2011. "Bundle-size pricing as an approximation to mixed bundling." The American Economic Review, 263-303.

Collard-Wexler, Allan, Gautam Gowrisankaran, and Robin S. Lee. 2019. " "Nash-in-Nash" Bargaining: A Microfoundation for Applied Work." Journal of Political Economy, 127(1): 163-195.

Conlon, Christopher T., and Julie H. Mortimer. 2019. "Efficiency and Foreclosure Effects of Vertical Rebates: Empirical Evidence." NBER Working Paper w19709.

Crawford, Gregory S., and Ali Yurukoglu. 2012. "The Welfare Effects of Bundling in Multichannel Television Markets." American Economic Review, 102(2): 643-685.

Crawford, Gregory S., Robin S. Lee, Michael D. Whinston, and Ali Yurukoglu. 2018. "The Welfare Effects of Vertical Integration in Multichannel Television Markets." Econometrica, 86(3): 891-954.

Cremer, Jacques, and Michael H. Riordan. 1987. "On Governing Multilateral Transactions with Bilateral Contracts." RAND Journal of Economics, 18(3): 436-451.

Cuesta, José Ignacio, Carlos Noton, and Benjamín Vatter. 2019. "Vertical Integration between Hospitals and Insurers." Unpublished.

de Fontenay, Catherine C., and Joshua S. Gans. 2014. "Bilateral Bargaining with Externalities." Journal of Industrial Economics, 62(4): 756-788.

DeGraba, Patrick, Patrick Greenlee, and Daniel P. O’Brien. 2017. "Conditional Pricing Practicies — a Short Primer." Unpublished.

De los Santos, Babur, Daniel P O'Brien, and Matthijs R Wildenbeest. 2021. "Agency Pricing and Bargaining: Empirical Evidence from the E-Book Market." Kelley School of Business Research Paper.

Demirer, Mert, and Alexander L. Olssen. 2021. "Drug Rebates and Formulary Design: Evidence from Statins in Medicare Part D." Unpublished.

Draganska, Michaela, Daniel Klapper, and Sofia B. Villas-Boas. 2010. "A Larger Slice or a Larger Pie? An Empirical Investigation of Bargaining Power in the Distribution Channel." Marketing Science, 29(1): 57-74.

Dubin, Jeffrey A, and Daniel L McFadden. 1984. "An econometric analysis of residential electric appliance holdings and consumption." Econometrica: Journal of the Econometric Society, 345-362.

Dubois, Pierre, and Morten Sæthre. 2020. "On the Effect of Parallel Trade on Manufacturers' and Retailers' Profits in the Pharmaceutical Sector." Econometrica, 88(6): 2503-2545. 
Dubois, Pierre, Ashvin Gandhi, and Shoshana Vasserman. 2020. "Bargaining and International Reference Pricing in the Pharmaceutical Industry." Unpublished.

Eizenberg, Alon. 2014. "Upstream Innovation and Product Variety in the U.S. Home PC Market." The Review of Economic Studies, 81(3): 1003-1045.

Ellickson, Paul B., Pianpian Kong, and Mitchell J. Lovett. 2018. "Private Labels and Retailer Profitability: Bilateral Bargaining in the Grocery Channel." Unpublished.

Fan, Ying, and Chenyu Yang. 2020. "Competition, Product Proliferation, and Welfare: A Study of the US Smartphone Market." American Economic Journal: Microeconomics, 12(2): 99-134.

Genchev, Bogdan, and Julie Holland Mortimer. 2017. "Empirical Evidence on Conditional Pricing Practices: A Review." Antitrust Law Journal, 81(2): 343-370.

Ghili, Soheil. 2021. "Network Formation and Bargaining in Vertical Markets: The Case of Narrow Networks in Health Insurance." Unpublished.

Gomes, Armando. 2005. "Multilateral Contracting with Externalities." Econometrica, 73(4): 1329-1350.

Gomes, Armando, and Pehilippe Jehiel. 2005. "Dynamic Processes of Scoial and Economic Interactions: On the Persistence of Inefficiencies." Journal of Political Economy, 113(3): 626-667.

Gowrisankaran, Gautam, Aviv Nevo, and Robert Town. 2015. "Mergers When Prices Are Negotiated: Evidence from the Hospital Industry." American Economic Review, 105(1): 172-203.

Grennan, Matthew. 2013. "Price Discrimination and Bargaining: Empirical Evidence from Medical Devices." American Economic Review, 103(1): 147-177.

Grennan, Matthew, and Ashley Swanson. 2020. "Transparency and Negotiated Prices: The Value of Information in Hospital-Supplier Bargaining." Journal of Political Economy, 128(4): 1234-1268.

Grossman, S., and O. Hart. 1986. "The Costs and Benefits of Ownership: A Theory of Vertical and Lateral Integration." Journal of Political Economy, 94: 691-796.

Hagiu, Andrei, and Robin S. Lee. 2011. "Exclusivity and Control." Journal of Economics and Management Strategy, 20(3): 679-708.

Hart, Oliver, and Jean Tirole. 1990. "Vertical Integration and Market Foreclosure." Brookings Papers on Economic Activity, Microeconomics, 1990: 205-286.

Hart, Oliver D., and John Moore. 1990. "Property Rights and the Nature of the Firm." Journal of Political Economy, 98: 1119-1158.

Hastings, Justine S., and Richard J. Gilbert. 2005. "Market Power, Vertical Integration and the Wholesale Price of Gasoline." Journal of Industrial Economics, 53(4): 469-492.

Heckman, James J. 1979. "Sample selection bias as a specification error." Econometrica: Journal of the econometric society, 153-161.

Ho, Justin, Katherine Ho, and Julie Mortimer. 2012. "The Use of Full-line Forcing Contracts in the Video Rental Industry." American Economic Review, 102(2): 686-719.

Ho, Kate. 2006. "The Welfare Effects of Restricted Hospital Choice in the US Medical Care Market." Journal of Applied Econometrics, 21(7): 1039-1079.

Ho, Kate. 2009. "Insurer-Provider Networks in the Medical Care Market." American Economic Review, 99(1): 393430.

Ho, Kate, and Robin S. Lee. 2017. "Insurer Competition in Health Care Markets." Econometrica, 85(2): 379-417.

Ho, Kate, and Robin S. Lee. 2019. "Equilibrium Insurer-Provider Networks: Bargaining and Exclusion in Health Care Markets." American Economic Review, 109(2): 473-522. 
Horn, Henrick, and Asher Wolinsky. 1988. "Bilateral Monopolies and Incentives for Merger." RAND Journal of Economics, 19(3): 408-419.

Hortaçsu, Ali, and Chad Syverson. 2007. "Cementing Relationships: Vertical Integration, Foreclosure, Productivity and Prices." Journal of Political Economy, 115(2): 250-301.

Igami, Mitsuru. 2017. "Estimating the Innovator's Dilemma: Structural Analysis of Creative Destruction in the Hard Disk Drive Industry, 1981-1998." Journal of Political Economy, 125(3): 798-847.

Inderst, Roman, and Christian Wey. 2003. "Bargaining, Mergers, and Technology Choice in Bilaterally Oligopolistic Industries." RAND Journal of Economics, 34(1): 1-19.

Iozzi, Alberto, and Tommaso Valletti. 2014. "Vertical Bargaining and Countervailing Power." American Economic Journal: Microeconomics, 6(3): 106-135.

Jackson, Matthew O., and Asher Wolinsky. 1996. "A Strategic Model of Social and Economic Networks." Journal of Economic Theory, 71(1): 44-74.

Jehiel, Philippe, and Benny Moldovanu. 1995. "Cyclical Delay in Bargaining with Externalities." Review of Economic Studies, 62(4): 619-637.

Jehiel, Philippe, and Benny Moldovanu. 2000. "Auctions with Downstream Interaction among Buyers." The RAND Journal of Economics, 31(4): 768-791.

Joskow, Paul L. 1985. "Vertical integration and long-term contracts: The case of coal-burning electric generating plants." Journal of Law, Economics, \& Organization, 1(1): 33-80.

Katz, Michael L. 1987. "The welfare effects of third-degree price discrimination in intermediate good markets." The American Economic Review, 154-167.

Krattenmaker, Thomas G., and Steven C. Salop. 1986. "Anticompetitive Exclusion: Raising Rivals' Costs to Achieve Power over Price." The Yale Law Journal, 2: 209-293.

Lafontaine, Francine. 1992. "Agency theory and franchising: some empirical results." RAND Journal of Economics, 263-283.

Larsen, Bradley J. 2021. "The efficiency of real-world bargaining: Evidence from wholesale used-auto auctions." The Review of Economic Studies.

Lau, Lawrence J. 1982. "On identifying the degree of competitiveness from industry price and output data." Economics Letters, 10(1-2): 93-99.

Lee, Robin S. 2013. "Vertical Integration and Exclusivity in Platform and Two-Sided Markets." American Economic Review, 103(7): 2960-3000.

Lee, Robin S., and Kyna Fong. 2013. "Markov Perfect Network Formation: An Applied Framework for Bilateral Oligopoly and Bargaining in Buyer-Seller Networks." Unpublished.

Liebman, Eli. 2016. "Bargaining in Markets with Exclusion: An Analysis of Health Insurance Networks." Unpublished.

Luco, Fernando, and Guillermo Marshall. 2020. "The Competitive Impact of Vertical Integration by Multiproduct Firms." American Economic Review, 110(7): 2041-2064.

Manea, Mihai. 2016. "Intermediation and Resale in Networks." Journal of Political Economy, 126(3): 1250-1301.

Marx, Leslie, and Greg Shaffer. 2007. "Upfront payments and exclusion in downstream markets." RAND Journal of Economics, 38(3): 823-843.

Maskin, Eric, and Jean Tirole. 1992. "The Principal-Agent Relationship with an Informed Principal, II: Common Values." Econometrica, 60(1): 1-42. 
McAfee, R. Preston, and Marius Schwartz. 1994. "Opportunism in Multilateral Vertical Contracting: Nondiscrimination, Exclusivity, and Uniformity." American Economic Review, 84(1): 210-230.

Molina, Hugo. 2019. "Buyer alliances in vertically related markets." Unpublished.

Monteverde, Kirk, and David J Teece. 1982. "Supplier switching costs and vertical integration in the automobile industry." The Bell Journal of Economics, 206-213.

Mortimer, Julie H. 2008. "Vertical Contracts in the Video Rental Industry." Review of Economic Studies, 75: 165199.

Myerson, Roger B. 1977. "Graphs and Cooperation in Games." Mathematics of Operations Research, 2(3): 225-229.

Nash, John. 1953. "Two-Person Cooperative Games." Econometrica, 21(1): 128-140.

Navarro, Noemí. 2007. "Fair allocation in networks with externalities." Games and Economic Behavior, 58(2): 354364.

Nevo, Aviv. 2001. "Measuring Market Power in the Ready-to-Eat Cereal Industry." Econometrica, 69(2): 307-342.

Nocke, Volker, and Patrick Rey. 2018. "Exclusive dealing and vertical integration in interlocking relationships." Journal of Economic Theory, 177(C): 183-221.

O'Brien, Daniel P., and Greg Shaffer. 1997. "Nonlinear Supply Contracts, Exclusive Dealing, and Equilibrium Market Foreclosure." Journal of Economics \& Management Strategy, 6(4): 755-785.

O'Brien, D. P., and G. Shaffer. 1992. "Vertical control with bilateral contracts." RAND Journal of Economics, 23: 299-308.

Ordover, J., G. Saloner, and S. Salop. 1990. "Equilibrium Vertical Foreclosure." American Economic Review, 80: $127-142$.

Perry, Martin K. 1990. "Vertical Integration: Determinants and Effects." In Handbook of Industrial Organization. Vol. 1, , ed. Richard Schmalensee and Robert Willig. Amsterdam:North Holland.

Porter, Michael E. 1974. "Consumer behavior, retailer power and market performance in consumer goods industries." The Review of Economics and Statistics, 419-436.

Rasmusen, Eric B., J. Mark Ramseyer, and John Shepard Wiley. 1991. "Naked Exclusion." American Economic Review, 81(5): 1137-1145.

Rey, Patrick, and Jean Tirole. 2007. "A Primer on Foreclosure." In Handbook of Industrial Organization. Vol. 3, , ed. Mark Armstrong and Rob Porter, Chapter 7. Amsterdam:North-Holland Press.

Rey, Patrick, and Joseph Stiglitz. 1995. "The Role of Exclusive Territories in Producers' Competition." RAND Journal of Economics, 26(3): 431-451.

Rey, Patrick, and Michael D. Whinston. 2013. "Does retailer power lead to exclusion?" The RAND Journal of Economics, 44(1): 75-81.

Rey, Patrick, and Thibaud Vergé. 2004. "Bilateral Control with Vertical Contracts." The RAND Journal of Economics, 35(4): 728-746.

Rey, Patrick, and Thibaud Vergé. 2010. "Resale Price Maintenance and Interlocking Relationships." The Journal of Industrial Economics, 58(4): 928-961.

Rey, Patrick, and Thibaud Vergé. 2020. "Secret contracting in multilateral relations." Unpublished.

Riordan, Michael H. 2008. "Competitive Effects of Vertical Integration." In Handbook of Antitrust Economics. , ed. Paolo Buccirossi, Chapter 4, 145-182. Cambridge, MA:MIT Press.

Robles-Garcia, Claudia. 2019. "Competition and incentives in mortgage markets: The role of brokers." Unpublished working paper. 
Rubinstein, Ariel. 1982. "Perfect Equilibrium in a Bargaining Model." Econometrica, 97-109.

Salop, Steven C., and David T. Scheffman. 1983. "Raising Rivals' Costs." American Economic Review, 73(2): $267-271$.

Schmalensee, Richard. 1981. "Output and welfare implications of monopolistic third-degree price discrimination." The American Economic Review, 71(1): 242-247.

Scott Morton, Fiona M. 2013. "Contracts that Reference Rivals." Antitrust, 27(3): 72-79.

Segal, Ilya. 1999. "Contracting with Externalities." Quarterly Journal of Economics, 64(2): 337-388.

Segal, Ilya. 2003. "Coordination and discrimination in contracting with externalities: divide and conquer?" Journal of Economic Theory, 113(2): $147-181$.

Segal, Ilya, and Michael D. Whinston. 2000. "Naked Exclusion: Comment." American Economic Review, 90(1): 296-309.

Segal, Ilya, and Michael D. Whinston. 2003. "Robust Predictions for Bilateral Contracting with Externalities." Econometrica, 71(3): 757-791.

Sinkinson, Michael. 2020. "Pricing and Entry Incentives with Exclusive Contracts." Unpublished.

Spengler, Joseph J. 1950. "Vertical integration and antitrust policy." The Journal of Political Economy, 347-352.

Stigler, George J. 1963. "United States v. Loew's Inc.: A note on block-booking." The Supreme Court Review, 1963: 152-157.

Stole, Lars A., and Jeffrey Zweibel. 1996. "Intra-Firm Bargaining under Non-Binding Contracts." Review of Economic Studies, 63(3): 375-410.

Suzuki, Ayako. 2009. "Market foreclosure and vertical merger: A case study of the vertical merger between Turner Broadcasting and Time Warner." International Journal of Industrial Organization, 27(4): 523-543.

Town, Robert J., and Gregory Vistnes. 2001. "Hospital Competition in HMO Networks." Journal of Health Economics, 20: 733-753.

Varian, Hal R. 1985. "Price discrimination and social welfare." The American Economic Review, 75(4): 870-875.

Villas-Boas, Sofia B. 2007. "Vertical Relationships between Manufacturers and Retailers: Inference with Limited Data." Review of Economic Studies, 74(2): 625-652.

Villas-Boas, Sofia Berto. 2009. "An empirical investigation of the welfare effects of banning wholesale price discrimination." The RAND Journal of Economics, 40(1): 20-46.

Waterman, David, and Andrew A. Weiss. 1996. "The Effects of Vertical Integration between Cable Television Systems and Pay Cable Networks." Journal of Econometrics, 72(1-2): 357-95.

Whinston, Michael D. 2006. Lectures on Antitrust Economics. Cambridge, MA:MIT Press.

Whinston, Michael D. 2007. "Antitrust Policy toward Horizontal Mergers." In Handbook of Industrial Organization. Vol. 3, , ed. M. Armstrong and R. Porter, Chapter 36, 2369 - 2440. Elsevier.

Willamson, Oliver. 1985. The economic institutions of capitalism. New York, NY:Free Press.

Yang, Chenyu. 2020. "Vertical structure and innovation: A study of the SoC and smartphone industries." $R A N D$ Journal of Economics, 51(3): 739-785.

Yi, Sang-Seung. 1997. "Stable Coalition Structures with Externalities." Games and Economic Behavior, 20(2): 201237. 